\title{
WestVirginiaUniversity
}

THE RESEARCH REPOSITORY @ WVU

Graduate Theses, Dissertations, and Problem Reports

2010

\section{Ethnicity, boundaries, and nationalism in a "European" Croatia}

Jennifer L. Titanski

West Virginia University

Follow this and additional works at: https://researchrepository.wvu.edu/etd

\section{Recommended Citation}

Titanski, Jennifer L., "Ethnicity, boundaries, and nationalism in a "European" Croatia" (2010). Graduate Theses, Dissertations, and Problem Reports. 847.

https://researchrepository.wvu.edu/etd/847

This Thesis is protected by copyright and/or related rights. It has been brought to you by the The Research Repository @ WVU with permission from the rights-holder(s). You are free to use this Thesis in any way that is permitted by the copyright and related rights legislation that applies to your use. For other uses you must obtain permission from the rights-holder(s) directly, unless additional rights are indicated by a Creative Commons license in the record and/ or on the work itself. This Thesis has been accepted for inclusion in WVU Graduate Theses, Dissertations, and Problem Reports collection by an authorized administrator of The Research Repository @ WVU. For more information, please contact researchrepository@mail.wvu.edu. 


\title{
ETHNICITY, BOUNDARIES, AND NATIONALISM \\ IN A "EUROPEAN" CROATIA
}

By

\section{Jennifer L. Titanski}

Thesis submitted to the Eberly College of Arts and Sciences at West Virginia University in partial fulfillment of the requirements for the degree of

\section{Master of Arts \\ in Geography}

\author{
Approved by: \\ Dr. Ann Oberhauser, Ph.D., Chair \\ Dr. Karen Culcasi, Ph.D. \\ Dr. Robert Blobaum, Ph.D. \\ Department of Geology and Geography \\ Morgantown, West Virginia \\ 2010
}

Keywords: European Union, Boundaries, Nationalism, Croatia

(C) 2010 Jennifer L. Titanski 


\begin{abstract}
$\underline{\text { Abstract }}$
ETHNICITY, BOUNDARIES, AND NATIONALISM IN A "EUROPEAN" CROATIA
\end{abstract}

\author{
By \\ Jennifer L. Titanski
}

Despite the E.U.'s attempts to create a sense of European homogeneity between its members, issues of nationality and identity continue to play a vital role in both its function and expansion. This research examines the shifting role that the nation plays in Croatia's transition to the European Union. Employing discourse analysis of state documents and online surveys of Croatian youth, this study analyzes the role of the state in perpetuating an image of stability and westward thinking toward greater Europe; identifies the perspective young Croatian adults have on European integration; gauges the importance of nationalism for a post-socialist generation; and demonstrates that although tensions remain, national relationships are improving between Croatia and its neighbors. Additionally, this research reveals the effect that perceived cultural and historical boundaries between Southeastern and Western Europe have had on Croatia's E.U. negotiation process. Both within and outside the region, beliefs in ultra-nationalism and Balkanism have engaged Croatia, and other Southeastern European states, in a process of othering that excludes them from the rest of Europe. 


\section{$\underline{\text { Acknowledgements }}$}

First and foremost, I'd like to thank my advisor, Dr. Ann Oberhauser, and my committee members Dr. Karen Culcasi and Dr. Robert Blobaum. Their continued support, encouragement, and ability to push me to continue to think from different theoretical vantage points have been invaluable during this process. I would also like to thank the Department of Geology and Geography for supporting me financially over the last two years, as well as providing me with ample opportunities to develop myself professionally and academically. Without the encouragement of my committee and this program, the completion of this project would not have been possible.

Secondly, I would like to thank my research participants for all their efforts. In addition to taking the time to participate in this project, many of them showed a great deal of interest in my research, and were gracious enough to encourage their friends and contacts to participate as well. I'm truly indebted to each and every one of you for your time and honest responses!

Most of all, thank you to my wonderful family, who have loved and supported me through all of my endeavors. My parents have worked and sacrificed immeasurably to get me where I am today, always encouraging me to ask questions, to believe in myself, and to work hard to achieve my goals. Thank you to my partner in life and love, Mike, who has supported me in every way possible, and continues to encourage me to pursue all of my dreams. You will never know how much I appreciate everything you've done for me! 


\section{Table of Contents}

Abstract

Acknowledgements

iii

Table of Contents

iv

List of Figures \& Tables

List of Abbreviations

Chapter I: Introduction

Chapter II: Theoretical Framework

A. The Nation \& Nationalism

Theories of the Nation

The End of Nationalism 16

B. Geopolitical Perspectives 19

$\begin{array}{ll}\text { Imperialism } & 19\end{array}$

Ethnicity, Territoriality, and the State 20

C. Western Perceptions and the Process of Othering 22

Summary $\quad 25$

Chapter III: Study Area \& Statement of the Problem $\quad 27$

A. Case-Study Geography $\quad 27$

B. Nation-Building \& the Western Response in Croatia and Southeastern Europe 33

Summary $\quad 40$

Chapter IV: Research Questions \& Methods

A. Research Questions $\quad 42$

B. Research Methods 44

Description of Methods $\quad 44$

Sources of Data $\quad 44$

Online Research: Merits and Drawbacks $\quad 46$

Discourse Analysis $\quad 49$

Online Surveys \& Facebook $\quad 53$

Positionality \& Reflexivity $\quad 58$

Chapter V: Data Analysis \& Findings

$\begin{array}{ll}\text { A. Online Surveys } & 60\end{array}$

$\begin{array}{ll}\text { Introduction } & 60\end{array}$

Respondent Statistics and Basic Content Analysis $\quad 61$

Descriptive and Analytic Coding $\quad 64$

Geographic Perceptions $\quad 67$

$\begin{array}{ll}\text { Slovenian Territorial Dispute } & 72\end{array}$

$\begin{array}{ll}\text { Post-War Relations } & 74\end{array}$

$\begin{array}{ll}\text { Government and Corruption } & 77\end{array}$

E.U. Integration $\quad 81$

$\begin{array}{lr}\text { Impacts and Summary } & 85\end{array}$

B. Textual Analysis $\quad 86$

$\begin{array}{lr}\text { Introduction } & 86\end{array}$

$\begin{array}{ll}\text { Selecting Texts } & 87\end{array}$

Analyzing Texts to Reveal Discourses $\quad 88$ 
E.U. Documents $\quad 92$

State Documents $\quad 101$

Impacts and Summary 106

$\begin{array}{ll}\text { Summary } & 107\end{array}$

Chapter VII: Discussion \& Conclusion $\quad 109$

$\begin{array}{ll}\text { Overview } & 109\end{array}$

Discussion $\quad 111$

Limitations \& Areas for Further Exploration $\quad 114$

Contribution to Geographical Research $\quad 117$

$\begin{array}{lr}\text { Bibliography } & 118\end{array}$

Appendices $\quad 124$

A. Methods Materials $\quad 124$

$\begin{array}{ll}\text { Survey Questions } & 124\end{array}$

Sources for Textual Analysis $\quad 126$

B. Institutional Requirements 127

IRB Approval 127 


\section{$\underline{\text { List of Figures \& Tables }}$}

$\begin{array}{ll}\text { Figure 3.1- Study Area } & 28\end{array}$

Figure 3.2- Croatia's Changing Boundaries 30

Figure 3.3- Ethnic \& Religious Demographics 32

$\begin{array}{ll}\text { Figure 4.1- Methodology Matrix } & 47\end{array}$

Figure 4.2- Generational Breakdown $\quad 53$

Figure 4.3- IRB Approved Survey Advertisement 56

$\begin{array}{ll}\text { Figure 4.4- Website } & 57\end{array}$

$\begin{array}{lr}\text { Figure 4.5- Cover Letter } & 57\end{array}$

Table 5.1- Content Analysis $\quad 62$

Figure 5.1- Geographic Distribution of Survey Respondents 64

Figure 5.2- Codes $\quad 66$

Figure 5.3- Perceptions of Croatia’s Geography 69

Table 5.2- Strategies for Examining Discourse 90 


\section{Chapter I: Introduction}

This study examines how ethnicity and nationalism are framing Croatia's transition to the European Union. Theoretical perspectives on the nation are examined, as well as the historical and geographical processes that contribute to the development of the nation and nationalism in Croatia and Southeastern Europe. Online surveys and textual analysis expose discourses that demonstrate the role that nationalism plays for a post-war generation of Croats, how the Croatian state addresses the issue of the nation, and how these issues affect Croatia's ability to integrate with the international community. The research findings explore the remaining national tensions between Croatia and its neighbors, and examine how the process of othering continues to affect Croatia's admittance to the E.U.

The West has historically characterized Southeastern Europe, and in particular the Balkan Peninsula, as wild, barbaric, and forever engrossed with the national question (Banac, 1984). When compared to the perceived enlightenment and developed disposition of Western Europe, these perceived characteristics of ultra-nationalism and barbarism have engaged Southeastern Europe in a process of othering (Todorova, 1997). Beliefs in a political backwardness or underdevelopment are reflected in the use of terms like Balkanism or Balkanization, which refer to hostile division and political break-up (Oxford English Dictionary, 1989). In the late 1980's and early 1990's, the dissolution of Yugoslavia, in combination with the revolutions in the Eastern Bloc states, further perpetuated an image of the "Other Europe" (McDermott \& Stibbe, 2006, p. 1). This research is concerned with how these beliefs in "Other Europe" and Balkan nationalism affect Croatia's transition to the European Union.

When Slovenia announced its succession from Yugoslavia in 1990, there was little resistance from the central government in Belgrade. However, when Croatia planned its own 
succession, a concern over Serb minorities within Croatia's borders, made the dissolution of Yugoslavia a conflict of nationalisms (Kenney, 2006). To the dismay of the international community, war broke out in Croatia, and eventually in Serbia and Bosnia. Thousands were killed under the watch of leaders, like Slobodan Milošević and Franjo Tuđjman, who used the media to promote an ethnic politics and perpetuate the ethnic and national divisions between Yugoslav republics (Lampe, 2000, p. 365).

In 1995, Croatia’s fight for independence was successful (Glenny, 1999, Epilogue), but a new struggle began as the state worked tirelessly to strengthen itself domestically and improve its relationship with its neighbors. In addition to improving regional relations, the state has also tried to demonstrate to the West that it is a stable, democratic state worthy of acceptance into international organizations, like the E.U. This research will show that Croatian geopolitical discourse seeks to project an image of political and economic stability and of international cooperation. In an attempt to prove its European-ness, the Croatian state has worked to combat the unfair Western beliefs in an ultra-nationalistic and barbaric Balkanism by demonstrating itself as economically and politically stable, and by repairing its relationship with its neighbors.

Despite these efforts, Croatia still has not been granted E.U. membership after nearly eight years of negotiations. The international community maintains that Croatia's economic, political, and judicial systems do not meet E.U. standards (Commission of the European Communities, 2004), and a recent territorial dispute with Slovenia, Croatia's neighbor to the west, has further halted E.U. ascension. However, even with its existing economic and political problems, many other states have been given E.U. membership despite their weaknesses, in particular former Eastern Bloc states. 
This research goes beyond Croatia's economic and political problems to examine how the Western perceptions of Balkan identity and nationalism affect Croatia's E.U. negotiation process by asking to what extent Western perceptions and issues of nationalism continue to hinder Croatia's ability to fully integrate with the European community. More specifically, how does the Croatian state officially deal with charges of nationalism, and how does it represent itself in relation to other former Yugoslav republics? Additionally, how does the Croatian population, in particular the post-war generation, view its country's growth, development, and impending E.U. integration? These questions lend to a greater understanding of the shifting role that the nation plays in Croatia, as well as the struggles that all states face when transitioning into international communities, like the E.U.

Chapter II begins by reviewing some of the major theories of the nation, and attempts to reconcile these perspectives with geopolitical views on the state, ethnicity, imperialism, territoriality, and the process of othering. This theoretical framework will shed light on how politics, history, and geography intersect to contribute to both the development of the nation, as well as the marginalization and uneven development of Croatia, and Southeastern Europe as a whole. Perhaps more importantly, this framework will also lead to an understanding why issues of the nation continue to play an important role in an increasingly globalized world.

Chapter III builds upon the theoretical framework by introducing Croatia as the area of study. A brief description of Croatia's physical and social geography is followed by a historical discussion of some of the major social events and actors that have contributed to nation-building in Croatia and Southeastern Europe as a whole. In conjunction with the theoretical framework, this exploration of the case-study area lays the groundwork to examine the current role that the nation plays in Croatia's impending E.U. integration. 
Chapter IV introduces the research objectives in more detail, and discusses the qualitative methodologies used in this project. Textual analysis of Croatian state press releases and E.U. publications are used in the examination of discourse at the state and international scales, respectively. To gain access to discourse at the scale of the individual, a small number of online surveys were conducted with Croatian students recruited from the social networking site, Facebook, and further analysis was conducted on Facebook groups. To connect these surveys to a larger population, responses were also compared with several Gallop polls. These methodologies highlight the role the state plays in perpetuating an image of stability and westward thinking toward greater Europe; it identifies what perspective young Croat adults have on European integration, and gauges the importance of nationalism for a post-socialist generation.

Chapter V discusses data analysis and findings. The analysis of the data involves the use of coding to draw out specific themes, and to expand on similarities and differences found between the surveys and the various sources used for textual analysis. Microsoft Excel was used to organize and analyze this data. The research findings reinforce the supposition that the West engages the Balkans in a process of othering (Todorova, 1997). Additionally, these findings expose a Croatia that still struggles with issues of the nation, is increasingly concerned with its global image, and has, to a degree, accepted its role as an 'other' in Europe.

The concluding Chapter VI discusses that although real economic and political hurdles remain, the perceived cultural and historical boundaries between Southeastern and Western Europe have contributed to the delay in Croatia's admittance to the E.U. This research demonstrates that both within and outside the region, beliefs in militant nationalism and a Balkanism that must be overcome have engaged Croatia, and other Southeastern European states, 
in a process of othering that marginalizes them from the rest of Europe. By acknowledging how historical preconceptions of the nation continue to affect inter-state relations, this case-study contributes to understanding how perceived boundaries and geographic imaginaries, as well as concepts of the nation and identity, remain important forces in global politics. 


\section{Chapter II: Theoretical Framework}

What ties us to our individual ethnicities, nationalities, and states, and how do our national loyalties affect the relationships we have with those outside our borders? Nationalism triggered two world wars in Europe, and has been at the root of countless conflicts across the globe, including Northern Ireland, the Basque Region, and the Balkan Peninsula. In an attempt to understand why the nation is valued and where and how it originates, many academics have tried to develop theories on the subject. These theories explore the origins and purpose of the nation, and try to interpret what role the nation and nationalism continue to play in the world.

This theoretical framework reviews some of the major theories of the nation, and attempts to reconcile these perspectives with geopolitical views on the state, ethnicity, imperialism, territoriality, and the process of othering. This analysis will lend to a comprehensive understanding of how the nation comes to be valued, the role that it plays in global politics, and how geographic imaginaries and beliefs in the "Other Europe" continue to hinder Croatia's integration with the European Union. Ultimately, despite claims that the state is becoming less important in international organizations, like the E.U., the nation is still a force to be reckoned with at all geographical scales.

The first section of this chapter examines some of the major perspectives on the nation, and explores why it's an important component of geographical (specifically geopolitical) research. The second section narrows the focus to geopolitical perspectives on imperialism, ethnicity, territoriality, and the state to determine how these concepts contribute to the development of the nation. Lastly, the concluding portion of this chapter introduces the role that geographic imaginaries and the "process of othering" play in the process of globalization and E.U. integration. 


\section{A. The Nation \& Nationalism}

Generally, nationalism is expressed and can be defined in multiple ways. A simplistic and concrete definition explains that nationalism can present as (1) a state cause, which reinforces the role or idea of the nation-state, (2) an anti-colonial cause, which focuses on throwing off the rule of a larger or more powerful state, and (3) an ethnic cause, which emphasizes the idea of a shared experience, culture, and language in demanding sovereignty (Gregory, 2000, p. 533). As will be discussed later, all three of these definitions can be applied to nationalist struggles in Southeastern Europe and Croatia, but these categories do not answer some of the deeper questions regarding the formation of the nation.

The unique national experiences of different places, spaces, and scales, have made it incredibly difficult for academics to develop some generalizable theory on the origin of the nation. Modernist perspectives, based in the Enlightenment Era, are often most popular, but social scientists draw on a variety of theoretical and ideological perspectives for answers. The result is that there is no dominant view on the nation, and a variety of opinions exist to determine if nationalism is inherent to the human condition, how and why the nation forms, and whether its existence is a positive or negative force. Benedict Anderson, one of the main contributors to modern theories of the nation and nationalism, frames the debate on nationalism when he queries; "How is universality to be reconciled with its [nationalism's] necessary concrete particularity? What discipline helps inquiry the most profoundly... why have so many seminal thinkers of modernity...had so little to say about it" (Anderson, 2000, p.1).

In debating the nation and nationalism, scholars have conflicting opinions on whether the nation is something real and material, something constructed or imaginary, or some combination of both reality and fantasy. One thing that most theorists can agree on is that the nation, as we 
know it, is a relatively modern concept. Although cultural, linguistic, religious, and ethnic differences have existed since the beginning of civilization, the concept of a "nation" or "nationness" as Anderson would call it, has only been around since the $19^{\text {th }}$ century, and, for many theorists, coincides with the development of capitalism as a mode of production (Anderson, 1996). However, here again there is a debate on the role that unique social and historical processes, including capitalism, play in forming the modern national identity.

Before proceeding to a discussion of the many different theories of the nation, it's important to note the differences between the concepts of state, nation, and nation-state. Throughout this study, the state is seen as a geographic entity with an institutional framework and system for governing a territory that may include multiple nations of people. A nation is used to describe a population of people who share beliefs in historical myths, a common culture, and a historic tie to some territory or space. The term, nation-state, can be used to characterize a state whose policies are designed to support the interests of a single nation of people.

Since its secession from Yugoslavia, Croatia exists as a sovereign state, but the entire Croatian nation does not reside within the borders of the state. Instead, the Croatian nation is spread out across many states throughout the Balkan Peninsula, and other places in the world. However, because the state is almost entirely homogenous and has, in times of increased nationalist discourse, focused on the preservation of a Croatian national identity, Croatia can be characterized as a nation-state. Some of the theorists discussed below see the state as a container for the nation (Gellner, 2000), while others recognize the nation as having a fluid existence that can transcend the boundaries of state entities (Smith, 1996). A closer look at the differing perspectives on the nation can inform how the nation, state, and nation-state are used in this project. 


\section{Theories of the Nation}

Ernest Gellner published Nations and Nationalism in 1983 (about the same time as Anderson's seminal work, Imagined Communities), and argued that although nations exist in the modern world, the root of nationalism is based on entirely false concepts. According to Gellner, the modern world is run by nation-states, which in themselves are false geographical entities designed to support industrial production. In a highly technological age, states must continuously expand for production opportunities and resources. In order to facilitate this growth, a homogenous culture is a necessity, because people must learn the rules of employment in order to operate in an industrial society. Without a homogenous culture, or nationalism, society will be unable to produce a standardized culture for industrial expansion and will ultimately fail (Gellner, 2000, pp. 98-145).

Although Gellner tries to distance himself from Marx, his theory on nationalism is related to Marx's views on the role of the state. Gellner tries to distinguish between Marx's feudalism to capitalism transition by insisting that our modes of production have moved from agrarian to industrial. Instead, he argues that class is not the root of conflict and is as much of a false construction as nationalism. Despite this, there are some similarities between Gellner's and Marx's ideas. Marx would argue that the state exists to support the accumulation of capital, which requires the necessary reproduction of the working class. This is very similar to Gellner's claim that the state must expand for resources and production opportunities, which requires a standardized cultural education of the state's citizens. Where Marx and Gellner both lack, is in their ability to distinguish between the state, the nation, and the nation-state as separate entities.

In many ways, Gellner's 1983 arguments are similar to traditional geopolitical theories that use the state as the primary scale of analysis. His claim that states must expand for 
production and resource opportunities places the state at the utmost level of importance in explaining how nations and the ideology of nationalism develop. This notion of the state needing to expand harkens to the days when geopoliticians like Friedrich Ratzel saw the state as an organic entity that needed to grow. Because of this, Gellner runs the risk of falling into Agnew's "territorial trap," which warns against viewing the state as a sovereign unit that acts as a container for society (Agnew, 1994). In other words, Gellner neglects to acknowledge that the nation may transcend the boundaries of the state, and that, conversely, the state may not necessarily represent a single nation.

Benedict Anderson's work, Imagined Communities (1983), begins to move the scale of analysis away from the state to focus on individual nations. Like the title of his book denotes, for Anderson, nationalism is the result of communities that we imagine. Unlike Gellner, Anderson argues that our cultural differences are real, and not just the result of the interaction between politics and industrial production. Distinguishing between nations as "real" and "imagined" is a hard concept to reconcile. To clarify, Anderson argues that our cultural differences do exist, but "nations" are imagined as limited, as sovereign, and as a community. Anderson argues that:

"The nation is imagined as limited because even the largest of them, encompassing perhaps a billion living human beings, has finite, if elastic, boundaries, beyond which lie other nations...nationalist do not dream of a day when all the members of the human race will join their nation..It [the nation] is imagined as sovereign...nations dream of being free...The gage and emblem of this freedom is the sovereign state...it is imagined as a community, because the nation is always conceived as a deep, horizontal comradeship" (Anderson, 1983, pg.7).

Some of Anderson's ideas are both Marxist and post-structural in nature, because he focuses on how the use of language and discourse has helped form and enable a sense of nationness, while at the same time giving credit to the motor-force of capitalism as a large contributor 
in spreading ideas of the nation. For example, he argues that the printing press was an important agent in the production of nationalist identities. For Anderson, the printing press helped to usher in the age of capitalism as the dominant mode of production, and once newspapers began to be circulated over a wide range, discourse allowed communities to begin to be imagined as unified or connected. Anderson also discusses the use of maps as "a territorial specific imagined reality" to perpetuate ideas of the community in classrooms (Anderson, 1983, pg. 122).

One of the largest criticisms of both Gellner and Anderson is that they focus on nationalism from a Western perspective. Partha Chatterjee has contributed to the debate on nationalism both by criticizing the traditional narrative on nationalism and by taking into consideration the post-colonial world's view of the nation. In his article, "Whose Imagined Community?," Chatterjee counters Benedict Anderson's claims that nationalism is a product of Western civilization. More specifically, he finds fault in Anderson's view that the West has provided a set of models for subsequent national movements to adopt. He argues that if postcolonial societies must adopt already proven Western models for the nation and state, then there is nothing left for them to imagine (Chatterjee, 2000).

Instead, Chatterjee argues that post-colonial movements specifically try to define their nation-ness in terms that oppose existing Western traditions. He sees anti-colonial movements as creating sovereignty by separating the 'material' from the 'spiritual.' The material represents an outer domain consisting of the economic and technological arenas where the post-colonial world must accept that the West excels, and therefore must adopt Western models for their own societies. On the other hand, the spiritual is the inner domain, where individual cultural identity is formed in opposition to the traditions of the West. Anti-colonial movements are often built upon this spiritual domain which emphasizes the uniqueness of culture, language, and ethnicity 
(Chatterjee, 2000, p. 217). Chatterjee argues that the traditional study of nationalism does not allow for a language in which nations may express their difference.

Eric Hobsbawm and Terence Ranger further expand on the idea of difference in the book, The Invention of Tradition (2000). They claim that a great deal of our cultural customs, though rooted in the past, have been a recent invention that enables an idea of cultural community or nationalism. A historian, and self-declared Marxist, Hobsbawm sees nationalism as a modern "political programme" that promotes the idea of nations having a right to form autonomous and territorial states (Hobsbawm, 2000, p. 256). Nationalism is ultimately rooted in a concept of ethnicity (often defined in terms of a linguistic identity), which is not a political force, but a "real sense of group identity which links the members of 'us' because it emphasizes the differences from 'them"' (Hobsbawm, 2000, p. 258).

Hobsbawm's acknowledgement of a sense of community and ethnicity that is rooted in historical processes, as well as Chatterjee's contention that the popular narratives on nationalism are written from a colonial perspective, further remove the study of nationalism from the scale of the state and from the perspective of the West. If we are open to multiple scales of analysis, then there are many more questions concerning the role that history (i.e. imperialism), identity (ethnicity, religion, etc.), and location play in a study of nationalism.

Hobsbawm, Gellner, Chatterjee, and Anderson seem to agree that the nation is an imagined if not all together false concept. Even if it is rooted in real historical, ethnic, and linguistic differences, nationalism is something that has developed in the modern era, and has appeared in conjunction with or as a consequence of the development of capitalism. However, others, like Miroslav Hroch and Anthony D. Smith, question both the assumption that nations are imagined and that they are purely modern concepts. 
Miroslav Hroch is a Czech political theorist who has studied the effects of nationalism in Eastern Europe. Hroch expresses dissatisfaction with what he sees as the overproduction of theories on nationalism at the expense of comparative research (Hroch, 1993, p. 1). For Hroch, it is too simple an answer to claim that nations are the sole product of modernity and the spread of nationalism as an ideology. Instead, he chooses to highlight the long, historical processes that have contributed to the creation of separate national identities.

Gellner interprets Hroch as arguing that "nations really exist and express themselves through nationalist striving...At the same time, the transition between the past Marxist 'modes of production' remains the basic event of the time, and the (autonomous?) nationalist development is plotted against that event" (Gellner, 2000, p. 132). Gellner criticizes Hroch on both of these points, denying the existence of a real nation, and reiterating his own belief in an agrarianindustrial transition in place of Marx's modes of production. Rather than focusing on what a nation is, Hroch is more interested in how the concept of nation has expressed itself in both a historical and contemporary context. In his own words;

"My own work has not sought to advance a theory of nation-building, but rather to develop effective methods for the classification and assessment of experiences of nation-building as a process set within a wider social and cultural historytreated not as so many singular and unrepeatable events, but as part of a broad transformation of society that is amenable to controlled generalizations" (Hroch, 1993, p. 1).

Hroch's decision to focus on historical process rather than a generalized theory has interesting implications both for the study of nationalism as a whole, and for this research. The decision to examine comparative historical processes indicates that not all nations may develop or express themselves on the same linear trajectory that Western nations have. In understanding the role that the nation continues to play in Croatia, Hroch's work allows this research to move 
beyond the question of what the nation is, to how it was formed and changed in relation to historical processes (i.e. imperialism, the Yugoslav Wars, the transition from socialism to capitalism).

The last major contributor that will be reviewed in this chapter takes a much more moderate approach to the study of nationalism than the previous scholars that have been explored. Anthony D. Smith criticizes existing theories of the nation as focusing too heavily on the modernist origins of nationalism and ethnicity, and instead proposes a greater examination of the pre-modern origins of ethnic communities and nations through the study of the relationship between cultural and politics (Smith, 1996, p. 445). Whereas Hroch argues that there has been too great an emphasis on the creation of theories, Smith contends that the theories that have been proposed have not fully explored how nations develop and how ethnicity is valued to such an extent that people are often willing to die for it.

In order to better understand the relationship between ethnicity, the nation, and nationalism, Smith clarifies each concept. He defines an ethnic community as sharing an alleged common ancestry, culture, and a specific link to territory; a nation as a population sharing a territory, common myths and historical memories, culture, economy, and legal rights and duties; and nationalism as a movement for autonomy, unity, and identity by a population who believe they share a nation (Smith, 1996, p. 447). References to an alleged common ancestry, a specific link to territory, and common myths suggest that Smith does believe to some extent in an imagined sense of community, but also alludes to the importance that geography can play in analyzing a population's historic territory. In addition to defining each of these concepts, Smith seeks to highlight the long-term processes (historical, social, and otherwise) that populations undergo, which lead them to become attached to an ethnic identity or the idea of a nation. 
Smith argues that these long-term processes are still at work today. It is only through acknowledging the existence of these social, historical, and political formations that we might be able to encourage the creative features and control the violence that often accompanies national pride (Smith, 1996, p. 458). It is true that both World Wars, the fall of communism in Eastern Europe, and the dissolution of Yugoslavia may be explained, at least partially, in nationalist terms. Geography, and especially geopolitics, is uniquely poised to take up the nationalist debate in terms of space, place, and human-environment relations.

Generally, geography has not contributed, in large part, to the production of theories of the nation and nationalism. Geographers like D.J. Zeigler use cartography to examine Eastern Europe from a post-communist perspective (Zeigler, 2002). Others discuss post-socialist transition, E.U. integration, and remaining cultural and nationalist conflicts between Southeastern European states (Dragojevic, 2005; Okey, 2005). These works contribute to a greater understanding of national issues in specific places, but don't necessarily connect these issues to the global scale. If geography can begin to reconcile some of its own particularities with universalities, the discipline's study of the interaction between space, place, and environment could lend a great deal to theories of the nation.

Perhaps the most difficult part of relating the particular movements of nationalism to a larger understanding of the subject is that nationalist movements view themselves as, and are in some ways, inherently unique or special. Whether it is state, ethnic, or anti-colonial nationalism, there are unique historical and social processes that are at the root of nationalist conflicts, which make it hard to generalize on a broader scale. However, as researchers we need to ask ourselves if we agree with David Harvey when he says that the "perpetuation of those political identities and loyalties requires the perpetuation of the oppressive conditions that gave rise to them" 
(Harvey, 1996, p. 40). Although Harvey was discussing advocating for industrial workers, this statement is applicable to the study of nationalism. By lifting up nationalist conflicts as heroic or special, are we enabling the very imperialist, capitalist, or discriminatory structures that gave rise to them in the first place, and are we perpetuating the idea that national recognition can only come from conflict or struggle?

Of course, perpetuating nationalism is only a negative thing if nationalism itself is negative. The concluding portion of this section discusses the protection and security that nations can offer, and the violent movements that often accompany national ideologies. Beliefs in nationalism have spearheaded democratic revolutions, but have also bred xenophobia, discrimination, genocide, and war. So, it is pertinent to ask if it possible for society to move beyond ideas of the nation to a place where humanity is valued over other ties?

\section{The End of Nationalism}

For a long time, academics have pursued the idea that nationalism was something reserved for the developing world. Once a country becomes economically developed, politically stable, and socially heterogeneous, it follows that they will have less of a need for ethnic and anti-colonial nationalism. For many, the end of the Cold War signaled the end of ideological conflict in the developed world, but not necessarily the end of national and ethnic conflicts for those states that have not reached the Western world's level of development (Fukuyama, 1989). On one hand, this belief can be completely disregarded when discussing the recent increase in nationalism in the West (particularly with the rise of right-wing movements in the U.S.), but on the other, it seems to be supported with the ethnic conflicts that have occurred in the former Yugoslavia, and the rise of right-wing nationalist groups in Eastern European states. 
Instead of the transition from socialism to democracy or imperialism to independence bringing about social equality, the opposite has occurred. Eastern Europe has experienced "the gradual retreat of the liberal-democratic tendency in the face of the growth of corporate national populism which includes all its usual elements, from xenophobia to anti-Semitism" (Žižek, 1993, p. 200). Although this resurgence of nationalism has, in many ways, been blamed on the suppressive nature of communism in the region, it also indicates that free-market democracies do not necessarily diminish the importance of the nation.

Slavoj Žižek, a Slovenian philosopher, has expanded the debate on nationalism to understanding the violence and conflict that results from it. He argues that "a nation exists only as long as its specific enjoyment continues to be materialized in a set of social practices and transmitted through national myths that structure these practices” (Žižek, 1993, pg. 202). In other words, as long as people receive some enjoyment or security from being a part of a community or group, nations will continue to be a part of politics and society. However, as space and time continue to be annihilated through the technological developments associated with modern capitalism, the role of individual states is said to be diminishing, and some might argue that nation-states and nationalism will no longer provide the sense of enjoyment and security they once did.

One of the most prominent examples of the role of the state diminishing may be found in the European Union. Members of the E.U. have had to minimize their nationalist platforms in order to work most effectively with other member-states. If the E.U. is able to provide economic and political stability for its members, then the nation may become less important. However, not all members of the E.U. have experienced equal success, particularly in Eastern Europe. The uneven spread of development across the E.U. (Hudson, 2000), hesitations over E.U. expansion 
to post-socialist states (Virkkunen, 2001), and an increase in the importance of nationality in post-communist Europe (Haller \& Ressler, 2006) have demonstrated the continuing importance of the nation-state despite the E.U.

For these reasons, this project has special significance in examining the role of the nation in Croatia's E.U. transition. This research demonstrates that, because of Croatia's recent history with national conflict, the state struggles to prove it is developed, Western, and stable enough for E.U. integration. At the same time, the state still places importance on the traditions and cultural practices that are important to the preservation of the Croatian nation. These issues demonstrate, to some degree, that in spite of the supposed lessening role of the state and nation, the nation still offers a sense of protection, security, and belonging.

Despite the merits of all of the previously discussed theories and perspectives, I generally accept Anthony D. Smith's view that nations are imagined concepts, but that they are rooted in both modern and pre-modern social and historical processes. Additionally, despite the many claims that the nation and nationalism are becoming less important in a postmodern world, I approach this project with the assumption that the nation is still one of the most important forces in global politics. By accepting the important role that the nation plays globally, it is important to explore the specific social and historical processes that have helped to give the nation value. An examination of how the geopolitical perspectives on imperialism, territoriality, ethnicity, and the state can be helpful in this aim. 


\section{B. Geopolitical Perspectives}

\section{Imperialism}

In a geopolitical analysis, one cannot ignore the long-term effects that colonization and imperialism have had in drawing physical boundaries between states and ethnic groups. Imperialism has also created imaginary boundaries between what is perceived to be the developed and developing world. Additionally, the process of colonization created unequal power relations between the colonizer and the colonized through unequal trade relations and the perpetuation of an imperial culture in place of indigenous identities (Jeffrey \& Painter, 2009). These unequal power relations often remain in place long after imperial rule ends.

In post-colonial and post-imperial societies, there is often a focus on the restoration of indigenous culture and identity that was suppressed during foreign rule. This restoration often presents as a national movement in which post-imperial spaces engage with Partha Chatterjee's spiritual domain by trying to reclaim the traditional practices that separate them from the West (Chatterjee, 2000). In this way, imperialism has increased the presence of nationalist ideologies and movements in Southeastern Europe and across the globe.

Instead of recognizing the important role that imperialism has played in creating national movements, the West often blames national tendencies on underdevelopment or undesirable cultural behaviors. The West engages in a form of Terry Eagleton's 'terrible twins': amnesia and nostalgia; the West's "inability to remember and the incapacity to do anything else" (Gregory, 2004, p. 9). This shifting of blame has occurred in many post-imperial and post-colonial spaces throughout the world. In Southeastern Europe, Western states have often ignored the effects that imperial powers have had on creating the dynamic and conflict ridden history of the Balkans 
(Glenny, 1999), and instead blame underdevelopment and conflict on regional practices and traditions.

Understanding how nationalism is formed and viewed in post-imperial states contributes to this study's research findings in multiple ways. Firstly, it helps conceptualize how beliefs in an ultra-nationalist Balkanism have affected Croatia's E.U. transition. Secondly, it partially explains why the Croatian state has had to work to combat the preconceptions and memories that Westerners have of the region as a post-imperial space. The third section of this chapter will explore further how Western perceptions affect relations in Croatia.

\section{Ethnicity, Territoriality, and the State}

Although imperialism can increase a national consciousness amongst populations seeking to define themselves in opposition to foreign rule, it is not the only social process that contributes to the formation of a national identity. In addition to cultural practices and historical myths, nations are often built on beliefs in a collective ethnic identity, and on a historic tie to territory (Smith, 1996). In movements for national independence, as well as in established nation-states, the belief in a necessary expansion of a homogenous culture (Gellner, 2000) can involve drawing on those ethnic and territorial memories. A brief discussion of why ethnicity and territoriality are important to national causes, as well as how states use these concepts to perpetuate a national identity is a necessary component of this research.

Ethnicity originated as a term to replace the usage of race to describe the varying origins of people (Gregory, 2000, p. 235). However, the process of how a person comes to identify with a particular ethnic group involves more than a connection to a racial identity. As previously mentioned, an ethnic community shares an alleged common ancestry, a culture, and a specific 
link to territory (Smith, 1996, p. 447). More specifically, ethnicity can be seen as “...both a way in which individuals define their personal identity and a type of social stratification that emerges when people form groups based on their real or perceived origins...ethnic groups believe that their specific ancestry and culture mark them as different from others" (Gregory, 2000, p. 235).

In this way, when groups use ethnicity as the basis for engaging in a nationalist movement or struggle, they draw on imagined historical and social processes as well as real experiences. This relationship between the real and imagined roots of ethnic identity has a special significance when examining nationalist conflict in Southeastern Europe. The term ethnic genocide has been used to define the violence associated with the dissolution of Yugoslavia, despite the fact that Balkan nations share a historical connection to the Slavic ethnicity. Even with this common ethnic heritage, the real experiences and perceived differences that Balkan nations have from each other (as Croats, Serbs, Albanians, etc.) have made nationalism in the region an ethnic issue.

In regions like Southeastern Europe, where complex histories and ethnic make-ups exist, culture and territoriality are often contested. In these cases, conflicting memories and identities are negotiated through the process of building a collective memory (Herb, 2004, p. 142), and national traditions are created through anthems, monuments, and symbols (Hobsbawm \& Ranger, 2000). Although groups of people shape these traditions and memories, the state can play an important role in deciding which of these memories, symbols, and ideas better serve national needs or political desires.

In examining the construction of the nation in East and West Germany, Guntram Herb defines the process in which nations and the state connect with and interpret historical memories and events as territorial bonding/territorial script. Firstly, a border for the national territory is 
established through territorial differentiation, which helps to distinguish who is included in the nation ('us') and who isn't ('them'). Secondly, an emotional relationship between the nation and the established territory is created through territorial bonding. To create this emotional bond, the state often uses a narrative, or territorial script, which involves the use of stories and myths surrounding geographical locations, landmarks, symbols, and monuments (Herb, 2004). Territorial bonding/territorial script has played an important role in establishing national identities in Croatia and Southeastern Europe.

Although imperialism, ethnicity, and territoriality are not the only historical processes that lead to the formation of a nation, these concepts have a special significance in exploring the nation in Croatia and Southeastern Europe. Croatia's history with imperial rule, the construction of an ethnic identity, and the development of a sense of territorial bonding have all contributed to the image that Croats have constructed of themselves. However, these forces have also affected how Croatia is viewed by the world, and how it is constructed as an 'other'. The concluding section of this chapter briefly examines how the process of othering affects relations between nations, and introduces how Croatia and Southeastern Europe have been constructed as an 'other' in Europe.

\section{Western Perceptions and the Process of Othering}

In constructing an image of what constitutes a particular nation, people also construct an image of what and who is not included (Hobsbawm, 2000; Gregory, 2000; Herb, 2004). In Southeastern Europe, this relationship between who is included and excluded has resulted in ethnic and national conflict. However, the process of nation-building in the region has also affected the way Southeastern Europe is viewed by the rest of the world. A brief analysis of how 
the process of othering creates varying geographic imaginaries and perceptions can provide the support needed to examine how Western perceptions of nationalism in Southeastern Europe affect Croatia's E.U. transition.

One of the most well-known works dealing with the process of othering and the creation of geographical imaginaries from a post-colonial/post-imperial perspective is Edward Said's, Orientalism (1979). In it, Said sought to examine the "political vision of reality whose structure promoted the difference between the familiar (Europe, the West, 'us') and the strange (the Orient, the East, 'them')" (Said, 1979, p. 43.). He analyzed how the West constructed an imaginative geography to represent the social, political, cultural, and economic boundaries that separates 'us' from 'them' (Said, 1979). His work has been absolutely critical in understanding the colonizers view the colonized, as well as how we geographically separate what is familiar and near to us from what is 'over there.' He calls this process of categorization and exclusion, 'the process of othering'.

Maria Todorova built on Said's work in, Imagining the Balkans (1997). Todorova set out to understand the historical and political narrative constructed by the West to identify those peoples residing in the Balkan Peninsula. She argues that

"By being geographically inextricable from Europe, yet culturally constructed as 'the other' within, the Balkans have been able to absorb conveniently a number of externalized political, ideological, and cultural frustrations stemming from tensions and contradictions inherent to the regions and societies outside the Balkans. Balkanism became, in time, a convenient substitute...exempting the West from charges of racism, colonialism, eurocentrism, and Christian intolerance against Islam. After all, the Balkans are in Europe; they are white; they are predominantly Christian...the Balkans have served as a repository of negative characteristics against which a positive and self-congratulatory image of the 'European' and the 'West' has been constructed' (Todorova, 1997, p. 188). 
In addition to constructing a cultural and political narrative of the Balkans, Todorova also discusses how the West constructed the geographical boundaries of the Balkans to have varying definitions throughout history. The boundaries that geographers have prescribed to the Balkans have swollen and shrunk to include states as north as Austria and Hungary, as east as Romania, Bulgaria, and Turkey, and as South as Albania and Greece. The changing geographical imaginary of the Balkans has contributed to the conflicting ideas of territoriality and identity.

For example, Croats and Slovenes have often viewed themselves as more Western in identity, while Hungarians often identifies more with Central Europe. Despite this selfidentification, geographers have often included all three of these nations in their definition of the Balkan region. Todorova defines Albanians, Bulgarians, Greeks, Romanians, and most of the former Yugoslavs as Balkan. She does not include Slovenes in this definition, but includes Croats because of their experience with the Ottoman Empire. Todorova also includes Turks due to their central role in the Ottoman experience (Todorova, 1997, pp. 30-31). The view of the Balkans as something Eastern or sharing an Ottoman history has allowed the West to engage the region in a geographical, political, and cultural process of marginalization.

As an aside, despite the purely geographical origin of the term, "Balkan," Todorova emphasizes the word's modern association with ultra-nationalism, barbarism, and a certain mentality that carries with it negative connotations (1997). As such, I have tried to avoid using this term in favor of the less politicized phrases of "Southeastern Europe" or "former Yugoslav Republics." In cases where the term "Balkan" is mentioned, it is done so to make connections to historical events or is used in a purely geographical sense.

Said and Todorova demonstrate that by constructing the nation, we automatically marginalize, or other, populations that have cultural, ethnic, and political values different from 
our own. These characterizations lend to the creation of geographic imaginaries that not only affect how we perceive the world, but also shape how nations and states are able to interact with to each other. The process of othering has not only contributed to the difficulties in how Croatia relates to neighboring nation-states, but has also affected the perceptions that other nation-states have of Croatia. The research findings will explore how geographic imaginaries and the process of othering continue to affect Croatia's ability to gain access to the European Union.

\section{Summary}

This chapter has attempted to reconcile some of the most popular perspectives on the nation with geopolitical theory. The nation and nationalism are the results of long-term social and historical processes (Smith, 1996), and geography's use of space, scale, place, and time allows for a closer examination of those processes. Imperialism influenced the need for the postcolonial world to express their national identities (Chatterjee, 2000), and also created uneven power relations between the colonized and colonizer that still exist today (Gregory, 2004; Jeffrey \& Painter, 2009). An attachment to ethnic identity that is founded on real and perceived experiences (Gregory, 2000) helps nations to categorize who belongs and who doesn't. Issues of territoriality allow nations to create geographical boundaries, and produce a collective memory perpetuated by myths and symbology (Herb, 2004; Hobsbawm \& Ranger, 2000). Geographic imaginaries and the process of othering define nations and groups by their difference or uniqueness from outsiders (Said, 1979; Todorova, 1997).

These theoretical perspectives inform the overall research goals in multiple ways. This framework allows for an investigation of how the nation has evolved in Croatia, which lends to explaining the importance of the nation for a post-war generation of Croats, and supports an 
analysis of the current role that nationalism plays in Croatia's E.U. transition. A closer examination of issues of ethnicity, imperialism, and territoriality conceptualize the importance of the nation in Croatia. Lastly, theoretical perspectives on the process of othering contribute to understanding the relationship between Croatia, its neighbors, and the rest of Europe. The research findings will demonstrate that the nation remains an important force in Croatian society, and will expose how preconceptions of Balkan nationalism and 'Other Europe' produce uneven relations between Croatia and the E.U. 


\section{Chapter III: Study Area \& Statement of the Problem}

In Croatia, a dynamic history with imperialism, ethnic conflict, and geographic change has given the nation and nationalism a unique importance. This chapter takes a closer look at some of the specific events and processes that have helped shaped the question of the nation in Croatia and Southeastern Europe. This examination of the case-study area is essential to the understanding how Croatia's relationship with Europe is affected by nationalism, what role nationalism plays in Croatia's transition to the E.U., and how important the nation remains to Croatia's youth.

The first half of this chapter outlines some of the basic geographic features of Croatia in order to understand some of the country's locational, political, and social characteristics. The second half discusses the changing importance of the nation through a brief historical analysis of how the nation has expressed itself in Croatia and Southeastern Europe. In conjunction with the information in Chapter II, this chapter will lay the groundwork needed to support the research methodologies and findings discussed throughout the remainder of this paper.

\section{A. Case-Study Geography}

Croatia, one of the northernmost states in the Balkan Peninsula, is bordered by Slovenia, Hungary, Serbia, and Bosnia and Herzegovina, and has a long coast along the Adriatic Sea (Figure 3.1). According to the Croatian government website, approximately 4.4 million people inhabit the Republic of Croatia's 56,500 square kilometers, which include the country's mainland and some 1,185 islands, cliffs, and reefs off the coast. The country is diverse climatically, with a Continental (or Highland) climate in the north, a mountain climate in the 
central and southern Dalmatia region, and a Mediterranean climate along the coast (Identity Card, 2009).

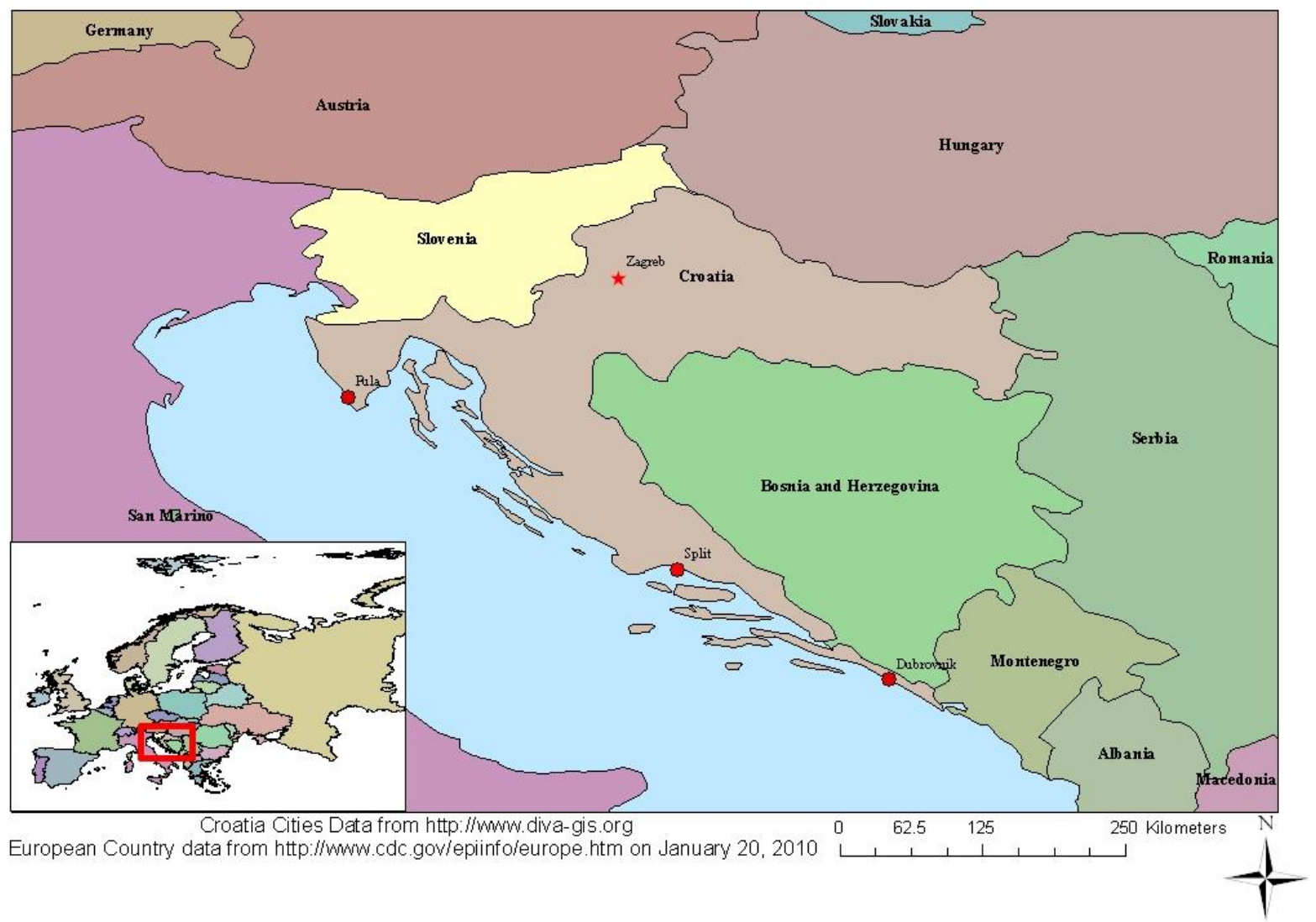

Figure 3.1 Study Area

Croatia's geographical location is unique historically and politically. Because of the imperial influence from the Ottoman Empire and the Austro-Hungarian Empire, the Balkan Peninsula and Croatia have often been seen as a borderland between the East and West. Imperialism has also created a north-south divide within the Balkans. For example, the Croats and Slovenes in the north are culturally and religiously linked to the Catholic Austro-Hungarian and Italian heritage, while the Serbs, Macedonians, and Kosovan in the south have been influenced by Orthodox Christianity and Islam from the Ottoman Empire (Glenny, 1999; Tanner, 1997; Todorova, 1997). 
However, these generalizations are not even across all geographical scales. In many ways, Croatia identifies with Western Europe, due to imperial influence from the AustroHungarian Empire. However, there were pockets of Croatian territory that were under Ottoman control as well. Because of this, Croatia represents the same East-West/North-South divide that the Balkan Peninsula is often associated with as a whole.

In addition to creating cultural and political divides, the region's dynamic history has also influenced physical boundaries. In Croatia, as in other Southeastern European states, physical boundaries have swollen and shrunk depending on the political climate (Figure 3.2). The current boundaries of the Croatian state are influenced by historical memories of the medieval Kingdom of Croatia, which existed prior to imperial intervention (Tanner, 1997). Despite gaining its independence, territorial issues still affect Croatia's regional relations. The conflicting claims from Croats and Serbs over Bosnian territory led to the most violent part of Yugoslavia's dissolution to be fought on Bosnian soil. Also, a more recent territorial dispute with Slovenia has proven to be a large obstacle in Croatia's quest for E.U. admittance.

Due to these territorial issues and the role of imperialism in the region, the ethnic makeup of the modern Croat is a unique mix of Croat, Czech, German, Hungarian, Greek, Serb, Jew, and countless other Slavic and European ethnicities (Tanner, 1997). Despite this, Croatian citizens overwhelmingly identify with a Croatian ethnicity, which further supports the argument that ethnicity is equally tied to real and perceived experiences (Smith, 1996; Gregory, 2000). As of the 2001 census, over $89 \%$ of citizens define themselves as ethnically Croatian, and over $87 \%$ identify as Roman Catholic (Figure 3.3). 


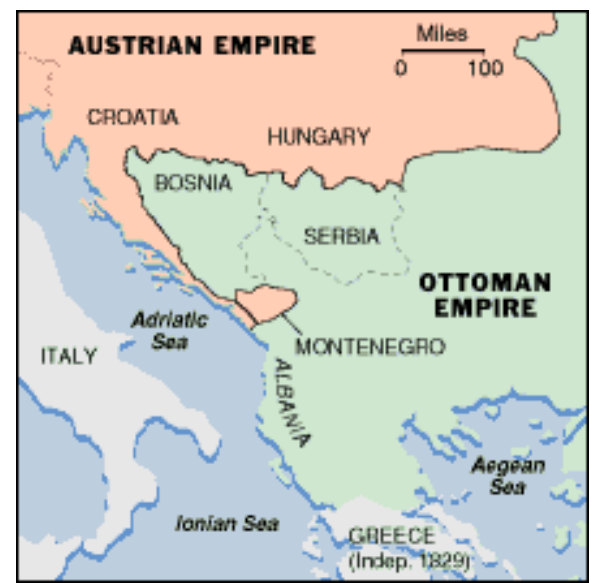

1815 to 1839: After the Congress of Vienna

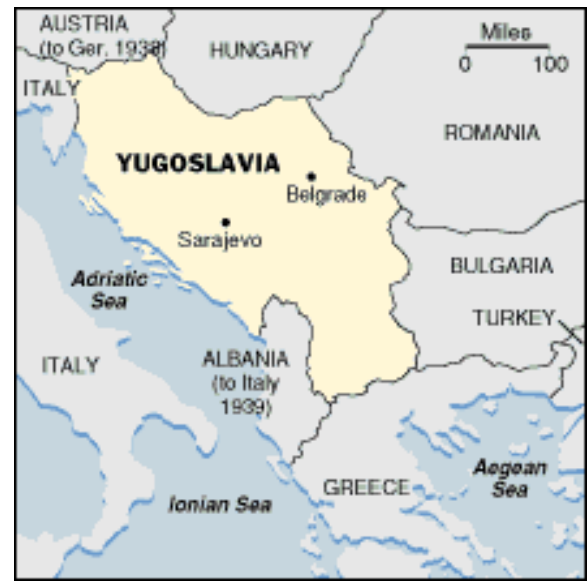

Between the Two World Wars

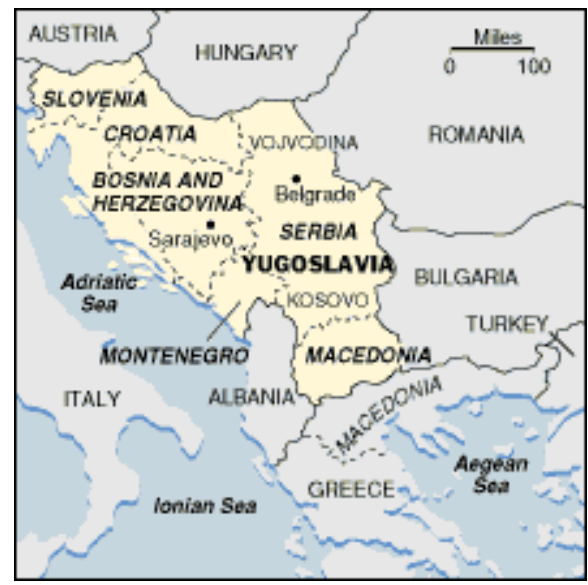

1945 to 1990: Cold War Stability

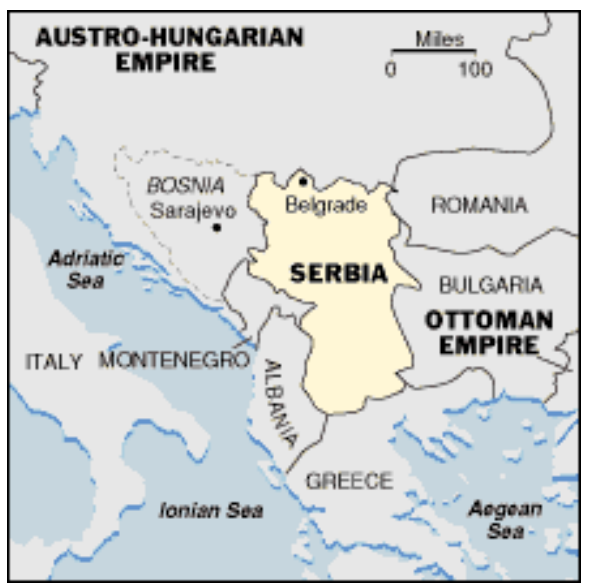

1914: Eve of the First World War

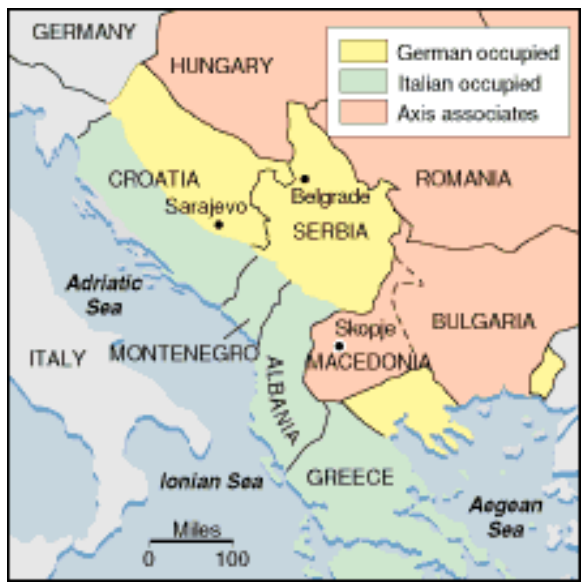

Nov. 1942: Height of Axis Occupation

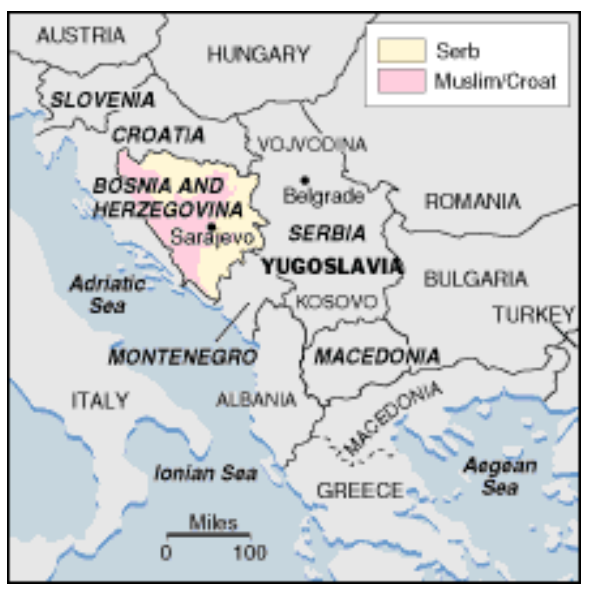

1991 to 1995: Open Warfare

Figure 3.2 Croatia's Changing Boundaries (Source: New York Times, 'Bosnia: Uncertain Paths to Peace,' 1996) 
Although Croats have always been the dominant nation within Croatia's borders, the population has become increasingly homogenous over time. In times of increased nationalist political discourse, non-Croat minorities were often pushed into exile or killed as a part of larger discriminatory or genocidal movements. In 1991 , more than $12 \%$ (some 580,000 people) of Croatia's population identified themselves as Serbian. Within a single decade, that number dropped to a little over $4 \%$ (a little over 200,000 people). There is a similar trend in the overall minority population, which comprised nearly $10 \%$ in 1991, and dropped almost half to a little over 5\% by 2001 (Figure 3.3). The reason for this population change is most certainly due to the break-up of Yugoslavia. The violence associated with the Croat independence war began in the Serb dominated region, called the Krajina. Many Serbs who lived in this region were killed or forced into exile during this time.

Economic development has also created regional geographic divides in Croatia and the rest of the former Yugoslav republics. The dissolution of Yugoslavia seriously hindered the economies of the successor states, creating levels of uneven development across the region. Although the northern republics, including Croatia and Slovenia, were more successful in postwar economic privatization and stabilization, the southern republics of Serbia, Montenegro, and Bosnia-Herzegovina struggled to recover from the war (Lampe, 2000, pp. 403-404). These economic relationships perpetuated a developed-underdeveloped/North-South divide. An examination of regional uneven development could further expose the post-war environment of the former Yugoslav republics, but ultimately these economic factors are secondary to questions of the nation and geographic perception in this research.

The experience of transitioning from socialism to free-market capitalism also makes the former Yugoslav republics an interesting space for a case-study. Many works have focused on 


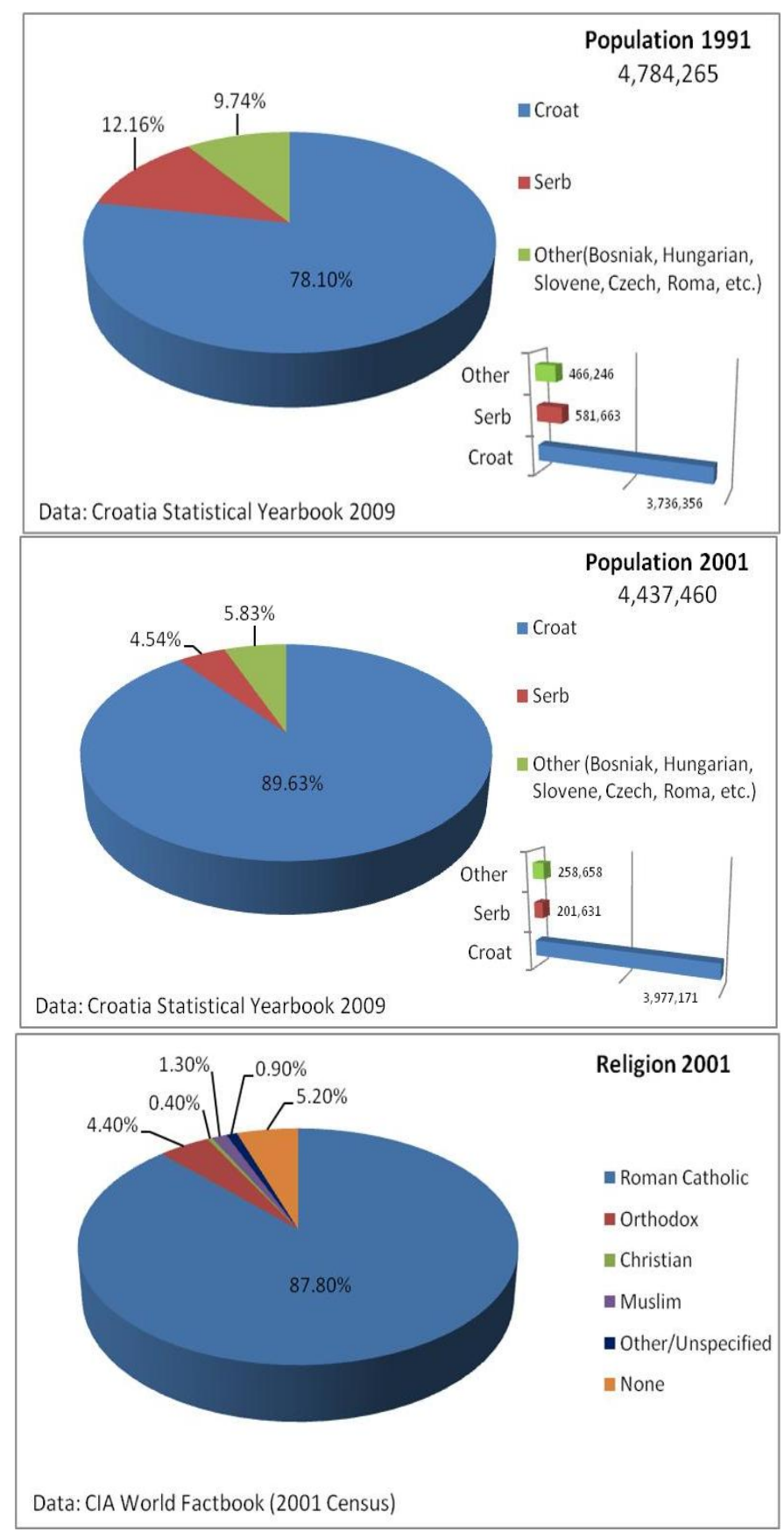

Figure 3.3 Ethnic \& Religious Demographics (Source: Croatia Statistical Yearbook, 2009)

how post-socialist spaces in Southeastern Europe deal with economic, political, geographical and social change (Petrovic, 2008; Virkkunen, 2001; and Zeigler, 2002). Understanding the role that the nation and nationalism played in bringing about the end of communism in the region could expose the relationship between economic conditions and nationalist ideologies. Since this 
research is interested in the current state of nationalism, Croatia's experience with socialism is only briefly mentioned in a historical context, so the question of a post-socialist space is reserved for a possible future research project. However, as part of this project's data collection, online surveys were conducted with young Croat adults who have spent most of their lives in a postwar/post-socialist Croatia. As such, Croatia as a post-socialist space is acknowledged to some degree in the survey responses.

Imperialism, changing boundaries, social and political change, and a strong desire to preserve an ethnic identity has given the process of nation-building a special significance in Croatia and the rest of Southeastern Europe. Despite the cultural and political similarities that many Southeastern European nations share, significant efforts have been put forth to emphasize what it means to be Croatian by highlighting how different, and sometimes superior, Croats are linguistically, culturally, politically, and religiously from their neighbors.

\section{B. Nation-Building \& the Western Response in Croatia and Southeastern Europe}

This research project seeks to examine the current importance of nationalism in Croatia and to identify how Western perceptions of Balkan nationalism have affected Croatia's E.U. ascension. In order to fully understand the importance of these goals, it is necessary to examine some of the ways that nationalism and the process of nation-building have presented themselves throughout history in Croatia and the rest of Southeastern Europe. The scope of this project does not allow for a complete historical analysis of nationalism in the region, so a brief discussion of some of the key people, groups, and events that contributed to national movements and conflict in Croatia, and the broader Balkan Peninsula follows. 
As an East-West borderland, the Balkan Peninsula was a great source of interest for Western explorers, travelers, and rulers. In addition to a desire to control the area for territory and resources, there was also a fascination with Balkan culture. A Western discourse of the Balkans was created from travel journals, personal accounts, and literature, which describe the region as something barbaric, wild, culturally rich, and utterly different but familiar from the nations of Western Europe (Todorova, 1997; Banac, 1984). In these early descriptions, the Balkans weren't seen as a threat, but as uncivilized and underdeveloped. It wasn't until the twentieth century that "Balkans" as a term became associated with negative ideas surrounding war and nationalism, due, in part, to a series of nationally driven conflicts in the region beginning in the nineteenth century.

By the 1800's, many nations in the Balkan Peninsula, specifically Serbs, Croats and Greeks, began to rebel against their imperial rulers. These early conflicts were more focused on territoriality, state-building, and a desire to overthrow imperial rule, rather than on a cultural or ethnic-based move toward nation-building. The topic of nationality, who belonged, and who didn't, was a confused subject in the Balkan Peninsula at this time. The strength of imperial powers and disagreements over contested territories, particularly in Bosnia, made it necessary for Croats to cooperate with the Serbs in order to successfully defend against Austria, Hungary, and the Turks, and so the national question was postponed (Glenny, 1999, pp. 57, 69).

This necessary regional cooperation gave ideas of Pan-Slavism a great deal of popularity in Southeastern Europe. Pan-Slavism was founded on the idea that all Slavic peoples might one day be united in a single state. The difficulty in this lies in the geographic separateness of the Slavic nations. Juraj Križanić, a $17^{\text {th }}$ century priest interested in unifying Slavic cultures, determined that Slavs "could be sub-divided into six groups, Russians, Poles, Czechs, Serbs, 
Croats, and Bulgars" (Tanner, 1997, p. 46-47). The Balkan Peninsula is considered to be the home of the southern Slavs, while the Poles and Czechs are said to be a part of the western Slavs, and Russia is eastern Slav territory. For southern Slavs, Pan-Slavism held the dream of Russian support for anti-imperial movements, and, with the creation of Yugoslavia (which means Land of the Southern Slavs), a form of Pan-Slavism was realized for a time. However, the idea of unifying all Slavs ultimately never played the kind of role that individual national movements would eventually play in the Balkan Peninsula.

Although Balkan conflict was not "national" in nature in the early 1800's, financial problems in the Ottoman Empire, as well as major changes in the rest of Europe (The French Revolution, Napoleonic Wars, and German unification), signaled that unrest in the Balkan Peninsula would begin to have wide-spread implications (Glenny, 1999). When it became obvious that political unrest in the Balkans would affect Western stability, the alleged unpredictable and wild nature of the region no longer provided a fascination. Western discourse began to shift, and it is during this time that Southeastern Europe became associated with violence, war, and ultra-nationalism.

In Croatia, local leadership saw an opportunity for gaining some autonomy when Hungary revolted against the Habsburgs in 1848. The Croatian governor, Ban Josip Jelačić, was loyal to the Austrian Empire, and led armies to fight against the Hungarians both in an attempt to push Hungarians out of Croatia's territory, and in the hopes of gaining some political and social autonomy for the Croatian province. However, because he was loyal to the Habsburgs and there could be no agreement between Croats and Serbs over Bosnian territory, Jelačić did not support Pan-Slavic unity with Serbia, and his attempt at gaining autonomy for Croatia was relatively ineffective (Lampe, 2000, 46). Karl Marx criticized attempts by Balkan nations, like those from 
Jelačić, calling them out as, "dying nationalities, the Bohemians, Carinthians, and Dalmatians [who] had tried to profit by the universal confusion of 1848 in order to restore the political status quo of AD 800" (Tanner, 1997, p. 93). Although Jelačić desired autonomy for the Croatian province, he was not a nationalist, but his fight against the Hungarians is still referenced as a nationalist victory by the modern Croat. As is evidenced by the statue bearing his likeness in Zagreb's city center, Jelačić's reign as the Croatian Ban has been mythologized as a pivotal moment in Croatian history, and has played an important role in Croatia's nation-building process.

By the 1900's, tensions in the Balkans reached their height, and conflict threatened European stability to such an extent that Western discourse began to describe the situation as “the Balkan powder-keg." In 1912, with the help of Bulgaria, Greece, and Montenegro, Serbia led forces to defeat a weakened Ottoman Empire in Macedonia. Another war followed in 1913, when Serbia, Greece, and Romania fought and defeated Bulgaria over contested territory in Macedonia. Serbia's victory in both of these conflicts encouraged ideas for the creation of a Yugoslavia in Croatia and Slovenia, and lent support to a growing Serbian movement that sought to create a Pan-Slavic state. Serb nationalists and supporters of Pan-Slavic unity then sought to remove Habsburg control from the region, and organized the assassination of the Austrian heir, the Archduke Franz Ferdinand, on June 28, 1914, which inadvertently triggered World War I (Lampe, 2000, pp. 71-100). The conflicts of the early 1900's, and the subsequent horrors of WWI solidified the Western image of the Balkans as dangerous and ultra-nationalistic. The research findings will discuss how this image continues to affect Croatia's present-day relationship to the rest of Europe. 
Following WWI, the old empires could no longer maintain control of their lands, which enabled Serbia, along with the Croatian and Slovenian provinces, to create the first of two Yugoslav states, but the new conglomerate had many limitations. In addition to post-war economic problems, the new state faced governmental and cultural issues. Firstly, the state was run as a Serb dominated parliamentary kingdom, which not only concerned non-Serb citizens, but also made it difficult for the government to unify the different political and legal systems of the former Habsburg and Ottoman lands. Secondly, the state had poor relations with its neighbors, in particular Italy. The new state would also face issues in uniting the Catholic, Orthodox, and Muslim religions. These issues would lead the state to become authoritarian, and ultimately fail as a result of nationalist movements throughout the conglomerate and the invasions of Nazi Germany and Mussolini’s Italy during WWII (Lampe, 2000, pp. 129-162).

One of the most well-known and notorious groups created during the first Yugoslavia was the Croatian Ustaša. Meaning, 'insurgent', the Ustaša sought to liberate Croatia from the Serbian dominated Yugoslavia (Banac, 1984, p. 269). Promoting fascist ideologies, the Ustaša was not only interested in gaining independence for Croatia, but was also a proponent of eliminating non-Croatian minorities from the nation's borders. The group was responsible for the ethnic cleansing of Serb minorities living in the Krajina region of Croatia. By the end of the war, the socialist partisans removed the Ustaša from power, but their legacy was long lasting. The ethnic cleansing conducted by the movement not only promoted ideas of Balkan ultranationalism in the West, but also intensified the divides between Croats and Serbs. Serbs would use the memories of Ustaša violence to justify the aggression used against Croatia during the independence wars. The Ustaša also has a legacy in Croatia where the group's former flag was 
adopted by the state, and is still used today (Banac, 1984; Glenny, 1999; Lampe, 2000; Tanner, 1997).

The socialist partisans, who gained popularity during WWII and defeated the Ustaša, were led by a Croat, Josip Broz Tito. As a Croat, Tito's ethnicity would help to improve post-war relations between Croats and Serbs; his disapproval of the Ustaša and disaffection for nationality would discourage nationalist movements; and his leadership would make it possible for a new, communist Yugoslavia to be formed. The communist party was pushed underground during the authoritarian reign of the first Yugoslavia, but was able to gain power as fascism and Nazism threatened the region (Banac, 1984, pp. 329, 339). Tito created a disciplined communism in Yugoslavia, which unified the nations of Southeastern Europe without serving the interests of one group over another. The decrease in nationalist activity improved the Western image of the Balkans, but the image of Southeastern Europe as an 'other' persevered as Europe became divided between communist and non-communist states.

By the 1980's, Tito's death, increasing economic problems throughout Yugoslavia, and a growing Serb nationalist movement caused Yugoslav relations to deteriorate (Lampe, 2000). By the 1990's, the hopes for a single Yugoslavia were destroyed and individual republics began to declare independence. Slovenia seceded first with relatively little resistance from the central government in Belgrade, but Croatia's declaration of secession revived old tensions between Serbs and Croats, and the resulting war in Croatia lasted from 1991 till 1995 (Glenny, 1999; Kenney, 2006). These tensions were manifested in the form of genocide, the realignment of state boundaries, and the creation of governments with nationalist platforms and agendas.

The Western response to the dissolution of Yugoslavia was mixed. Initially, Western Europe and the United States praised Slovenia and Croatia for ending communism and declaring 
independence, but as the war turned violent in Croatia, and genocide occurred in BosniaHerzegovina and Kosovo, Western discourse once again discussed the region's disposition toward ultra-nationalism. It's during this time that the term, "ethnic cleansing," was first used. Western journalists adopted the term from the Serbian use of the phrase, "čišćenje terena" (cleansing the terrain), which was used to describe the process of removing non-Serb minorities from Serbian controlled territory (Tanner, 1997, p. 255). Although, this term has since been used to define acts of genocide across the globe, its creation indicates that the West viewed the ethnic and national violence in Southeastern Europe as more extreme or different than other acts of ethnic and national genocide that have occurred throughout European history.

During and after the dissolution of Yugoslavia, leaders of the newly independent republics focused their attention on promoting a nationalist discourse, which drew on historical symbols and memories to foster a belief in uniqueness or difference of one group over another. In Croatia, Franjo Tuđjman, the head of the new Croatian state, emphasized the importance of Croat history and culture in forming a Croatian identity. At this time, great emphasis was put on the uniqueness of the Croatian language, which up until that point had been known as SerboCroat. Croatia's short period as an independent medieval kingdom was also drawn upon to support the right of Croatians to an independent state. Leaders, like Ban Josip Jelačić, were discussed as important leaders of the Croatian national movement. Tuđjman and his national party also chose the former Ustaša flag to represent the new Croatian state, and emphasized the group's contribution to the national cause, while downplaying the violence and genocide committed against Serbs.

After more than a decade of independence, Croatian leaders are less reliant on the use of nationalist rhetoric in order to unify their population. As this study will show, national and ethnic 
tensions remain, but rather than promote a nationalist platform, Croat leaders now work toward the preservation of the state and not the nation. The discourse of the state is now focused on global integration, specifically in trying to gain membership to the European Union, rather than isolation.

Croatia has been awaiting E.U. membership since 2003, but the European community claims that the country has a great deal of change to make before admittance will be granted. E.U. members argue that Croatia must improve its economy, promote social justice, and combat political corruption in order to gain membership. Even with the acknowledgement of Croatia's social, political, and economic problems, the negative historical imaginaries of the West may still play an active role in Croatia's E.U. negotiation process. As will be examined in later chapters, the results of this study support the idea that the process of othering, specifically the preconceptions that Southeastern Europe is ultra-nationalistic and possessing of a Balkan attitude, have contributed to Croatia's inability to gain access to the European Union.

\section{Summary}

This chapter has outlined some of the geographical and historical factors that have contributed to nation-building and nationalism in Croatia and Southeastern Europe. Combined with the theoretical framework, this brief examination of how Croatia's changing political, social, and historical geography has influenced the role of the nation provides the necessary conceptual foundation for this study. An historical analysis of Southeastern Europe's experience with imperialism, war, and regional unity and strife help to explain the importance of nationalist movements, territoriality, and the development of Western perceptions of the Balkan Peninsula as barbaric, war-torn, and ultra-nationalistic. 
As a borderland between the East and West, Southeastern Europe has found itself a main actor in some of the last century's most important social and political upheavals. Balkan experiences with imperialism, revolution, socialism, nationalism, and ethnic genocide have shaped the way that Southeastern European nations interact with one another and with the rest of Europe. An understanding of some of the social and historical processes that have affected Croatia and other Southeastern European states, helps conceptualize the overall research goals, which seek to examine the current role of the nation in Croatia, how nationalism affects Croatia's E.U. negotiation process, and its relationship with broader Europe. 


\section{Chapter IV: Research Questions \& Methods}

Although the overall research goals have been mentioned throughout the theoretical framework and case-study description, a closer examination of the specific questions and methods utilized in this study are necessary. This first section of this chapter outlines each research question in detail, and explains the importance of the questions in understanding Croatia's transition to the E.U. The second section of this chapter examines the use of discourse analysis, online surveys, and textual analysis as methods for qualitative research, and discusses some of the benefits and limitations of the methods in this study.

\section{A. Research Questions}

Three specific research questions were chosen for this project. The questions are designed to examine the role that nationalism plays in Croatia as it transitions to the European Union, to gauge the importance of the nation for a post-war generation, and to understand how issues of ethnicity and nationalism continue to affect Croatia's relationship to its neighboring states and greater Europe. As will be discussed in Chapter V, the answers to these questions reveal how geographic imaginaries of Croatia and Southeastern Europe continue to hinder the ability of the Croatian state to gain access to the E.U.

Question 1: How do ethnicity and nationalism contribute to framing Croatia's transition into the European Union?

This first question focuses on the state scale to explore how issues of ethnicity and nationalism affect the image that the Croatian state represents to the rest of the world. The data for this research question was collected primarily through the textual analysis of Croatian embassy and government websites to explore the discourse of the Croatian state, and more 
specifically, how the state addresses its past with nationalism and its desire to fully integrate with the international community. Additionally, this question examines how remaining difficulties between Croatia and its neighbors in Southeastern Europe continue to affect Croatia's transition to the European Union.

Question 2: How important is the nation to Croatia's youth now that independence has been achieved?

My second research question uses online surveys and textual analysis of social networking groups on Facebook to examine the personal discourse of Croatia's post-war generation to determine the role that the nation continues to play. The importance of analyzing a post-war generation is discussed later in this chapter but generally, this question allows for an analysis of the scale of the individual in Croatia by examining the perspectives that Croatian youths have on E.U. integration, regional relationships, and nationality. The survey responses are also compared to some national polls in order to gain access to a larger portion of the Croatian population. Exploring how youths view E.U. integration and Croatia's relationship to other former Yugoslav states can indicate how important the nation will be in the future.

Question 3: How does nationalism help or hinder Croatia's inclusion in and relationship to the broader European region?

The third and final research question focuses on discourse at the international scale, and is explored through the textual analysis of E.U. documents. This question reveals how Croatia and Southeastern Europe are viewed by the international community, and how Croatia's history of conflict and nationalism have created a geographic imaginary that engages Croatia in a process of othering with the rest of Europe. More specifically, is Croatia's ability to be accepted 
as a stable, democratic nation-state hindered by the West's preconceptions of Croatia as being ultra-nationalistic and possessing of a "Balkan" mentality?

The analysis of all three of these research questions will lend to a partial understanding of the struggles that many Southeastern European states face as they continue to integrate with the international community. Additionally, this research encourages a reevaluation of the historical and social processes that have lent to the creation of a discourse that encourages the marginalization and othering of post-socialist and post-imperial states. The following is a closer examination of the methodologies used to answer these questions.

\section{B. Research Methods}

Description of Methods

A combination of qualitative methodologies were employed in this project in an attempt to answer the above discussed research questions. Online surveys and textual analysis of social networking groups, Croatian government and embassy websites, and European Union documents and press releases were the sources of analysis. This section explores these research methodologies in detail to demonstrate why online surveys and textual analysis of state documents and web-based media are appropriate research methods for examining discourses of the nation in Croatia. Also, this section further discusses the merits and drawbacks of the use of these methodologies in a geographical study.

\section{Sources of Data}

A variety of government documents and web-based media were examined in an attempt to gain a greater understanding of the role that nationalism plays in Croatia's geopolitical 
discourse as the country works toward E.U. integration. The data can be split into three main categories: 1) Web-based media, which included an examination of social networking pages on Facebook, as well as the online surveys with young Croat adults, 2) State documents obtained from the Croatian government and embassy websites, and 3) International documents gathered from the European Union websites. A complete list of these documents can found in Appendix A.

To gain access to the opinions of the individual Croat, I analyzed online surveys recruited from the social networking site, Facebook, and examined multiple student groups also on Facebook (i.e. "Students and Workers for BALKAN SOCIALIST FEDERATION," "Organization for the Boycott of Slovenian Goods and Services," and "Balkan Power"). The Facebook groups and surveys were chosen to gain access to a population of young Croatian adults who have spent most of their lives in an independent, democratic Croatia. An analysis of these sources contribute to answering research questions 1 and 2 by exposing how important the nation is to Croatia's youth and revealing how Croats view their country's impending E.U. integration.

In order to analyze Croatian political discourse at the state scale, I examined state documents and publications that emphasized Croatia's E.U. negotiation process, and its relation to other European states. These documents were accessible from the Croatian government and the Croatian embassy to the United States websites (Government of the Republic of Croatia, 2009; Ministry of Foreign Affairs and European Integrations of the RC, 2006). A close look at these websites and the documents and press releases contained within them reveals the image that the Croatian state tries to present to the Western World. The information derived from this 
state scale can be compared with the individual and international scales to determine the relationship between the internal and external images that exist of Croatia.

E.U. documents that describe Croatia's E.U. negotiation process serve as the data to analyze discourse at the international scale. Whereas the first two categories of data sources expose the perceptions of individual Croatians and the image that Croatia tries to project to the world, these documents reveal how the international community views Croatia. The information that the E.U. provides explains why member states have continued to halt Croatia's entrance to the organization, and what progress the union declares as necessary for membership, specifically in dealing with issues of social inclusion, economic stability, and political justice. An examination of these resources is indicative of the social, historical, and political power relations that exist between East and West, E.U. and non-E.U., and the Balkans with the rest of Europe. The documents examined at both the state and international scales help to answer research question 3, which seeks to examine Croatia's relationship with its neighboring states and the rest of Europe. Figure 4.1 is a diagram of all of the data sources in this project and the geographic scales they contribute to analyzing.

\section{Online Research: Merits and Drawbacks}

Using web-based media for this project seemed an obvious choice for several reasons. Firstly, the internet is one of the most popular methods of accessing information. Secondly, the scope of this thesis would not allow me to travel to Croatia to obtain hardcopy sources, and the internet provides the quickest way to overcome this time-space divide. Finally, I do not speak Croatian, and the internet provides a plethora of Croatian resources that have been translated into English. Internet research is also quickly becoming a respectable form of qualitative data 
collection. The last decade has seen a dramatic increase in research topics and methods that include the internet, digital media, online newsgroups, etc. (Rice, 2005). Not only are researchers becoming increasingly interested in using the internet, but they are also concerned with who uses the internet in the general populace, and what website characteristics attract more visitors. Despite this, challenges remain.

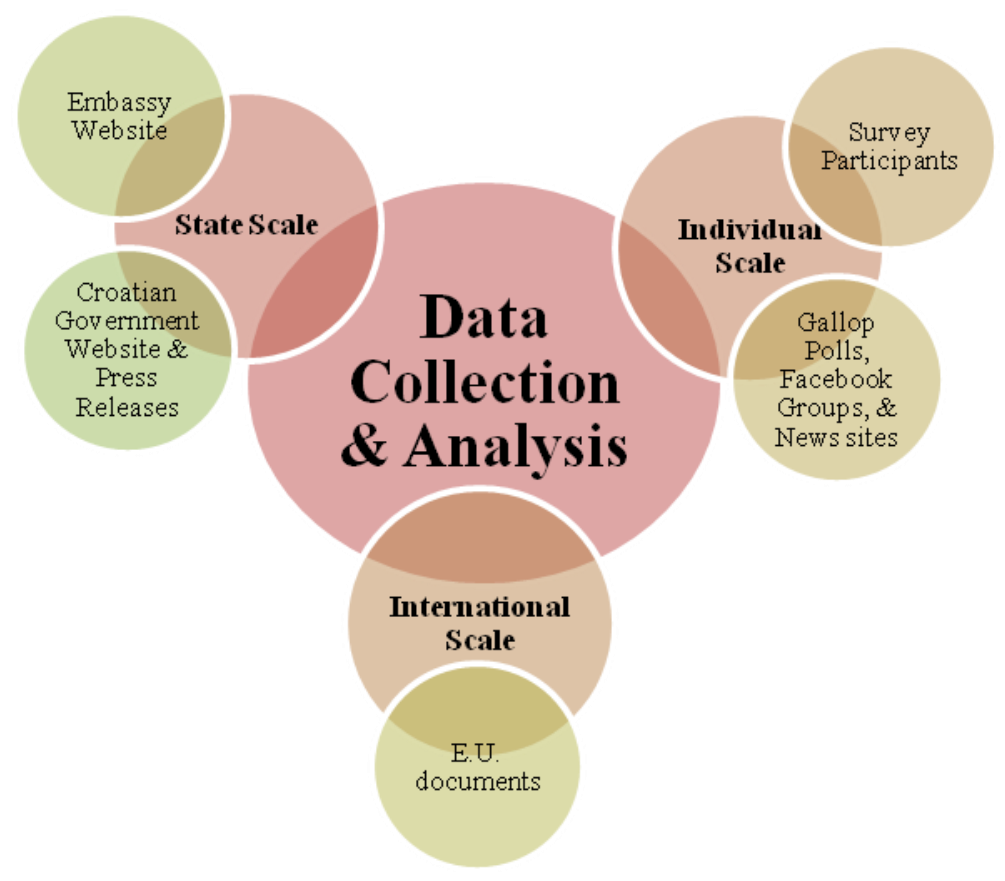

Figure 4.1 Methodology Matrix

Online data collection is inherently subjective due to the authorless nature of the internet (Warnick, 2004). Although I feel like I have addressed this by analyzing government and E.U. documents in addition to web-based media, my own perceptions and subjectivity can affect how I read and interpret these online sources. Flavian and Guerra discuss how usability, familiarity, privacy, trust, and reputation all affect the reading of digital newspapers (2007). Despite all this, it's important to recognize that there is a certain level of subjectivity inherent in all research, and 
we must make some generalizations in order to gain a greater understanding of societal processes and relations.

Beyond convenience, the use of online methods contributes to this study's research questions in a unique way. In its March-April 2009 issue, Foreign Policy published a short article, which discussed the implications of the internet on nationalism. "A Melting Pot it's Not" briefly describes how the internet and digital communications have created a space that not only transcends geographical boundaries, but can also facilitate a growth in nationalism through the use of blogs and social networks that use imagery and symbology to increase a national consciousness (Morozov, p. 26, 2009). If this is the case, then the examination of online sources, like Facebook, are the perfect platforms for examining the role that nationalism plays in Croatia.

Internet research is also beneficial in terms of gaining access to "hard to reach" or "hidden" populations (Cramer \& Matthews, 2008). I previously mentioned how the internet provided an opportunity to overcome the spatial and temporal limitations of this project, and although Croatians aren't a hidden population in the same sense as some special interest groups or movements in areas of conflict, the opinions and perceptions of Croatians are not necessarily readily available on a global scale. The internet provides access to information that was previously unreachable.

Online research also has interesting implications for geographers. If the internet is viewed as a space, and different social networking sites are viewed as places, then geographers are in a unique position to contribute to expanding the debate on critical reflexivity and online research ethics. Clare Madge (2007) discusses how geographers can contribute to developing online research ethics by examining the inequalities between online spaces and by imagining research ethics in a post-colonial framework. It is my hope that this case-study, in some small way, can 
contribute to this ever expanding debate by showing that online research methods can be reflexive and rigorous.

\section{Discourse Analysis}

Given that discourse analysis is such a large part of my methodology, a discussion of what it is, as well as how it is used in this study is necessary. Discourse analysis is part of a poststructuralist approach to qualitative methodology. Traditionally, textual-analysis has been used to examine the functionality and meaning behind specific qualitative sources (i.e. documents, photos, etc) in a process called hermeneutics. Discourse analysis builds upon textual-analysis to analyze "the effects of a particular cultural text on what an individual may do or think by unraveling its production, social context, and intended audience" (Waitt, 2005, pp. 165-166).

Discourse analysis is designed:

" (i) to explore the outcomes of discourse in terms of actions, perceptions, or attitudes rather than simply the analysis of statements/texts; (ii) to identify the regulatory frameworks within which groups of statements are produced, circulated, and communicated within which people construct their utterances and thoughts; and (iii) to uncover the support or internal mechanisms that maintain certain structures and rules over statements about people, animals, plants, events, and places in existence as unchallengeable, 'normal,' or 'common-sense' rather than to discover the 'truth' or the 'origin' of a statement" (Waitt, 2005, pp. 164$165)$.

Discourse analysis is rooted in Foucault's methodological approaches to history. Rather than looking for history's unities and epics, Foucault looks for discontinuities in discursive structures, which inform our understanding of events and objects, and discursive formations, which set limits, like making the 'nation' appear real (Foucault, 1972, p. 4, Parts II and III; Waitt, 2005, p. 171). This focus on discontinuities signaled a change in thought that moves research away from an objective search for truth to one that includes subjectivity. With a basic 
understanding of what discourse analysis seeks to do, it's important to evaluate the positive and negative aspects of using this methodology.

David Harvey claims that "we use discourses to persuade ourselves and others to a certain way of understanding (and often acting towards) a subject matter we regard as important" (Harvey, 1996, p. 76). He acknowledges the important role that discourse analysis can play in examining social process, but warns that it can also lead to a "circularity" in which discursive formations are intertwined to the point that very little can be concluded from their examination (Harvey, 1996). Instead, Harvey chooses to view discourse dialectically as part of a larger system of internal relations, rather than as individual discursive objects.

Discourse is only one of six "moments" that Harvey outlines as a part of social process: Language/Discourse; Power; Beliefs, Fantasies, Values, and Desires; Institution Building; Material Practices; and Social Relations. He uses the term moments to avoid creating a sense of permanence or precedence of one moment over another, and argues that these moments must all interact together to produce social change. However, Harvey does encourage the researcher to look for how these moments may interact together to produce a sense of permanence and social causation. For example, the nation-state successfully appears as a permanent force because of its ability to draw upon all of these moments at once (Harvey, 1996, pp. 78-82). Ultimately, Harvey differs from Foucault in that he doesn't see discursive formations as the only containers of power and change. Instead, he argues that all six moments must be altered in order for change to be registered as real (Harvey, 1996, p. 94).

I generally accept Harvey's view of discourse analysis over Foucault's. Although I believe that the examination of discourse is fundamental to understanding underlying processes and relationships, I do not agree that discourse is the only agent of change. Rather, discourse is 
only one part of social process. Croats imagine themselves as a nation not because it was written or discussed as so, but because of a series of historical processes and relationships that made it so. I approach discourse in this research as a reflection of real-world process and practices. It is my hope that the discourses I chose to examine in this project are representative of real geopolitical issues that Croatia is facing as it transitions to the E.U.

Although there are many discourses I could have chosen to examine with regard to Croatia's E.U. transition, I decided to focus on the relationship between the imperial discourse of the West, which sees Croatia as ultra-nationalistic and underdeveloped, and the state discourse of Croatia as democratic and stable. I also looked for indications that the nation still plays a very large role in the Croatian consciousness. More specifically, I use discourse analysis to examine how these ideas permeate online surveys, and international and state documents, as the E.U. determines what steps Croatia needs to take to become economically and politically developed, and the Croatian government attempts to counter the preconceptions that Croatia is not ready for global integration. Additionally, Facebook group pages demonstrate that the question of the nation is still very active in Croatia, as it tries to balance the preservation of its identity with its desire to integrate with the international community.

\section{Online Surveys \& Facebook}

Given the time, funds, and scope of this research project, it was unrealistic for me to attempt traveling to Croatia to obtain any surveys or interviews in the field. However, I did not want to rely solely on textual analysis as my main form of data collection. To combat this, I decided to collect surveys online, using the social networking site, Facebook, as a recruiting tool. Although surveys typically offer much less information than in-depth interviews or focus groups, 
they are cost-effective, can be administered over a large geographical area, and can give important insight into social processes (Berg \& Mansvelt, 2005, p. 248). The surveys used in this project used a mixed-method format, and were collected through a combination of criterion, snowball, and opportunistic sampling.

It was decided early on that my surveys would be conducted in English for multiple reasons. Firstly, I do not speak Croatian, so it became necessary to leave the questionnaires and responses in English in order to promote a rigorous analysis process. Secondly, most Croatians, especially the younger generation that I drew my sample from, speak and understand English relatively well. Lastly, using English ensured full disclosure for the IRB (see Appendix B), and made it possible for my research to be categorized as exempt. Despite these benefits, not being able to understand Croatian may have hindered my ability to recruit larger numbers of respondents, and in the case of textual analysis, prevented me from analyzing sites and documents that might have been helpful to the overall project.

To reflect my second research question, young Croatian adults were my target sample group. More specifically, I was looking for participants between the ages of 18 and 30, because this age group has spent most of their lives in a post-Yugoslav, post-war Croatia, and as a result, they have a very unique perspective on issues of nationalism, ethnic relations, and global integration. Although the examination of this one age group does not lend to indicators about Croatian society as a whole, I believe that I have combated this through textual analysis, and as will be examined in the data analysis chapter, by comparing some of my survey responses with national polls that were conducted across a larger segment of the population. Additionally, this particular age group makes up nearly $20 \%$ of the entire Croatian population, which indicates that this generation can have a large effect on future Croatian politics (Figure 4.2). Ultimately, an 
analysis of this particular age group can expose generational changes that occur in post-socialist spaces.

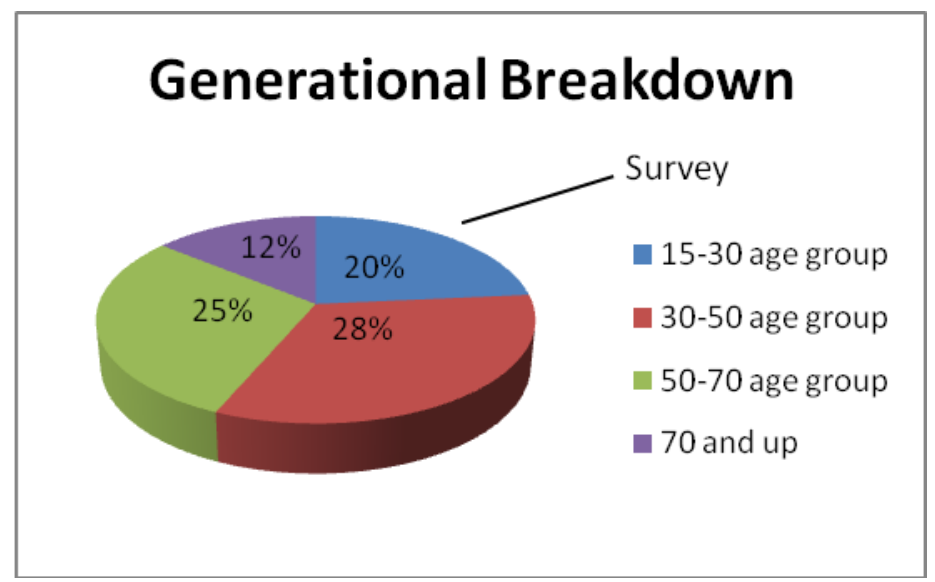

Figure 4.2 Generational Breakdown

The surveys themselves were designed in a mixed-method format, which includes a combination of quantitative and qualitative questions (McGuirk \& O’Neill, 2005, p. 147). The questionnaires were split into two sections. The first section focused on basic demographic information, and asked respondents for their sex, age, ethnicity, religion, and hometown. The second section of the survey was a mix of multiple-choice and open-ended questions designed to elicit information from the respondents regarding geographical differences in Croatia, perspectives on E.U. integration, Croatia's relations with neighboring states, and the status of non-Croat minorities within and outside of Croatia's borders. These questions were created not only to reveal opinions about the E.U., but also to indicate how important the national question remains in Croatia. A copy of the whole survey is available in Appendix A.

Although surveys are one of the most common and widely used methods of data collection and qualitative analysis, the use of online surveys presents some challenging issues and obstacles for researchers. In addition to the common issues of informed consent and confidentiality, online surveys are only able to reach populations that have internet access, 
thereby narrowing the possible sample (Ritter \& Sue, 2007). Researchers must also be aware that response rates from online surveys may differ from the traditional mail-in format due to confusions with the ability to access the survey, or its format (Archer, 2008). For the purposes of this research project, I not only had to address these issues, but also contend with the crosscultural nature of this study, and the time-space divide between myself and potential survey respondents.

I chose Facebook as a forum for survey collection; because it is one of the most popular social networking sites on the internet, and allows for the creation of group pages as well as individual profiles, which increased my ability to network and advertise. Survey respondents were recruited from Facebook in three ways. I started with a very general criterion sampling to search for participants who were over 18 and lived in Croatia; advertisements were placed on the public message boards, or 'walls' of 28 different Croatian Facebook groups (these groups had anywhere from 20-100,000 members) and an additional 137 advertisements were sent to individuals. I also used opportunistic sampling to recruit respondents from my existing Croatian contacts that to a Facebook group I created, called "Croatian Student Survey," which at its height had 32 members. A great deal of my survey respondents ended up coming from snowball sampling, where people who completed the survey recommended their friends and contacts to participate as well.

Despite these multiple recruiting methods, I was only able to elicit 19 total responses, due to Facebook security settings and a lack of incentive for survey participants. Facebook flags accounts that appear to be harassing other users with corporate advertisements or spam. This security measure is one of the reasons that so many people feel comfortable using Facebook, but because I was sending many survey advertisements out at once, Facebook would periodically 
warn me that further activity would result in the deactivation of my account. In order to avoid this, I had to space out the number and frequency with which I messaged potential respondents. Ultimately, this security measure lowered my potential sample, and future research projects involving Facebook should not only be aware of this obstacle, but should consider purchasing advertising space from Facebook itself.

From each advertisement, potential respondents were directed to my personal website, outside of the Facebook domain and hosted by West Virginia University, where the cover letter and survey could be found, as well as information about me and my research (Figures 4.3, 4.4, 4.5). I established this website, and a Facebook profile, in order to create a sense of security and professionalism for research participants. One of the challenges of doing research online is the seemingly authorless environment of the internet, and people tend to rely on site structure and design to determine if a site is credible (Warnick, 2004). By providing multiple sources for survey respondents to confirm my identity and purpose, I hoped to set my participants at ease about my intentions.

Although this approach allowed multiple opportunities for participants to confirm my identity, it may also have been a deterrent for potential participants who did not want to take the extra time to visit a website outside of Facebook. Complicated designs and unclear instructions can also deter survey responses (Archer, 2008). In trying to avoid these issues, I made the webpage and survey instructions as straightforward as possible. I also focused on several strategies to maximize response rates; including making survey questions concise, sending out reminder messages, and following-up responses with thank you emails (McGuirk \& O'Neill, 2005, p. 159). 
Once all of my survey responses were collected, I began to analyze them using the process of coding. The purposes of coding qualitative data are organization, data reduction, and data analysis and theory building (Cope, 2005). Coding can be conducted in multiple ways; through content analysis, which looks for basic counts and demographic information, through the use of descriptive codes, which look for blatant themes and labels, and through the use of latent or analytic codes, which look beneath the surface of the data for relationships and context clues that help answer larger questions (Cope, 2005). All of these coding methods were applied to the analysis of the survey data in this project.

Hello! I am an American student at West Virginia University working towards a master's degree in geography. Before starting my master's program, I spent two months in Zagreb, Croatia, and I have become really interested in Croatian culture and society.

My master's thesis seeks to understand the opinions that young Croatian's have regarding both Croatia's transition to the E.U., and the relationship that Croatia has with other nearby countries, like Serbia and Slovenia.

I'm looking for young Croatian adults to complete a survey about these issues. These surveys are a part of a research study, and your participation is completely voluntary. If you are over the age of 18, and are interested in contributing to this survey, please visit http://www.geo.wvu.edu/ jtitanski or message me on my Facebook profile.

Your participation in this survey is greatly appreciated, and will most certainly lend to gaining a greater understanding of Croatian society and culture!!

Thanks for your time!!

Figure 4.3 IRB Approved Survey Advertisement 


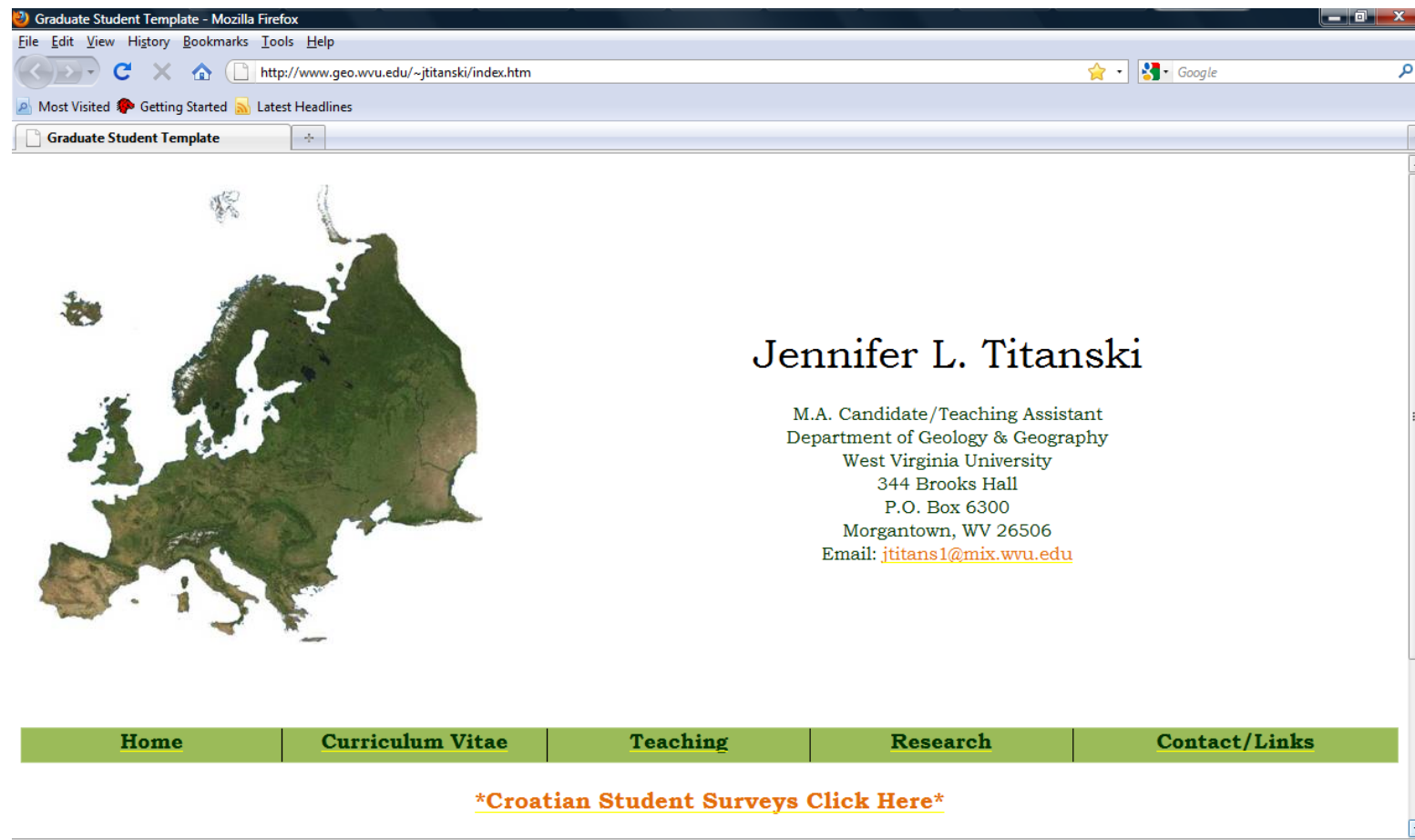

Done

Figure 4.4 Website

(3) Mozilla Firefor

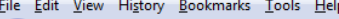

\&) Most Visited Getting Started \$ Latest Headlines

http://www.geo.wv...atia_surveys.htm $\div$

WestVrginiaUniversity

Eberly College of Arts and Sciences

Dear Participant,

This letter is a request for you to take part in a research study to assess how young people in Croatia view the country's transition to the E.U., and the relationship Croatia has with its neighboring countries and ethnic minorities. You will be asked to complete a survey that addresses some of these questions,

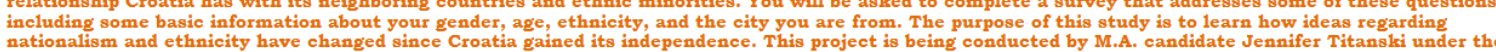
supervision of Dr. Ann Oberhauser. Your participation in this survey is greatly appreciated and it will take you approximately 15-20 minutes to complete the survey.

All of the answers that you provide will be kept completely confidential and only Ms. Titanski and Dr. Oberhauser will have access to the completed surveys. The only identifying information that will be collected from you is the email address that you use to submit the survey. Once the survey has been successfully

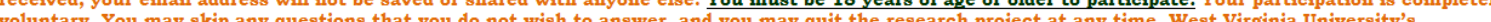
Institutional Review Board's acknowledgement of this study is on file.

I hope that you will participate in this research project, as it could be useful in understanding how young people view Croatia's transition to the European Union, and its relationship with other countries and groups. Thank you very much for your time. Should you have any questions about this letter or the survey, please feel free to contact me at jtitans1@mix.wvu.edu or on my Facebook profile.

Thanks you for your time and help with this project!

If you have any other questions or concerns that cannot be answered by Ms. Titanski, please visit either the WVU student services and counseling site, or the University of Zagreb's student services site.

wvU Student Services and Counseling

University of Zagreb Student Services

*Click Here to Download the Survey*

\begin{tabular}{l|l|l|l|l|} 
Home & Curriculum Vitae & Teaching & Research & Contact/Links
\end{tabular}

Done

Figure 4.5 Cover Letter 


\section{Positionality \& Reflexivity}

Earlier in this chapter, I discussed how online research helped me to overcome the timespace divide between myself and the Croatian respondents I'd hoped to recruit. However, the cross-cultural nature of the research also poses some difficulties. Even though I have spent time in Croatia, and have some inside understanding of cultural norms, my own positionality and reflexivity keep me an outsider in the research process (Crang, 2002). Beverly Mullings discusses this balance between being an insider or outsider in cross-cultural research (1999).

As a Westerner, I entered this research with my own preconceptions about Croatia and about the concept of nationalism. Conversely, having spent time in Croatia, I have a great deal more knowledge of Croatian society and culture than someone who has never been. By acknowledging both my background and experience, I am able to strip away some of the preconceptions that can affect the outcome of this research. However, the researcher can never completely remove his/herself from the research process, and the act of critical reflexivity is a never-ending process.

I don't presume to have solved the issue of nationalism in Croatia through my examination of discourses, the analysis of online sources, or the use of surveys. However, as discussed in Chapter V: Data Analysis and Findings, I have been able to expose some of the power relations present both in Croatia and between Croatia and broader Europe. Future research can build upon the information revealed in this project to gain better insight into the role that nationalism and other issues of identity play in global politics.

Ultimately, these methodologies lend to understanding how geopolitical discourse in Croatia has since transitioned from centering on nation-building to a focus on projecting an image of political and economic stability and of international cooperation. With the ultimate 
goal being acceptance into international bodies, like the E.U., the states of Southeastern Europe have had to prove their European-ness by combating long-held misconceptions of an ultranationalist "Balkan mentality." 


\section{Chapter V: Data Analysis \& Findings}

This chapter discusses the process of data analysis and the findings associated with the online surveys collected from young Croat adults and the textual analysis of international and state documentation and websites. This chapter is divided into two main sections, which explore the findings associated with each research method used in this study, and draw larger conclusions about Croatia's E.U. negotiations and the status of ethnicity and nationalism on its processes of globalization. The first section discusses online surveys and their contribution to answering the research questions, especially research question two regarding the importance of nationalism for Croatia's youth. The surveys are also compared to some national polls and Facebook groups in order to connect survey responses to a larger population, and across a wider age distribution. The second section examines the use of textual analysis to expose the roles that identity and nationalism play in the discourses present in Croatia's E.U. transition. The analysis of these data sources contributes to understanding how issues of the nation and ethnicity contribute to Croatia's process of E.U. integration, and determine if the process of othering continues to affect how a geographic imaginary is constructed for Croatia and the rest of Southeastern Europe.

\section{A. Online Surveys}

\section{Introduction}

As discussed in Chapter IV, online surveys provided a convenient way to overcome the spatio-temporal boundaries inherent in a cross-cultural study. In addition to these benefits; however, conducting surveys online also presented difficulties associated with the overall response rate and the ability to connect the survey findings to larger Croatian society. The 
following discussion explores how I combated these issues through the use of national polls and the analysis of Facebook group profiles. Additionally, the process of using both content analysis and in-depth coding is described, and the findings associated with this qualitative sample of surveys are discussed in relation to the overall project's research questions. The survey findings provide a glimpse into the perceptions associated with E.U. integration and the status of the Croatian nation from the perspective of the individual.

\section{Respondent Statistics and Basic Content Analysis}

Despite the low response, 19 surveys proved to be very useful (as I was not interested in making any generalized statements based on statistical findings). I designed the survey to be part of a qualitative analysis, which would seek to uncover context, opinions, and relationships. The survey responses I received were very detailed, candid, and invaluable in understanding the role that nationalism plays for a post-war generation of Croats. To support my findings, I also compared survey responses with national polls and with an analysis of some of the Facebook groups where I advertised. These comparisons will be discussed later on in this chapter.

I began coding my survey data with a very basic content analysis, which revealed several patterns in the demographics and recruiting methods of the participants (Table 5.1). Firstly, all of my survey respondents were between the ages of 20 and 29. This was the target age group that I desired for this project in order to answer my second research question, which sought to examine the importance of nationalism for a post-war generation of Croats. The importance of this age group was discussed in Chapters III and IV, as it represents the first generation of Croats to live the majority of their lives in an independent and post-socialist Croatia. 
Secondly, 12 of the 19 responses came from women, and while gender issues weren't directly acknowledged in this project, a future project might be interested in exploring any differing opinions men and women have on issues of E.U. integration and nationalism in Southeastern Europe. A survey of American college students showed that women were much more likely than men to use Facebook to obtain information about events, products, and services, and consequently, those who were interested in using Facebook for information were much more likely to be politically and socially active (Kee, Park, \& Valenzuela, 2009). This could indicate that more women than men completed my survey, because women are more likely to be interested in participating in a study of a political or educational nature.

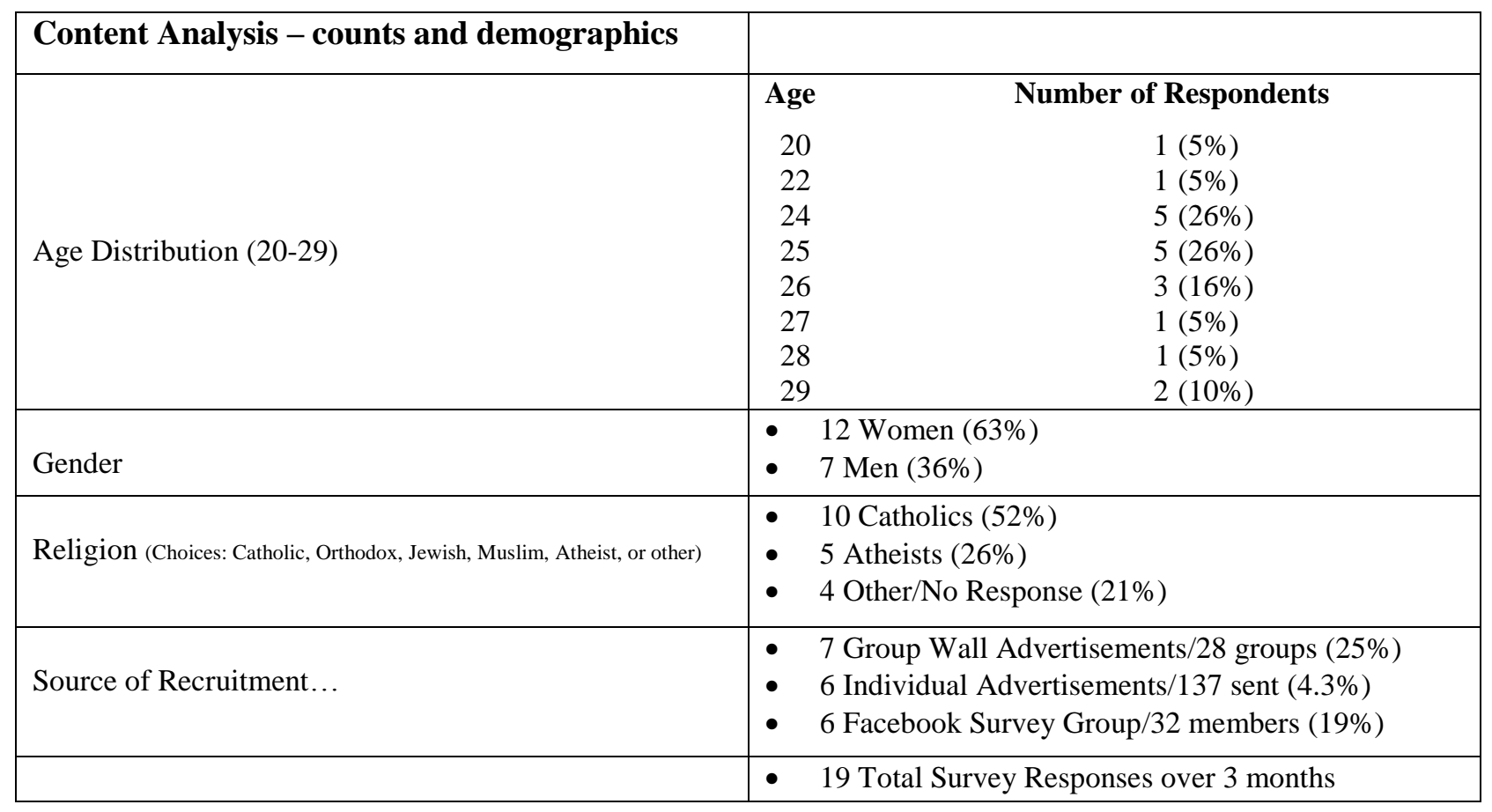

Table 5.1 Content Analysis

The third major pattern that I deduced from this basic content analysis referred to how survey participants identified religiously. While nearly half of my respondents identified Catholicism as their religion, the other half identified themselves as atheist, other, or none. As 
mentioned above, Croatia's history with imperialism and Western influence contributed to Croatia's religious identity being dominated by Catholicism. Similarly, the socialist government in Yugoslavia discouraged religion in an attempt to bridge the differences between Catholics, Muslims, and Orthodox Christians in the region, which may contribute to understanding why many of the survey respondents identified their religion as other, atheist, or none. Although a majority of the overall Croatian population still identifies with Catholicism, a larger survey sample with young Croats could reveal a decreasing trend in the number of people who identify themselves as Catholic.

The last pattern that I examined from the basic content analysis was related to the geographical distribution of my survey responses. Survey respondents were from seven different Croatian cities; Zagreb (the capital), Koprivnica, Osijek, Pula, Slunj, Sisak, and Ivanic-Grad. All of these cities are located in the northern half of Croatia, and all are inland, except for Pula, which lies on the Adriatic (Figure 5.1). The geographical location of the survey respondents could have affected the way certain questions were answered. For example, one of the first survey questions asked respondents to describe any regional differences between certain areas of Croatia (Appendix A). Many of the responses to this question referred to cultural differences, which could partially be explained by the previously discussed existence of a North-South divide within Croatia itself. The survey responses to this question are discussed in a later sub-section that examines the survey findings in more detail.

Although this basic content analysis cannot be used to make any generalized statistical statements, some interesting trends emerge from reviewing this demographic information. The geographic, gender, and religious distributions associated with such a small sample may not indicate larger trends or changes in Croatian society. However, the trends discussed here 
encourage further research into the roles that age, gender, geographical location, and religious identity play in how Croats view nationalism and E.U. integration. For the purposes of this study, these trends can lend to a greater analysis of the specific survey questions.

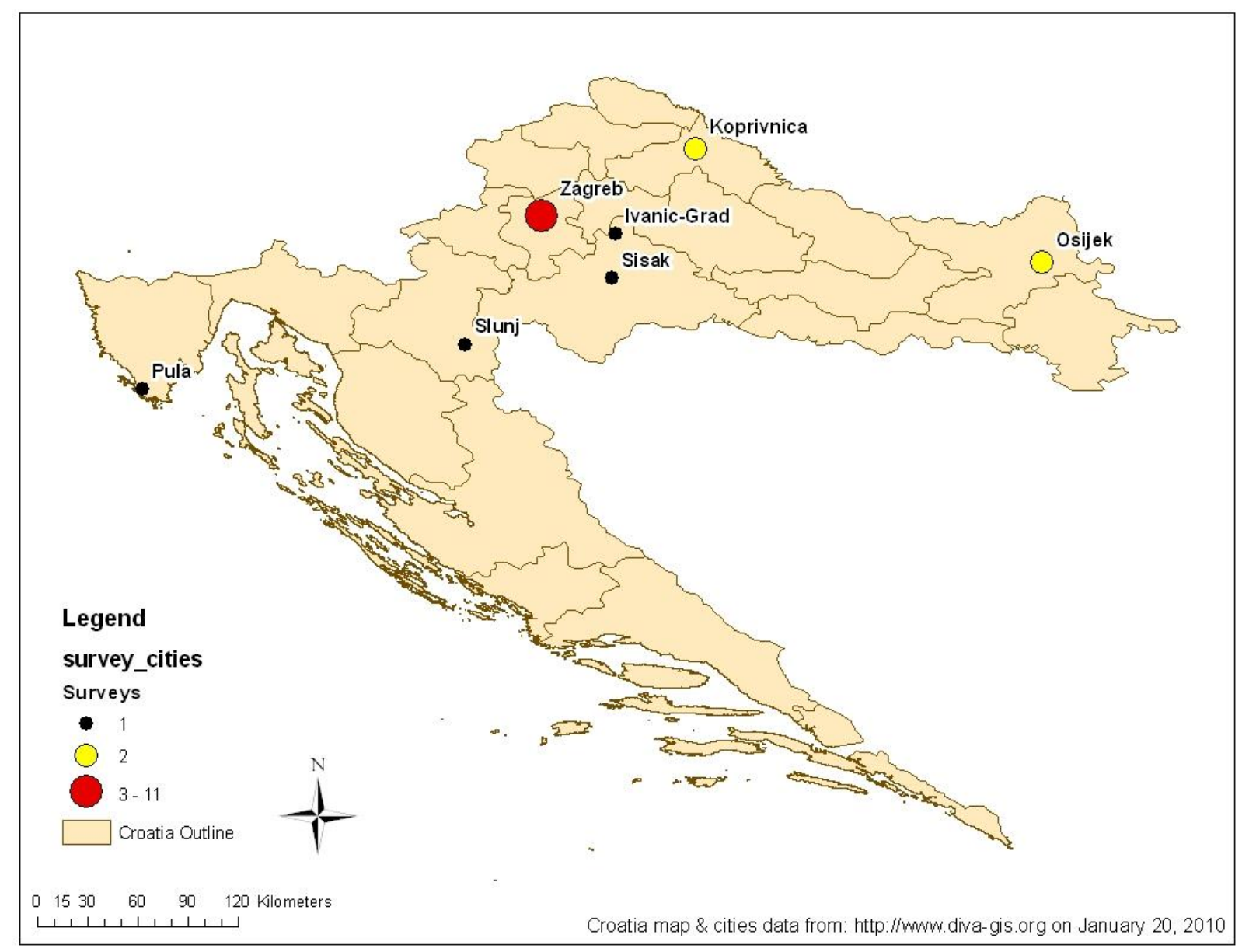

Figure 5.1 Geographic Distribution of Survey Respondents

\section{Descriptive and Analytic Coding}

After survey respondents answered basic demographic information, they were asked a series of ten open-ended questions that attempted to gauge their opinions on E.U. integration, Western influence, their country's relationship with other Southeastern European states (including the current territorial dispute with Slovenia), and their views on Croatian culture and 
society (Appendix A). The nature of the survey lent not only to answering research question two, but also contributed to the examination of research questions one and three, which were designed to determine the role that nationalism plays in Croatia's E.U. transition, as well as in its relationship with the rest of Europe.

As previously mentioned, this sample of surveys is too small to warrant a quantitative analysis, so it was much more valuable to analyze these surveys from a qualitative perspective. As such, I had to develop a coding scheme that would allow me to best answer my research questions. Meghan Cope takes a cue from Strauss and Corbin's work on developing techniques for qualitative research by suggesting that researchers begin the coding process by looking for strategies and tactics, consequences, conditions, and interactions among actors (Cope, 2005, p. 227).

In choosing both the descriptive and analytic codes, I had to think carefully about how each one would contribute to answering my overall research questions, and how my theoretical framework (Chapter II) would be helpful in determining which codes would be more valuable than others. The theoretical assumption that nations are the product of complex social and historical relations, specifically those geopolitical processes of imperialism, ethnicity, territoriality, and the state, led me to choose descriptive codes that discussed Croatia's unique historical and cultural experiences and relationships. Additionally, the assumption that a "process of othering" has engaged Croatia and other Southeastern European states in an unequal relationship with the rest of Europe, coupled with my specific research questions, contributed to my selection of analytic codes.

My descriptive codes focused on statements regarding Croatia's geography (as Balkan, European, etc.), post-war relationships, territorial issues, opinions of the E.U., and the role of the 
Croatian state. In order to broaden the analysis and look beneath the surface of the actual text of the survey responses, I also chose several analytic codes to expose issues of ethnicity, the nation, and attitudes toward global integration. I also looked for an indirect acknowledgement of Croatia as different or 'other' from its neighbors. Figure 5.2 is a diagram of the analytic and descriptive codes used in this analysis.

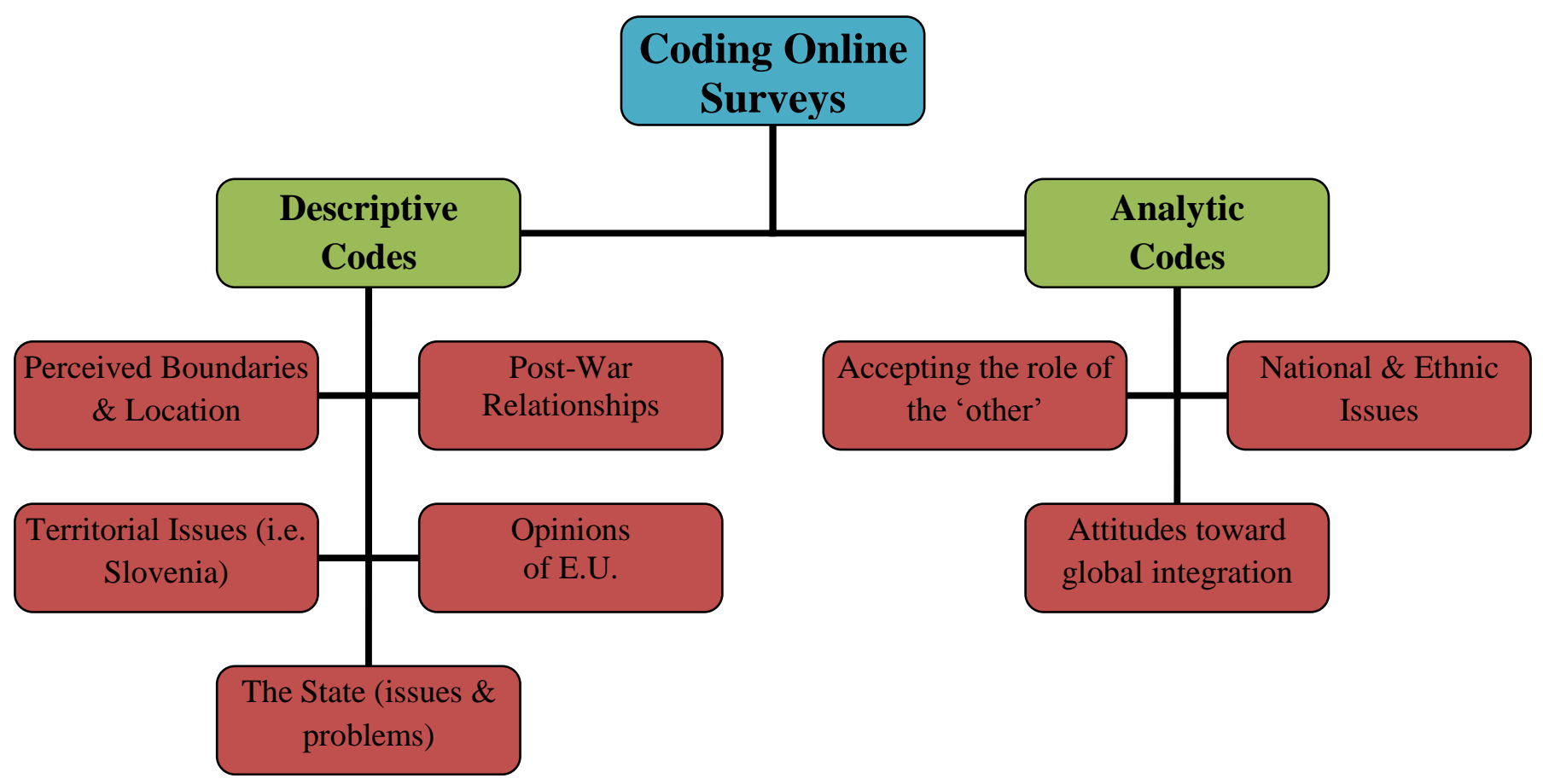

Figure 5.2 Codes

Careful organization of data is incredibly important, due to the inherently complex nature of the coding process. To ensure that both my coding process and analysis were rigorous, I used Microsoft Excel to organize survey responses. Each participant was given a unique identification number to keep their answers anonymous, and to ensure that my own preconceptions about respondents did not interfere with the data analysis. Normally a software program, like NVivo, would be used in the analysis of qualitative data, but since I did not have access to this program, Excel was the next best choice. Once all of the survey questions and responses were entered into 
an Excel table, I began coding the data. Each code was assigned a color, which made it easy to visualize commonalities and relationships across survey questions and responses. Once the survey data was organized and coded properly, certain themes across survey responses became visible.

Some of the major themes that I was able to extract from the survey data included: (a) an apparent trend in how the survey participants perceived Croatia's geography, (b) a general consensus that Slovenia is using its power as an E.U. member to make territorial claims, (c) conflicting opinions on post-war relations between Southeastern European nations, (d) concerns over the Croatian government's many unresolved problems, as well as unjust treatment from Western Europe, and (e) mixed opinions about the benefits and drawbacks associated with Croatia's impending E.U. integration. The following discussion of the survey findings explores each of these themes individually.

\section{Geographic Perceptions}

The first two survey questions were designed to gauge how young Croats perceived their country's geography both domestically and globally. These questions showed that respondents were very conscious of the cultural and political connotations associated with specific terms and locations (i.e. Balkans). Additionally, these questions revealed how this group of Croats has constructed a geographic imaginary, not just in reference to the other, but also by admitting Croatia's status as an 'other'. Both of these survey questions contribute to answering my second research question by examining the importance young Croats put on their nation-state's geographical position. 
Survey question 1 asked respondents to choose which geographical region they saw Croatia as a part of; the Balkans, Eastern Europe, Central Europe, or other, and why. This question is important to the overall research project for multiple reasons. Firstly, as discussed in Chapter III, the states of Southeastern Europe have often acted as a borderland between East and West (Glenny, 1999; Tanner, 1997; Todorova, 1997), so answers to this question provide some indication as to how young Croats view their country's relationship to neighboring states and the rest of the world. Secondly, the negative political and cultural feelings often associated with the terms, 'Balkans' or 'Eastern Europe', reveal whether the process of othering is still an active agent in Croatia's international relations (McDermott \& Stibbe, 2006; Todorovo, 1997). Lastly, responses to this question indicate how young Croats situate themselves ethnically and nationally.

Figure 5.2 uses a word cloud to visually demonstrate the most commonly used terms in the responses for question 1; the larger that a word appears in the cloud, the more frequently it was mentioned in the survey responses. I expected that most survey respondents would deliberately avoid using the term, Balkan, to describe Croatia's geography, because of the negative connotations associated with the term. However, as the word cloud demonstrates, Balkan was mentioned just as frequently as the term 'central' or 'Europe'. When examined more closely, the responses revealed that although a great deal of the respondents identified Croatia as a part of Central, Eastern, or Southeastern Europe, many respondents accepted Croatia as being part of the Balkans. Some respondents represented a middle-ground approach, and argued that Croatia is a border between the Balkans and Central or Eastern Europe. 


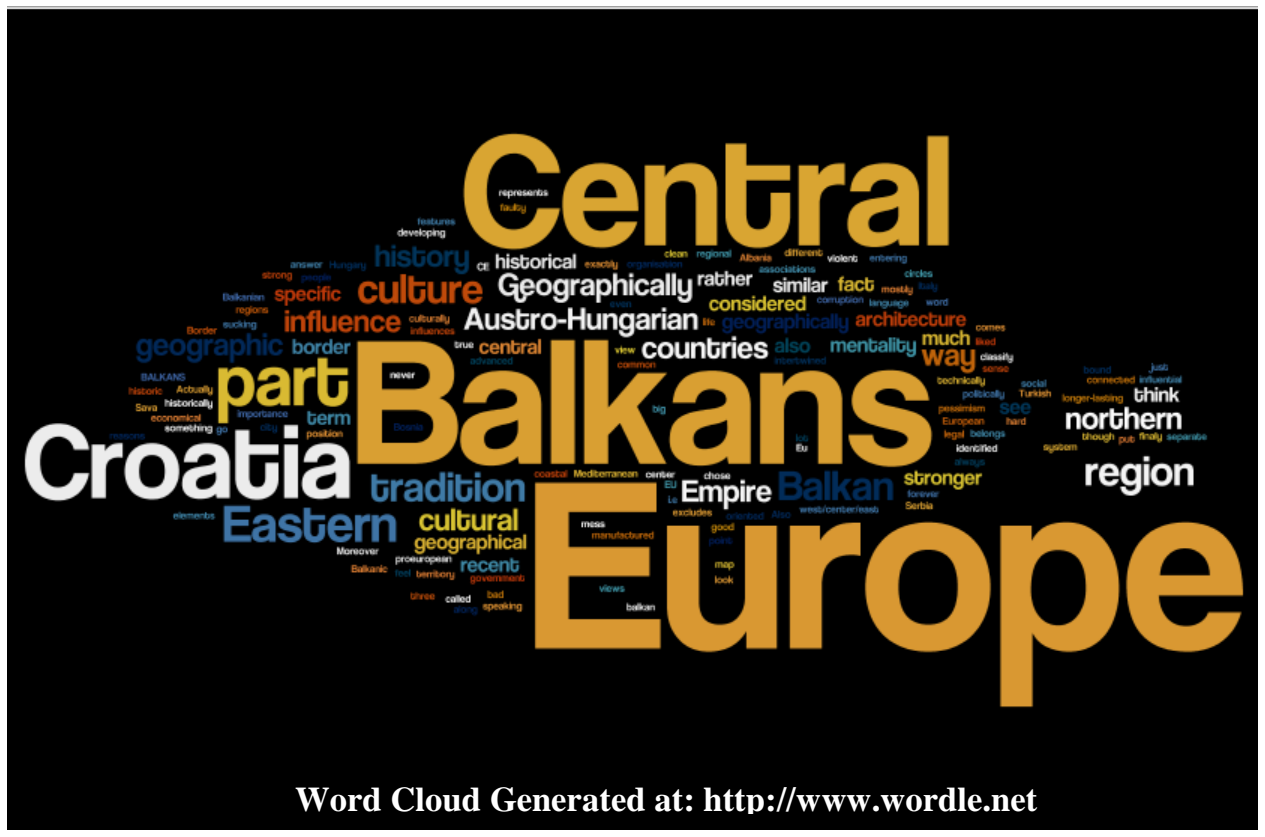

Figure 5.3 Perceptions of Croatia's Geography

What was more interesting was how each respondent justified their choice. While some respondents argued their answer by simply acknowledging what they saw as Croatia's geographical location, others offered more politicized answers. A reoccurring theme throughout the responses was that Croatia may or may not be located in the Balkans, but that it does possess a unique Balkan mentality or way of life (Respondents 9, 11, and 13). Respondents also referred to Croatia's history, both under imperialism and during the independence wars, as the reason that Croatia can be referred to as part of the Balkans. Many respondents also acknowledged that there are unfair, negative connotations associated with the term Balkans. Some examples are:

Respondent 10: “...we have much in common with other countries in Balkan similar language, tradition, culture. But in some way I see Croatia more advanced than other Balkanian countries - so because of that I classify Croatia also in Eastern Europe, which I see more prosperous than Balkan (sic)."

Respondent 14: “the Balkans isn't a geographic region but rather the term was manufactured to separate this part of Europe, because of its recent violent past and so on. I could go on forever on why this is so...from a west/center/east point of view Croatia is in the center part." 
Respondent 15: "CE (Central Europe) - historical reasons + our desire to be part of it + influence Austro-Hungarian Empire on architecture and tradition (and) BALKANS - recent history + social repercussions (pessimism, corruption, faulty legal system) of war (sic)."

Respondent 19: “...even though being a Balkan should not be considered as something bad, it mostly is... the word Balkan just represents our culture, specific as it is, and our tradition."

These responses indicate that the survey participants accept that, as a term, Balkan, is a Western invention that carries negative historical, cultural, and traditional connotations, even if it shouldn't. Even if participants saw their country as geographically separate, they seemed to acknowledge that Croatia's recent history and mentality make it a part of the Balkans. In this sense, it seems that these participants have accepted that Croatia is different, unique, and 'other' from the rest of Europe. The experiences of the Croatian nation seem to be more important in determining Croatia's geographical association than any real physical divides or boundaries.

Survey question 2 asked respondents to describe any regional differences that are present on Croatia's coast, in the North and South, in the Krajina (the former Serb dominated territory), and Slavonia. This question was designed to reveal how young people perceive the cultural, economic, and historical differences within their own country. I hoped that the answers to this question might indicate whether or not the respondents see the Croatian nation as a unified whole, and what importance they put on the role of the nation. The respondents highlighted each region's linguistic, cultural and historical influences, with specific mentions of the developmental differences and varying traditions of each region. Interestingly enough, references to specific mentalities and temperaments, like those from question 1, also permeated several of the participant's answers. 
Respondent 19 referred to the traditional differences on Croatia's coast by stating that each island was almost like a country of its own. Respondent 7 argued that the coast had the most Balkan way of thinking compared to the other regions. Five respondents highlighted the economic and developmental differences between the north, south, and the coast, while emphasizing each region's mentality. Several respondents also referred to the coast being lazier and possessing of a warmer mentality, and described the north as hard-working, but with a generally colder and less laid-back disposition (Respondents 3, 6, 7, and 12).

These responses seem to indicate that even within a single nation, geographical perceptions play an important role. The unique imperial and economic experiences and traditions of each region are emphasized here over any single national identity, which supports Anthony D. Smith's thesis (1996) that nations are the product of long-term social and historical processes and experiences. Despite this, the fact that these respondents highlight difference over likeness is not enough evidence to assume that the Croatian national identity is not strong given the nature of the survey question, and the fact that regional differences are common in nation-states where borders and populations are influenced by a long history with outside influence.

Additionally, the answers to this question may be influenced by the geographical location of the participants. As previously mentioned, all of my respondents are from northern Croatia, and only one respondent lives in a coastal city. These responses do seem to reflect the NorthSouth divide that was discussed in Chapter III, but it would be interesting to compare these responses to others, across a broader geographical range.

The responses associated with both of these survey questions indicate the importance of Croatia's geographical divides and overall position in determining how Croats identify themselves within their own borders and in reference to the other. In seeking to understand the 
role that the nation plays for a younger generation of Croats, these questions play an important role in identifying how these respondents perceive their country's historical experiences and differences. Generally, these participants have accepted both the positive and negative factors that make the Croatian nation unique or special in reference to the rest of Europe.

\section{Slovenian Territorial Dispute}

The second theme associated with the survey analysis refers to the recent territorial dispute between Croatia and Slovenia. I decided to make this issue a part of the survey, because it is one of the most current and pressing disagreements that Croatia has with one of its neighbors. As mentioned in Chapter III, this issue halted Croatia's E.U. negotiations in 2009, and although an agreement has been reached between the two countries, the issue has increased tensions between Slovenes and Croats. Survey responses reveal that tensions still exist between the two countries, and that these participants view Slovenia as abusing its power as an E.U. member. This theme contributes to the overall project by exploring how territoriality and the process of othering (Herb, 2004; Todorova, 1997) affect Croatia's relationship to broader Europe, as well as its E.U. negotiation process.

When asked if Slovenia had any right to the disputed territory, respondents unanimously answered, "no". Respondents 3, 6, 7, 14, and 17 all supported their answers by citing historical boundaries. They claimed that the disputed territory had always been Croatia's, and that Slovenia had agreed to these boundaries when Yugoslavia was dissolving in 1991. A few respondents argued that Slovenia submitted maps and documents during its own E.U. negotiation process, and that this territorial dispute wasn't mentioned then. For example, Respondent 8 discusses that "this is the first time in the history of the EU that a bilateral issue is being used to stop a country 
from joining the EU. It's interesting that that issue wasn't a problem for Slovenia joining the EU, when it had to submit the same kinds of documents (only Croatia is not an EU member, so it obviously didn't matter)." Only Respondent 12 seemed to acknowledge that there might be truth to both sides of the argument, “...Why wasn't that an issue (the territorial dispute) when Slovenia was in the process of entering EU ...I also think that our government did try to push some documents through that weren't historically correct..."

Many respondents also expressed frustration that Slovenia was abusing their power as an E.U. member. For example, Respondent 14 stated that, "now that Slovenia is in the EU it wants to make itself heard and feed it's inferiority complex of being in a big community like the EU." Respondent 15 admitted Slovenia's attempt to protect its own interests; “...I must acknowledge and respect their attempts to use their position of "power" to get what they want and protect their country's interests." Respondent 19 expressed more frustration by saying, "just because they are in EU doesn't mean that they can blackmale (sic) us...that is what they are doing...blackmailing us..." Other respondents claimed that Slovenia was acting out of greed, like Respondent 11; "they are greedy, they do have their one coastline but it's not enough for them." Respondent 17 blamed the situation on politics; “...certain political groups in Slovenia benefit from stopping Croatia from joining E.U...” Still others believe Slovenia makes territorial claims out of a feeling of superiority over Croatia. For example, Respondent 9 argues, “....it seems now that they were always jealous of Croatia in some sort of way, do not know which one exactly."

Again, references to historical boundaries reveal the importance that a perceived nationality and territoriality have on Croatia's relations with its neighbors. Behind the rhetoric that Slovenia is being greedy, or misusing its power as an E.U. member, respondents seem to be aware that Slovenia's E.U. status gives it a certain level of power that Croatia does not have. In 
this sense, there again seems to be another acknowledgement of Croatia as the other, not in an historical or imperial sense, but in its inability to achieve E.U. status.

An examination of the Facebook group, "Organization for the Boycott of Slovenian Goods and Services," supports some of the survey responses. This group advertises directly to young Croats and has over 1,500 members. The purpose of the group is both to inform members of Slovenia's attempts to block Croatia's E.U. negotiation process, and to encourage members to boycott Slovenian products. The group creator even provides a list of Slovenian owned corporations that members should avoid. Members post links to news stories that discuss recent developments in the Slovenian territorial issue, and discussions accuse Slovenia of acting in their own national interests and discriminating against Croatia.

The content in this group mirrors the survey responses associated with Slovenia's claim to Croatian territory. The consensus that Slovenia's claims are unfair, unwarranted, and are based in some Slovenian sense of national superiority are discussed both within the group and in the survey responses. In terms of the overall research project, information from this group and the survey responses reveal that issues of the nation and territoriality still affect the relationship between Croatia and its neighbors.

\section{Post-War Relations}

The third theme revealed by the survey further contributes to answering the national question by examining how respondents perceive changing post-war relationships between Croats and other Balkan nations, specifically Serbs. These perceptions were revealed through a combination of three survey questions, which asked respondents if post-war relationships have improved, if there could ever be another conflict in Southeastern Europe, and whether Serb 
minorities, who were pushed into exile during the independence wars, should be invited back. The responses to these questions reveal that nationalism has generally become less important over time, but that there remain many hard feelings and tensions between nations in the region.

In response to whether or not minorities should be encouraged to move back into Croatia, participants generally agreed that it wouldn't be a bad thing if minorities returned to Croatia. Those who hesitated to say yes, or completely disagreed, did so based on a concern for how those minorities may be treated (Respondents 8,11, and 19), because they believe that the government should focus on people (minorities included) who already live in Croatia (Respondent 15), or because they thought the government should not directly encourage immigration, but focus on creating an environment where people would want to come on their own (Respondents 8, 12, 14, and 16). Only Respondent 3 expressed concern that if minorities came back, there could be more conflict with the whole of Croatia. These responses show that, as far as immigration is concerned, these Croats did not generally feel threatened by minorities and that their concerns are not national in nature.

However, on the question of whether or not post-war relationships are improving, responses were a bit more mixed. Many respondents discussed how relations are improving amongst younger generations (Respondents 1, 4, 5, 10, and 11), which further supports the selection of this age group as the target survey sample. Six respondents focused on how relationships among individuals are improving, as people begin to realize that you can't blame an entire nation for war. Despite this, many respondents still mentioned feelings of hatred and insecurity between Serbs and Croats.

Respondent 8 felt that relationships had improved overall, but acknowledged that, “...distrust, resentment, and sometimes even hatred of Serbs, are still common in Croatia, and a 
lot of Serbs I think fear of coming or returning to Croatia. (regardless whether they really do have something to fear, or not)." Respondent 12 felt relationships hadn't changed that much; “...those who were open and non-racial remain the same, and those who were orthodoxly (sic) patriotic still hold hatred. We share a strong history and even stronger bonds (we always had that), but it will unfortunately take even more time to reach peace because we are from the Balkans (very proud and temperament)." Respondent 17 was even less optimistic; “...Croats tolerate Serbs, that's all. I doubt that relationship could ever be anything above that. It is hard to make parallels that would explain the relation between us and them (nazis and jews during and after ww2 might come close to explaining tensions and feelings on both sides)." Respondent 19 discussed the complexity of Croat-Serb relations; “...people remember individual members of families that were on Serbian side, and know who killed who...that is not easy to forget... those who don't know any of those individuals find it easier to forget and forgive...but those that know what happened and remember it vividly, I think, will never forget nor forgive...it's sad...but I understand them completely...you cannot pass over war that easy..."

Despite the mixed feelings towards Croatia's relationship with Serbs, most survey respondents are convinced that there will not be another war in the Balkans, at least not in the near future. Some argue that future conflicts will be based on economic or political issues (like the current territorial issue with Slovenia), rather than on issues of nationality or ethnicity, and will not result in open war. Those who do think that war is a possibility for the region see it as most likely to occur in Bosnia, where there are unresolved issues from the 1990's. In any case, the consensus among survey participants is that national or ethnic based conflicts are part of Croatia's past, and will not be a part of its future. 
The relationships revealed through exploring Croatia's post-war interactions further support the hypothesis that nationalism and ethnicity are becoming less important for younger generations of Croats. The survey participants admit that many issues remain to be solved between Croats and other nationalities, specifically Serbs, but their responses point to a generation of Croats that are much more interested in mending differences between groups than maintaining any type of separation. These findings are further supported in a later discussion of Facebook groups that celebrate the difference between Balkan nations, despite the fact that problems remain.

\section{Government and Corruption}

Another theme that was revealed in the survey analysis deals with how these young Croats perceive the functionality of their government and the treatment of their country by the West. Participants were asked if they agreed with the E.U.'s assessment that the Croatian government had many changes to make before membership could be granted. I hoped this question would reveal the degree to which respondents felt Croatia was being mistreated or marginalized by the international community. I was surprised to find that this group of Croats was highly critical of their government's policies and functionality.

Participants expressed frustration with Croatia's economic, political, and judicial systems, and indicated that a great deal of corruption is present in the government. However, even though they see faults in their own government, many of the respondents expressed concern over the West's motivation in demanding changes from Croatia. These responses further expand on the research hypothesis that nationality and ethnicity are becoming less important than global 
integration and overall social development, but also contribute to understanding how the processes of othering and marginalization continue to affect how the West interacts with Croatia.

Respondents mentioned several areas where they felt their government could improve and make changes. Ten respondents answered that corruption was one of the most important issues that Croatia had to combat. Croatia's need to focus on economic development was mentioned by five different respondents. The third largest problem that came up in a total of six participant responses was in reference to much needed improvements in the justice system. Once again, issues of a Balkan mentality and a general attitude or disposition were referenced by Respondents 9 and 14. Also mentioned were problems with ruling elites, nepotism in government practice, and the need for democratization and better education.

I was generally surprised at how critical respondents were of their government and overall Croatian society, but it is interesting to point out that the most popular responses (issues of corruption, justice, and economic development) are the key areas that the E.U. wants to see Croatia improve in before membership is granted (Commission for European Communities, 2009). It would be interesting to know to what degree these responses are influenced by popular discourse perpetuated by the media, government, and international community. Section B of this chapter examines some of these discourses more closely. Regardless of the influence, these responses show that this group of Croats is highly critical of their state and fellow citizens, which may indicate the lessening importance of the nation overall.

Croatian youths weren't always so critical of their government. A set of surveys were conducted on Yugoslav youths from 1956 to 1963, at the height of the socialist regime's power. One of the surveys, conducted in 1960, polled 3,291 Zagreb University students, of which, 63\% considered the Yugoslav system to be on par with or better than Western European democracies 
of the time (Skrzypek, 1965, p. 93). An additional survey, conducted with 2,621 Croatian high school students, showed that $50 \%$ of the respondents felt the Yugoslav system met their needs, and $90 \%$ felt Yugoslavia was making progress (Skrzypek, 1965, p. 94). In evaluating these surveys, there seems to be a difference in how satisfied Croatian youths were under socialism compared with the level of satisfaction the Croats in this study expressed.

This approval expressed by Yugoslav youths could be attributed to a satisfaction with socialism as an ideology, but might also be reflective of the strength of state institutions and the semi-isolated nature of the Yugoslav republics at the time. The frustration expressed by respondents in this study might then be reflective of Croatia's attempt to globalize, and the inability of the state to respond to political change. A comparable study with a larger sample may be able to reveal more trends that support or refute this observation.

The critique of government made by Croats in this study is supported by a Gallup poll conducted throughout 2006 and 2007, which surveyed the population of several Southeastern European states and E.U. member-states to see if they were confident in the judicial and court systems within their own country. Of 1,000 polled in Croatia, $30 \%$ of respondents said they were confident in their own country's judicial system, while over $60 \%$ of respondents are not (margin of error \pm 3 percentage points). These trends are similar to those of many of the Balkan states surveyed (English, 2008).

A second poll, with a margin of error between \pm 2.2 and \pm 3.5 percentage points, also showed that $83 \%$ of 1,000 Croats surveyed believe corruption to be widespread in business, while 77\% believe the same about government (Gravelle, and Nyiri, 2007). These results support the responses from survey participants, who repeatedly cited Croatia's political and judicial corruption as two of the country's largest obstacles. What remains to be seen is whether E.U. 
membership will help combat these issues, because, many of the respondents in this study have mixed opinions over whether Croatia should attempt to solve some of its own problems before entering the E.U.

Despite the concerns that this study's survey respondents expressed for their government and overall political system, many perceived the West as treating Croatia unfairly in the E.U. negotiation process. Once again citing Croatia's war-torn past, its mentality, and its transition from socialism to free-market democracy, eight respondents felt the West had Croatia's best interests at heart. On the other hand, many respondents accused the West of serving its own interests, like Respondent 6 who claimed that “...they are more interesting in what they could GAIN from Croatia, instead of what they could GIVE it," or Respondent 10 who sees some changes proposed by Western Europe as good, but believes “...that they don't do that because they care so much for us...They are focused on their interests, and when they would want us to be in EU they would do that...that moment will come when it would best suit them for some reason."

Respondent 3 accuses Western states of making false promises, and demanding too much of Croatia. Others accuse Western Europe as holding Croatia to a different standard than other E.U. applicants. For example, Respondent 8 thinks that “...a few countries during the course of Croatian negotiation to join the EU have used "excuses" to keep us out because we're pretty small and unimportant (i.e. not sitting on oil, or something like that)." Respondent 15 thinks that "sometimes double standards are used depending on different factors - e.g. market size and Western countries (economic) interests (for example some of recent EU members are not much economically better than Croatia, some have also faulty justice systems)." 
These concerns show that the survey respondents see Croatia as being marginalized or treated differently than other nation-states, which further contributes to the hypothesis that Croatia is engaged in a process of othering with the rest of Europe. Respondents also express pride in their national identity and in their country's potential, despite their criticism of government leaders, the powerful elite, and the overall functionality of the Croatian state. This evidence seems to disprove Gellner's theory (2000) that the nation only exists to support the function of the state, and instead suggests that the two can exist separately. Section B of this chapter will further expand on the constructed geographic imaginary of Croatia and Southeastern Europe through the examination of E.U. documents.

\section{E.U. Integration}

The last theme to be revealed by the survey data refers to the respondents' opinion of Croatia's impending E.U. integration. Multiple survey questions asked participants if they thought the E.U. would take away some of Croatia's independence, and to list some of the positive and negative aspects of E.U. membership. I expected that if international and state discourse had been successful in projecting a positive image, most survey respondents would be in support of E.U. integration. However, for every positive aspect to E.U. integration, respondents also expressed many concerns with how E.U. membership would affect Croatia.

Nearly every participant was able to name some benefit that E.U. membership would provide Croatia. They mention the E.U. as a positive force in ending Croatia's corruption, opening up markets for Croatian exports, providing economic and political protection, discouraging extremism, providing better educational opportunities, and allowing for a freer movement of Croatian students and workers to other countries, as well as bringing more people 
to Croatia for tourism and business. Even with all of the advantages global integration can provide, respondents are also hesitant about E.U. integration for several reasons.

Respondents 5 and 12 expressed concern over the financial problems Croatia might incur in order to meet E.U. standards. Respondent 6 discussed how opening Croatia's markets to the E.U. could ultimately make it harder for Croatian producers to succeed. However, the largest concern that the respondents expressed was over the potential loss of Croatian customs and identity:

Respondent 1: "I think it will take a bit of our independence because its (sic) like in big corporations during takeovers. We are too small and not so succesfull (sic) so we would have to listen for what ever EU should tell us."

Respondent 8: “As a small (but proud!) nation, I think it's important for us to protect and preserve our customs and traditions as much as possible (unfortunately, I think unrefrigerated eggs on open-air markets will have to go, which is just silly) to preserve our identity. However, we've been under foreign rule from the 12th century until 1918, and since we didn't forget our language or customs during those 800 years, I'm pretty sure it's not likely to happen."

Respondent 11: "bad things are that we will lose our customs like home-made wine, cheese and other products $\cos$ (sic) when we get to e.u. everything must have certificate or stuff like that, or paying more taxes."

Respondent 13: "There is still few rituals that we can do. In EU that will no be posible...(sic)."

Respondent 14: "Croatia is already playing someone elses music. Laws and regulations are passed to please the EU and Croatia hasn't the influence or the leadership to fight for its place in Europe as an individual country capable of great contributions to the European community."

Respondent 17: "That common sense tells you that no one will solve your problems, at least not for free. Other countries had time to live in democracy for well over 70 years now or more and in that time they had time to grow. I don't see why Croatia shouldn't grow her own way, without having to go through "speed class". There is no need to force 2 year old child to act in the same way as a 7 year old." 
Being that the largest concern these respondents have is over the potential loss of Croatian traditions and identity, it seems to indicate that national preservation is still an important issue for this group of young Croats. Respondents are afraid that their country is not large enough or strong enough to stand up to larger European states. In terms of the overall study, these responses show that although the nation and nationalism are less important for these young Croats, cultural traditions and customs are still highly valued.

These hesitations over Croatia's E.U. admittance are supported by a much larger Gallup poll conducted in February 2007. Gallup asked a sample of 1,000 Croats if they thought that E.U. membership would be a good thing, a bad thing, or neither. $34 \%$ of the respondents answered that E.U. membership would be good, while $29 \%$ thought membership would be bad, $28 \%$ said it would be neither good nor bad, and $9 \%$ had no opinion or refused to answer. Additionally, 35\% of the respondents believe that a majority of Croatians will support E.U. membership, while $45 \%$ do not think most people would support it (margin of error \pm 3 percentage points) (Rheault, 2007). This shows that Croats are still much undecided on the effects that E.U. membership will have on their social, economic, and political institutions. The results of this poll are similar to the results shown in this study's survey, where respondents have serious misgivings about how the E.U. will ultimately help or hinder Croatia's development.

Results from this poll and the survey responses also coincide with the findings from the E.U.'s bi-annual public opinion report, Eurobarometer. Croatia's fall 2009 report shows that the Croatian population sees E.U. membership as necessary to global integration, but also sees the E.U. in an increasingly negative light. The report highlights frustration with the negotiation process, especially regarding the amount of time it took to reach an agreement on the territorial issue with Slovenia. Much like the surveys in this study, the document also mentions that Croats 
are generally more confident in European institutions than their own, which indicates that Croats still desire E.U. membership (European Commission, 2009).

Two other Facebook groups also help to connect survey responses to a larger population. "Students and Workers for BALKAN SOCIALIST FEDERATION," has over 200 members, and encourages the nations of the Balkan Peninsula to rise up against imperialists and bourgeois society. Members of this group posts messages informing one another about left-leaning protests, organizations, and media sources. The group also has several discussions, which focus on Western intervention in the Balkans. These discussions indicate that members of this group believe that the ethnic and national conflicts are, at their root, based on class, and that it has been right-wing groups and Western intervention that have perpetuated conflict and unrest in the Balkans.

Although this group content cannot be compared to any specific survey questions, it does contribute to understanding the overall research goals in two ways. Firstly, it indicates that, despite the fact that the Croatian state, and other Southeastern European states, are trying to integrate with the E.U., some individuals still sympathize with the idea of regional isolation. Secondly, and perhaps more importantly, it shows that the members of this group are much more interested in ethnic and national unification than they are in any individual national identity. Generally, this group demonstrates that, at the scale of the individual, there exists the perception that the goals and ideals of greater Europe are different from those of the Balkan Peninsula. This indicates that individuals do perceive the Balkans as an 'other' within Europe.

The Facebook group, "Balkan Power," also attracts people from various Southeastern European nations, but rather than promoting socialism or regional unification, this group celebrates difference. With over 2,200 members, the group is intended to provide an outlet for 
people from the Balkans to share experiences and similarities about their traditions and culture. Topics include the creation of a Balkan flag and promoting a definition of the Balkans that does not carry the any negative political or historical consequences with it.

Despite these intentions, many messaging threads quickly turn to debates and heated arguments. Members disagree over which countries should be considered Balkan (for example, Slovenia, Turkey, and Hungary), over issues of Kosovo's independence, and over ethnic and political feuds that remain unsolved from the independence wars. Many members, including the group's creator, try to quell these arguments by reminding others that Balkan nations have much more in common with one another than they have different.

The content from "Balkan Power" relates to survey responses in many ways. Just like many of the survey participants, these group members acknowledge their Balkan-ness, but are incredibly aware of the negative connotations that come with that. Additionally, the mixed feelings that survey respondents have toward post-war relations are also expressed here, as members join the group to share commonalities and experiences, and end up in arguments over geography, nationality, and politics. Combined with the surveys, this group reveals that nationalism is still a very confused subject for younger generations of Southeastern Europeans, who want peace, but have a hard time reconciling with the past.

\section{Impacts and Summary}

The qualitative analysis of surveys, combined with a close examination of several Gallup polls and Facebook groups, contributes to examining the perspectives that young Croats have on E.U. integration and overall issues of the nation, ethnicity, the role of government, and regional relations (research question 2). The trends revealed here indicate that the younger generation of 
Croats is much more tolerant of other nationalities and minorities than those age groups who experienced the independence wars, and that Croats are highly critical of the overall functionality of their state. Additionally, this analysis indicates that, although globally minded, this group of young Croats is very hesitant about their country's ability to integrate with the E.U. and maintain its identity, customs, and overall economic and political sovereignty.

This examination of how young people perceive Croatia's geography in relation to the rest of Europe is very helpful in analyzing the scale of the individual. However, for this study to be as comprehensive as possible, a closer look at the state and international scales is necessary. Section B discusses the analysis and findings associated with the examination of E.U. publications, as well as government press releases and websites. Combined with the survey findings, textual analysis more fully examines the geographical imaginary that Western Europe has constructed of Croatia, and the image that the Croatian state is trying to project to the global community.

\section{B. Textual Analysis}

\section{Introduction}

The survey data revealed the importance of the nation for a post-war generation, and contributed to a greater understanding of how the nation, ethnicity, and nationalism continue to play vital roles in Croatia's E.U. transition, and its relationship to other European states. However, even with the comparison to national poll results and the additional analysis of Facebook groups, the surveys are too small in number and represent much too small a portion of the overall Croatian population to satisfy as the only data for this project. 
As discussed in Chapter IV, textual analysis of international and state documents and websites was used to remedy these issues. The following discusses how I applied the process of textual analysis to multiple documents, websites, and press releases. The findings associated with this portion of the data analysis are also discussed in relation to research questions one and three. Ultimately, the use of textual analysis expanded on some of the findings from the survey data, and it helped draw a clearer picture of how ethnicity and nationalism continue to affect Croatia's relationship to the E.U. and its neighbors.

\section{Selecting Texts}

Source selection is incredibly important, due to the complexities inherent in examining text for discourses, and the seemingly unlimited number of texts available for examination. Given the scope of this project, it would be impossible to analyze every E.U. document or Croatian government publication that referenced global integration and issues of nationalism. In order to narrow the number of texts to a manageable sample size, I had to consider which sources would be most helpful, would likely provide counter discourses, would be most interesting, and would be qualitatively rich to the overall research process (Waitt, 2005, p. 177). Additionally, I had to consider how many documents would satisfy for a valid sample size and the amount of time that it would take me to collect all of my sources.

Concerning sample size, because discourse analysis seeks to uncover relationships and context, there is no set number of texts that qualifies a research project as rigorous (Waitt, 2005, p. 178). As such, this project examines a small number of texts that I believe contribute to a greater understanding of the discourses that permeate Croatia's E.U. transition and the role that nationalism plays in the country's relationship with the rest of Europe. Admittedly, there are 
many other texts that could have been examined, and future projects may evaluate these in further depth.

Another important element in selecting sources for analysis is the amount of time that it takes to collect data. Selecting sources for discourse analysis is a continual process, so it is ineffective to attempt collecting data all at one time. Instead, I collected the data over a period of several months. This was especially helpful in analyzing government press-releases, because I was able to gain access to the most updated articles and posts; especially concerning the territorial dispute with Slovenia and Croatia's ongoing E.U. negotiation process.

Taking all of these issues into consideration, I ultimately decided to examine a few E.U. documents that refer, not to the specific negotiation process, but to the union's recommendations and demands for Croatia's economic, political, and social systems. To explore the image the Croatian government is projecting the rest of the world; the state's embassy website is analyzed in conjunction with the official government website and press releases. A complete list of the examined documents, publications, and websites can be found in Appendix A.

\section{Analyzing Texts to Reveal Discourses}

Once the sources for analysis were selected and the data was compiled, I had to consider how I would analyze each text to expose the discourses present within them. As mentioned in Chapter IV, this project is concerned with the relationship between two discourses; the Western, imperial discourse that Croatia is underdeveloped and ultra-nationalistic and the hypothesized state discourse that Croatia is stable, democratic, and "European". Gordon Waitt adapts strategies for examining discourse from Rose, Fairclough, and Tonkiss (Waitt, 2005, pp. 180- 
188). These strategies, as well as how they relate to my research questions and the examination of discourse, are discussed below and in Table 5.2.

The first strategy that I implemented to examine the discourses imbedded in selected sources and documents was to reveal the circumstances of production. This strategy involves exposing the social contexts in which a particular text was created, and further examining how this text affects or reflects social change. More specifically, this strategy involves asking basic questions like, what is the text, who is the author of the text, and what is the intended audience of the text (Waitt, 2005, pp. 185-186). Asking these questions allowed me to position each text according to its overall purpose. For example, when reviewing a text created by the Croatian government, I had to be mindful that the intended audience was not always the Croatian population. Instead, many of these state documents were designed for an international audience, to promote an image of Croatia as "E.U. ready".

The second strategy that I implemented involved the use of coding. As mentioned in Chapter IV, coding is valuable in drawing out key themes and concepts located within a particular text. To further relate the textual analysis to my survey findings, I used similar codes to that of my survey analysis. I specifically tried to relate the codes to my research questions by searching for references to Croatia's geographical position, the E.U. negotiation process, and Croatia's relationship to the rest of Southeastern Europe, as well as latent messages associated with Croatia's role as the other and issues of nationalism and ethnicity (See Table 5.2 in Survey Analysis).

The third strategy that I implemented involved the issue of incoherence. In addition to coding for themes located within the texts, it is important to examine any inconsistencies and contradictions within the text. These inconsistencies help to reveal other forces at play within the 
discursive formation (Waitt, 2005, pp. 183-184). For example, during the analysis of E.U. documents, it became obvious to me that, in addition to an apparent geographic imaginary or process of othering, the international community was making suggestions for Croatia that were based as much in the perpetuation of neoliberal economic and political policies as they were in changing a historical image of Croatia. In this sense, I was forced to consider that the process of othering and nationalism offer only a partial understanding of Croatia's relationship to the rest of Europe. Perhaps the West seeks integration with, instead of marginalization from, Croatia, if for no other reason than to expand its own capital interests.

\begin{tabular}{|c|c|}
\hline \multicolumn{2}{|c|}{ Textual Analysis to Reveal Discourses } \\
\hline $\begin{array}{l}\text { (1) Circumstances of Production } \\
\text { - Under what social context was the text created? } \\
\text { How can this text affect or reflect social change? } \\
\circ \text { What is the text? } \\
\circ \quad \text { Who is the author? } \\
\circ \quad \text { What is the intended audience? }\end{array}$ & $\begin{array}{l}\text { (2) Coding } \\
\text { What discourses, or mixture of discourses, are in } \\
\text { this text? } \\
\circ \quad \text { How does this text show the role or } \\
\text { perceptions of nationalism in Croatia? } \\
\circ \quad \begin{array}{l}\text { What does this text indicate about the } \\
\text { status of Croatia's relationship with } \\
\text { Europe? }\end{array}\end{array}$ \\
\hline $\begin{array}{l}\text { (3) Incoherence } \\
\text { - Are there inconsistencies in this text? } \\
\text { - What other forces, besides the process of othering } \\
\text { are at play here? }\end{array}$ & $\begin{array}{l}\text { (4) Persuasion } \\
\text { - What statements does the text make, and how are } \\
\text { they communicated as truth? } \\
\text { O What historical and political social } \\
\text { processes are drawn upon to support } \\
\text { statements about Croatian society and E.U. } \\
\text { ascension? }\end{array}$ \\
\hline $\begin{array}{l}\text { (5) Inclusions \& Silences } \\
\text { - Who/What is included in the text? Excluded? } \\
\circ \quad \text { Why are certain social processes drawn } \\
\text { upon and others neglected? } \\
\circ \quad \text { What does this relationship between } \\
\text { inclusion and exclusion say about the } \\
\text { status of Croatian nationalism and its } \\
\text { relationship to neighboring states? }\end{array}$ & $\begin{array}{l}\text { (6) Other Details } \\
\text { Is this text part of a series of texts? What other texts } \\
\text { are included/excluded? } \\
\text { How does this text relate to other texts that have } \\
\text { been examined? (are there contradictions or } \\
\text { similarities?) } \\
\text { Adapted from: Wait, 2005, p. } 187\end{array}$ \\
\hline
\end{tabular}

Table 5.2 Strategies for Examining Discourse

In addition to looking for inconsistencies, I also searched each text for elements of truth. This strategy exposes how persuasive a text is by examining what specific statements the text is making, and how these statements are communicated. For example, a text may draw up statistics 
or academic knowledge to make an argument seem valid (Waitt, 2005, pp. 182-183). For this study, I was careful to examine each text for references to historical or political processes that offer support for what a text was trying to say about Croatian society or the E.U. negotiation process.

All of these strategies involve looking for circumstances, themes, contradictions, and truths that are included within the text. However, discourse analysis also entails looking for the processes and themes that are excluded from a text. Who and what are included or excluded from a particular text has important political and social implications (Waitt, 2005, pp. 184-185). In examining texts for this study, I had to be conscious of what social processes were acknowledged or left out of a particular document, and subsequently explore how those exclusions relate to Croatia's relationships with other nations and states.

The last strategy for examining discourse is to simply look at details for each text. I had to consider if a text was part of a series of other texts, and how those other texts were included or excluded within the document being examined. Lastly, I had to consider how the text being analyzed related to other texts in this study. Examining important details allowed me to successfully familiarize myself with the text, which contributed to a rigorous research practice (Waitt, 2005, pp. 180-181, 187).

These strategies aren't meant to be a step-by-step guide to discourse analysis, but are instead designed to be performed both individually and simultaneously in order to explore the relationships and discourses imbedded in each text. The implementation of these strategies allowed me to successfully examine the relationship between the imperial discourse that Croatia has a "Balkan mentality" and is antidemocratic with the discourse that post-war Croatia is politically and economically stable. Additionally, discourse analysis allowed me to explore the 
role that nationalism and the process of othering play in Croatia's transition to the E.U. at the individual, state, and international scales.

Many of the themes associated with the survey analysis reappeared in the textual analysis portion of this study. Specifically, references to the territorial dispute with Slovenia, the remaining tensions and improvements in the relationships between Croatia and their neighbors, and concerns of Croatia's judicial system and corruption all appeared in both the survey analysis and textual analysis. A discussion of the discursive findings associated with textual analysis follows.

\section{E.U. Documents}

The European Commission on Enlargement's website (2010) contains information regarding the status of the European Union's potential members and candidate countries, including Croatia. Three E.U. documents were chosen from this source in order to examine the status of negotiations and the economic, social, and political progress being made by Croatia. A close analysis of these documents indicates how the E.U. perceives Croatia's ascension progress, and reveals how the European community perceives Croatia's history of conflict and socialism.

The first document to be examined was the "EU-Western Balkans Summit - Declaration" (2003). The declaration was signed at the Thessaloniki Summit on June 21, 2003, and is a ten point commitment by the leaders of Albania, Bosnia and Herzegovina, Croatia, The Former Yugoslav Republic of Macedonia, and Serbia and Montenegro to pursue membership in the European Union and to implement democratic, social, and economic reforms to achieve this aim. This declaration not only reveals the intents of the Western Balkan states to join the E.U., but also exposes the image that Balkan leaders hope to project to the rest of Europe. 
The points of the declaration affirm that nation-states from the Western Balkans value democracy, human rights, and a market economy, and that they pledge their condemnation of extremism:

" 1 . We all share the values of democracy, the rule of law, respect for human and minority rights, solidarity and a market economy, fully aware that they constitute the very foundations of the European Union. Respect of international law, inviolability of international borders, peaceful resolution of conflicts and regional co-operation are principles of the highest importance, to which we are all committed. We vigorously condemn extremism, terrorism and violence, be it ethnically, politically or criminally motivated" (European Commission for Enlargement, 2003).

But behind this rhetoric, there is an acknowledgement that the ethnic violence associated with the dissolution of Yugoslavia is un-European. By signing this declaration, leaders are separating themselves from the nationalist party lines of the previous decade, and promoting a discourse of stability and peace.

The declaration also recognizes that ethnic conflict is undesirable to the E.U.'s way of life: "5...Fragmentation and divisions along ethnic lines are incompatible with the European perspective, which should act as a catalyst for addressing problems in the region..." (European Commission for Enlargement, 2003). Here, Croatia and other Western Balkan countries are once again forced to acknowledge that the ethnic and national violence associated with the independence wars is un-European. Leaders have to prove themselves, and their states, as viable candidates for E.U. integration by promoting the discourse that Southeastern Europe can move beyond the ethnic fragmentation and the violence of the past.

The declaration also confirms that Balkan states recognize that E.U. integration is necessary for the development and sustainability of the region, and are confident in the E.U.'s ability to make decisions on the implementation of reforms: 
"2. The EU reiterates its unequivocal support to the European perspective of the Western Balkan countries. The future of the Balkans is within the European Union. The ongoing enlargement and the signing of the Treaty of Athens in April 2003 inspire and encourage the countries of the Western Balkans to follow the same successful path. Preparation for integration into European structures and ultimate membership into the European Union, through adoption of European standards, is now the big challenge ahead...The speed of movement ahead lies in the hands of the countries of the region" (European Commission for Enlargement, 2003).

"4....The Western Balkan countries welcome the decisions by the EU to strengthen its Stabilisation and Association policy towards the region and to enrich it with elements from the experience of enlargement..." (European Commission for Enlargement, 2003).

In this case, there is an acknowledgement that E.U. progress is in the hands of individual Balkan states, and that the speed with which they achieve membership is entirely dependent upon their ability to implement reforms. However, there is also an acceptance that the E.U. can make specific judgments and decisions with regard to Western Balkan progress. This seems to indicate that membership may be dependent upon the perceptions that the rest of the E.U. has on the development of the Western Balkans.

In addition to issues of social and political reform, the declaration also focuses on the importance of the free-market system and the implementation of neo-liberal policies. The free movement of goods, services, and people are discussed as necessary components of E.U. integration. These economic reforms are given equal importance to the social and political changes that Croatia, and other Western Balkan states, must make in order to achieve E.U. membership. Ultimately, this indicates that Croatia's status as a post-socialist state plays as important of a role in determining Croatia's E.U. ascension as issues of ethnicity or nationalism. 
The second document to be examined was the "Opinion on Croatia's Application for Membership of the European Union" (2004). Published shortly after Croatia's E.U. application was submitted, this document lays out the reforms and concessions Croatia will have to make in order to gain full membership to the union. The E.U. writes an "Opinion" for all new E.U. candidates, and as such, this document provided a logical basis to begin examining how the union perceives Croatia's historical experiences and political system.

The "Opinion" provides a brief historical and political context for Croatia's E.U. ascension, specifically referencing Croatia's transition from socialism to a democratic society, and follows with a detailed explanation of the political, economic, and social points that Croatia must improve upon in order to gain membership. Much like the "EU-Western Balkans Summit Declaration," this document makes it clear that issues of ethnicity, nationalism, and regional relations still matter for the European Commission. Also similar to the declaration, the Commission stresses the importance of implementing neo-liberal economic and political policies in order to fully integrate Croatia with the E.U. The Commission's suggestions and demands indicate that, although Croatia does have real problems, to some degree, the union perceives Croatia to be an 'other'.

For example, in the first few pages of the "Opinion", the Commission provides a context for Croatia's application for membership:

"The Croatian application for membership is part of an historic process, in which the Western Balkan countries are overcoming the political crisis of their region and orienting themselves to join the area of peace, stability and prosperity created by the Union...'the pace of further movement of the Western Balkans countries towards the EU lies in their own hands and will depend on each country's performance in implementing reforms..." (Commission of the European Communities, 2004, p. 4) 
In this statement, the Commission seems to be placing Croatia, and other Western Balkan countries, outside of the E.U.'s privileged space of prosperity and stability. In other words, the E.U. is part of a peaceful Europe, while Croatia is not. At the same time, the Commission makes it clear that future integration between the Western Balkans and the E.U. is solely dependent on the ability of the Balkan states to implement reforms that satisfy the standards of the union. In this sense, there not only seems to be a process of othering at work, but also a belief in selfdetermination that neglects to consider the historical processes that may disadvantage the Western Balkans in their attempts to meet E.U. standards.

The "Opinion" further expresses concerns over issues of ethnicity and nationalism. On one hand, the Commission seems satisfied with Croatia's progress in providing a safe environment for minorities: "The general level of security in Croatia remains satisfactory. There have been only a few ethnically related incidents" (Commission of the European Communities, 2004, p. 15). On the other hand, there is still skepticism regarding the ability of Croatia's ruling party to distance itself from nationalist politics and rhetoric:

"The Croatian Democratic Union (HDZ)...has showed a strong determination to transform itself into a democratic party with a pro-European vocation. However some statements made in the recent past...are still a matter of concern for the Commission. It still need (sic) to be demonstrated whether all elected members have really distanced themselves from radical nationalism" (Commission of the European Communities, 2004, p. 13)

Croatia's relationships with its neighbors are discussed as having improved, with tensions remaining. The territorial disagreement with Slovenia is mentioned, as well as economic and national tensions between Croatia and Serbia. However, the main focus is placed on Croatia's economic and political developments. The country is praised for its attempts to open markets, remove tariffs, and economically integrate with the E.U., but major concerns remain over the 
country's cooperation with the ICTY, its judicial system, and levels of corruption. These concerns mirror the survey responses, which discussed these same issues as areas where the Croatian state needed to improve. Generally, it seems that issues of economic and political development are just as important as issues of ethnicity and regional relations.

The third document selected for examination was the "Croatia 2009 Progress Report." Whereas the "Opinion on Croatia's Application for Membership of the European Union" indicated how the E.U. perceived Croatia at the beginning of its E.U. negotiation process, this progress report reveals if and how those perceptions have changed, and whether Croatia is any closer to achieving membership status. As such, the combined analysis of these two documents can greatly contribute to understanding how ethnicity and nationalism continue to affect Croatia's E.U. ascension and its relationship to the rest of Europe (research questions 1 and 3).

Despite their many similarities, this progress report is written in a different tone than the opinion report, because rather than emphasizing the reforms that Croatia has not achieved, this document focuses on the improvements that Croatia has made in restructuring its economic, political, and social systems. The progress report highlights Croatia's economic growth despite difficulties related to the global financial crisis, and discusses the successful opening of 28 of the 35 negotiation chapters, and the provisional closure of 12 chapters (Commission of the European Communities, 2009, p. 5). Even with its remaining problems, the report suggests that Croatia could near the end of the negotiation process very soon.

Much like the opinion report and the declaration, this progress report emphasizes the importance of Croatia's acceptance of neo-liberal policies based on free trade and open markets. Although the financial crisis continues to affect Croatia's unemployment levels, GDP, imports, and exports, the Commission is confident that Croatia's free-market system is stable enough to 
survive the economic down-turn, but concerns remain over issues of public spending. Also similar to the other two documents examined here, are concerns over the state's progress in ending corruption, improving the justice system, and over the treatment of minorities. For example:

“...corruption still remains widespread. The recently upgraded legal and administrative structures remain to be tested in practice. While the total number of corruption cases investigated so far has increased, the actual number of prosecutions remains low. The ratio between investigated cases and indictments also remains low. There has been limited investigation of high-level corruption, the prosecution of which is frustrated by political considerations." (Commission to the European Communities, 2009, p. 54)

"Further progress was made in reducing the backlog of cases before Croatian courts...The length of proceedings before the courts remains generally excessive and major problems continue to exist with the enforcement of court decisions.... Overall, improvements to the judicial system have been made, but major inefficiencies in the judiciary remain." (Commission to the European Communities, 2009, p. 23)

"With regard to the Serb minority, there have been fewer reports of ethnically motivated attacks. Police investigations of such incidents have improved, although few cases end in prosecution...Discrimination continues, particularly in the public sector at the local level. Croatia needs to encourage a spirit of tolerance towards the Serb minority and take appropriate measures to protect those who may still be subject to threats or acts of discrimination, hostility or violence." (Commission of the European Communities, 2009, p. 15)

These examples demonstrate that, although the E.U. claims that Croatia could be ending the negotiation process in the near future, the union is still dissatisfied with the ability of the Croatian state to ensure reforms are being enforced on the ground. Unlike the opinion report, this progress report does not directly discuss issues of nationalism or nationalist tendencies in government. However, it's clear from the Commission's concern over the status of minorities, and Croatia's relationship with its neighbors, that ethnic and national issues still play an important role in Croatia's E.U. transition. 
The examination of these three documents contributes to answering the research questions in multiple ways. Firstly, it is clear that issues of ethnicity and nationalism play a role in Croatia's E.U. ascension. The European Commission repeatedly refers to the political and social upheaval associated with Southeastern Europe's independence wars, and expresses concern over the ability of Croatia, and other former Yugoslav states, to overcome their ethnic and national differences. However, economic and political issues seem to be the main focus of the E.U. reforms.

Secondly, both the opinion report and the Western Balkan declaration contain evidence that the E.U. continues to construct an image of Croatia and the Western Balkans as an 'other'. References to Croatia's attempts to move away from the political and social upheaval of its past, and join the peaceful and stable E.U. indicate that there is an 'us' and 'them' mentality in the union. Additionally, despite Croatia's attempts at reform, it still has not combated ethnic issues, corruption, or the faults in its justice system to the satisfaction of the E.U. Given the selfdeterministic tone of both the Western Balkan declaration and the opinion report, the E.U. may perceive this as a reflection of Croatia's abilities, rather than as a result of unique historical and political processes that make Croatia's integration with the E.U. all the more difficult (i.e. the transition from socialism to free-market capitalism and the independence wars).

The third theme that emerges from the analysis of these three documents refers to the linear trajectory that Croatia is being forced to develop on. The emphasis that the E.U. places on the swift and comprehensive implementation of neo-liberal policies ensures that there is little room for Croatia to pursue post-socialist development on its own terms. Whereas most Western European states reached their level of development over a long period of time, post-socialist spaces, like Croatia, are forced to attempt accelerated development on Western terms. In this 
way, Croatia is engaging with Partha Chatterjee's material domain (2000), by accepting that the European Union is economically and politically more advanced.

One final observation that was extracted from the analyses of these three E.U. documents refers to the use of the word 'Balkan' or 'Western Balkan' to describe Croatia, Albania, Bosnia and Herzegovina, The Former Yugoslav Republic of Macedonia, and Serbia and Montenegro. As discussed in Chapter II and III, as well as in the survey analysis, there are negative historical connotations associated with the term, Balkans. The E.U.'s choice to use Balkans to describe former Yugoslav states may just be a reference to geographical location. However, it may also indicate the cultural and political preconceptions that Western Europe and the E.U. have of the former Yugoslav republics.

The examination of these three E.U. documents reveals the importance that neo-liberal ideologies play in the E.U's definition of development. Further, they demonstrate that Croatia has made progress toward E.U. integration, but that ethnic and national issues, combined with Croatia's inability to combat issues of corruption and judicial structure, continue to marginalize Croatia from the rest of Europe. There is also evidence within these documents that this marginalization is further affected by the geographical imaginary that the West has constructed, which defines Croatia in opposition to the stability and prosperity of the E.U. Combined, these observations reveal an international discourse that still sees Croatia, and other Southeastern European states as underdeveloped and nationalistic. The next section examines Croatian state documents to analyze the discourse that the Croatian state attempts to project to the rest of the world, which challenges the hegemonic, Western discourse of Croatia as an 'other'. 


\section{State Documents}

In order to examine the discourse that the Croatian state tries to project to the international community, I examined both the Croatian government website, and the Croatian Embassy to the United States website. The U.S. embassy site was chosen, because it is designed for a foreign audience, was in English, and because after examining other Croatian embassy websites, the content is nearly identical. The Croatian government website was chosen, because it offers the most comprehensive collection of information about Croatia, and is available to the widest audience. The examination of both of these sites revealed a discourse of the Croatian state, which seeks to project an image of stability, democracy, market opportunities, and peace to the rest of the world.

The Croatian embassy site provides information about Croatia's geography and society, and offers links to other Croatian consulates in the U.S., as well as information for Croats traveling in the United States. What is most pertinent to this study; however, are the embassy's "Foreign Policy Aims". Produced for an audience foreign to Croatia, the "Foreign Policy Aims" describe Croatia's desire to gain full E.U. and NATO membership, enhance relations with neighboring countries, develop bilateral and multilateral international co-operation, and promote Croatia's economy and the country as a whole.

Generally, these goals correspond to the reforms described in this study's analysis of E.U. documents. The "Foreign Policy Aims" focus on Croatia's role in an increasingly globalized world, its intent to repair relations with other Southeastern European states, its function in bringing peace to Southeastern Europe, and its status as a stable and democratic state. An excerpt from the "Foreign Policy Aims" webpage explains the role that Croatia sees itself playing in global politics: 
"Republic of Croatia, as a democratic and stable modern European country...plays an important role in... a world of globalisation, regional, political and economic integrations, democratisation of international relations, but also a world of international terrorism and violence. Croatia is located at the heart of Europe as a Mediterranean, Central European and Danube region country, and its geographical location is one of its key strategic advantages. The current European integration processes add a special value to its location, turning it into a potentially key impetus for the country's overall economic development.

Croatia's role in establishing permanent peace, stability and development in South East Europe is irreplaceable, but the establishing of a permanent security and stability system in this part of Europe is possible only on the principles of justice, equality and law, with the respect for the interests of all nations and countries in the region, and the agreement of the international community. In conducting its foreign policy, Croatia will adhere to these principles, thus giving its contribution to turning what once was a region of fierce and direct confrontation into a place of renewed co-operation and partnership" (Ministry of Foreign Affairs and European Integrations of the RC, 2006).

This text reveals important information regarding the discourse of the Croatian state. Croatia defines itself as stable, democratic, and modern. Nowhere in the text are there mentions of Croatia's continued efforts to end corruption or restructure its judicial system, but in a portion of the text not included here, there is a mention of Croatia's aims to address any remaining issues associated with the dissolution of Yugoslavia. Generally, the text positions Croatia as integral to global economic and political processes, including in the areas of fighting terrorism and violence.

The state also draws attention to the strategic importance of Croatia's geographical location in the 'heart of Europe'. The text describes Croatia's location as Southeastern European, Mediterranean, Central European, and Danube country, but the word Balkan is never used to situate Croatia's location. It's possible that the term Balkan is deliberately avoided in order to situate Croatia with the West, and so as not to generate any negative historical memories or 
generalizations. By associating Croatia with the Mediterranean and Central Europe, the state is able to connect itself with Western Europe, rather than as an Eastern or Balkan 'other'.

The "Foreign Policy Aims" also situate Croatia's importance in Southeastern European relations. A heavy emphasis is placed on the ability for Croatia to establish peace, stability, and development amongst its neighbors, but the state is careful to reiterate that this will be done with complete cooperation and respect for other nation-states. This language successfully highlights the value that Croatia can have as an E.U. member, while still carefully assuring the international community that its regional aims focus on cooperation and not dominance over other national or ethnic groups.

The embassy's emphasis on Croatia's geographical, political, and economic value has important implications in examining a Croatian state discourse. Whereas E.U. documentation repeatedly mentioned the restructuring and development that Croatia has yet to achieve, the embassy website allows the Croatian state a forum in which to represent itself as already developed, stable, and ready for global integration. In this way, the Croatian state successfully combats the discourse that Croatia is underdeveloped, corrupt, and economically weak.

The Croatian government website offers a much more extensive and detailed example of the discourse perpetuated by the state. Offered in both English and Croatian, the government website is designed for both a foreign and domestic audience, and content is updated frequently, which required me to periodically return to the site for new data. Within its pages, the website offers information about Croatian history and geography, press releases, multimedia and photos, downloadable documents and newsletters, and updates on Croatia's international relations and domestic projects. Despite this plethora of information, the "Actual Themes" section of the website was particularly useful to this research (Government of the Republic of Croatia, 2007). 
The "Actual Themes" section of the government website both reflects and counters some of the discourses present in the previously discussed E.U. documents. Although there are five themes, the webpage highlights "International Relations" and "Croatia and the E.U." most prominently (Government of the Republic of Croatia, 2007). Each of these themes has links to press releases, which focus on the positive steps that Croatia is making with its neighbors and in E.U. integration, and provides some interesting observations about how the government addresses issues of Croatia's geographical location, ethnicity, and nationalism.

In reference to the European Commission's 2009 Progress Report for Croatia, a press release quotes the Prime Minister as saying "This truly is a good report. We are confident that this is the last such report on Croatia and that this time next year we will finish our EU membership negotiations" (Hina, 2009). This reflects what the progress report said about Croatia nearing the end of its negotiations, but whereas the European Commission is still highly critical of Croatia's progress, the government website focuses on Croatia's growth and development.

Other press releases focus on the good relations between Croatia and other European states. In particular, relations between Croatia and Slovenia are celebrated, and the continuing negotiations over the two countries' border dispute are described as improving. Also discussed are the good relations between Croatia and the U.N., U.S., Germany, Macedonia, and Montenegro. The press releases are often accompanied by photographs that show the Croatian prime minister, or other important government figures, shaking hands or posing with foreign heads of state. In this way, the Croatian government is able to present itself as globally integrated, modern, and well-respected.

In addition to highlighting Croatia's positive improvements in international relations and the E.U. ascension process, there are also a few unique observations in how nationalism and 
Croatia's geography are discussed. Just like on the embassy website, the government site avoids the term Balkans when describing Croatia's location. Instead, Southeastern Europe is preferred, and when Balkans is mentioned, it is usually in reference to the E.U.'s use of "Western Balkans" as regional terminology. However, because the government website is designed for an international audience, it does not necessarily reflect the individual opinions of Croatia's policy makers. For example, a speech made by former Croatian President, Stjepan Mesić, at the “Europe's Balkan Partners" conference in 2006, discusses Croatia's difficulty in reconciling its geographic identity:

"I cannot deny that in Croatia too there still exist individuals and minor groups wishing to convince first themselves and then the whole world that Croatia does not belong to the region and that we have really nothing in common with the countries in the region. Both views are false and stupid. And neither reflects Croatian political positions. Geographically and partly historically we belong to Southeast Europe, the Balkans, the Western Balkans, regardless which term we use. We are there to stay and so are our neighbours. These are simply facts" (Ured Predsjednika Republike Hrvatske, 2009).

This quote reflects some of the survey responses, which acknowledged the negative connotations associated with being Balkan, but still identified Croatia as being geographically and culturally a part of the Balkans.

The Croatian state also claims to have eradicated nationalism. In 2007 the Croatian News Agency published an article in which the former Croatian Prime Minister, Ivo Sanader, stated that nationalism was still very strong in Southeastern Europe, but that it was reduced to a minimum in Croatia since the HDZ political party came to power. He went on to discuss how he hoped Serbia would follow in Croatia's footsteps, so that European unity could truly be achieved (Hina, 2007). Not only does this article demonstrate that the Croatian state is trying to shift its global image away from issues of nationalism, but it also shows that there is still some regional 
rivalry. Sanader's statement that Serbia will hopefully follow in Croatia's footsteps indicates that Croatia sees itself as having resolved post-war issues more quickly than Serbia. In this example, it is clear that national issues, although diminished, still exist in Croatia.

The analysis of government websites and texts demonstrates that the Croatian state is active in promoting an image of itself as a stable, democratic, free-market European nation-state that has managed to overcome its past with nationalism and ethnic conflict, and is now a beacon for peace in Southeastern Europe. In advancing Croatia's accomplishments, the state also promotes Croatia's superiority over other former Yugoslav states, especially in the realm of ending nationalism. Despite this, heads of state do not hesitate to acknowledge Croatia's geographical and cultural connection to the Balkans, regardless of the negative connotations associated with the region.

\section{Impacts and Summary}

Textual analysis of E.U. documents, the Croatian embassy website, and the Croatian government website revealed important information about the role that nationalism plays in the discourses surrounding Croatia's transition to the E.U. and in Croatia's relationship to other European states. The examination of the "EU-Western Balkans Summit - Declaration" (2003), the "Opinion on Croatia's Application for Membership of the European Union" (2004), and the "Croatia 2009 Progress Report" indicated to what degree the E.U. engages Croatia in a process of othering. Repeated mentions of Croatia, and other Balkan states, as underdeveloped, corrupt, unstable, and war-torn demonstrate the geographic imaginary constructed by the West. References to Croatia's history with nationalism and ethnic conflict indicate that the E.U.'s 
opinions of the Balkans are rooted in long-term social and historical processes, which have created a concept of the Balkans as an 'other' (Chapter II-III).

The analysis of embassy and government websites and press releases revealed the popular discourse of the Croatian state. To counter the negative perceptions of the West, and particularly of the E.U., these government sources attempt to project an image of Croatia as stable and democratic. More importantly, these sources show that the state is seeking to publicize the progress that Croatia has made in improving relationships with its neighbors, and in discouraging nationalism amongst its population. However, this analysis also reveals evidence that the state sees Croatia as more developed and E.U.-ready than some of its neighbors, especially Serbia. At the same time, the state acknowledges their Balkan identity, while simultaneously avoiding the use of the term, Balkan, when reaching out to a foreign audience.

\section{Summary}

A combination of textual analysis and online surveys were used to gauge the importance of the nation for a post-war generation of Croats, and to explore the role that the nation plays in Croatia's relationship with Europe, specifically the E.U. The data was analyzed through a process of coding that tried to expose discourses, relationships and themes related to the research questions. The analysis shows that, in seeking E.U. membership, the Croatian state seems to be engaging with Chatterjee's material domain by accepting that Western economic and political structures are superior to Croatia's, and attempting to project an image that demonstrates Croatia's European-ness. Conversely, survey respondents appear to be engaging with Chatterjee's spiritual domain by focusing on the uniqueness of Croatian identity and culture, whether it is in relation to some Balkan mentality or in reference to the unique social and 
historical experiences that Croatia has had (Chatterjee, 2000). In both of these domains, this study indicates that Croatia now views itself as an 'other' in relation to the rest of Europe.

The findings revealed here also indicate that the nation is becoming less important in Croatia since independence, especially amongst younger generations, and that the government continues to make improvements in areas of social equality. Despite this, the E.U. still has concerns over Croatia's past with nationalism and ethnic conflict. In addition to these social factors, the E.U. continues to see Croatia as economically and politically underdeveloped, and repeatedly references the region's past with socialism and national conflict. In this way, Croatia is involved in a process of othering, because of the perceived geographic imaginary constructed of the Balkan Peninsula as ultra-nationalistic, barbaric, and prone to conflict (Todorova, 1997). 


\section{Chapter VI: Discussion \& Conclusion}

Overview

Designated as a borderland between East and West (Glenny, 1999; Tanner, 1997), a barbaric and wild land (Banac, 1984), or the socialist, nationalist "Other Europe" (McDermott \& Stibbe, 2006), Croatia and Southeastern Europe have been at the center of some of the largest ideological and political conflicts of the last century. The goals of this research project were to expose how Croatia's history as an 'other' continues to affect its ability to integrate with the international community and gain E.U. membership. Further, this study sought to reveal how important the nation remains in Croatia since independence has been achieved.

This project revealed how Western perceptions of nationalism in Southeastern Europe have affected Croatia's E.U. negotiation process, determined what image the Croatian state projects in order to combat or change these opinions, and gauged the importance of nationalism and E.U. integration for a post-war generation of Croats. Through the analysis of international, state, and individual scales, this project sought to expose some of the difficulty that nation-states face when trying to integrate into international organizations, like the European Union.

A theoretical framework, which attempted to reconcile theories of nationalism with geopolitical perspectives on imperialism, the state, ethnicity, and territoriality, was used to inform the larger research goals. Ultimately, there is no universal definition of the nation (Anderson, 2000), but the forces of the nation and nationalism are the result of long-term social and historical processes (Smith, 1996). Croatia's experience under imperialism and its unequal power relations with Western Europe encouraged an attachment to national identity, territoriality, and collective myths and symbology (Chatterjee, 2000; Gregory, 2004; Herb, 2004; Hobsbawm \& Ranger, 2000; Jeffrey \& Painter, 2009). Further, the geographic imaginaries 
contructed by the West engage Croatia and the rest of Southeastern Europe in a process of othering (Said, 1979; Todorova, 1997).

This study used a combination of qualitative methodologies in an online environment. Textual analysis of E.U. documents exposed how the imperial discourse of Croatia as undemocratic and nationalistic continues to affect Croatia's E.U. negotiation process. Further textual analysis of state websites and press releases revealed how Croatian state discourse seeks to project an image of the state as stable and European in its values and thinking. Online surveys conducted with young Croats examined the role that the nation continues to play in Croatian popular discourse since the independence wars of the 1990's.

The textual analysis exposed the economic and political concessions the international community is demanding before Croatia gains acceptance to the E.U., and how these demands relate to a geographical imaginary that the West has constructed of Southeastern Europe. This analysis also revealed an effort by the Croatian state to counter the E.U.'s economic and political criticisms by projecting an image of Croatia as a stable, democratic state, who embraces freemarket capitalism and international cooperation. The online surveys indicated that although issues of the nation are still important, relationships are improving amongst the nations of Southeastern Europe, especially as concern grows over the functionality of the Croatian state and the unfair treatment of Croatia by the West. The historical imaginary of the Balkans not only affects how the E.U. approaches Croatia's E.U. negotiation process, but also continues to play a role in how Croatia perceives itself in relation to the rest of Europe. 


\section{Discussion}

This study demonstrated that the E.U. still draws on an imperial discourse of the Balkans when approaching Croatia's E.U. negotiation process. The historical perceptions of the Balkans as underdeveloped and nationalistic are revealed in the E.U.'s concerns over Croatia's ability to move beyond its past with nationalism and political unrest to demonstrate itself as an economically and institutionally stable Balkan state. Documentation further discusses that by moving into the space of the union, Croatia is leaving an area of instability for one of peace and prosperity. In this way, not only is the E.U. perpetuating an imperial imaginary of the Balkans, but is creating a new imaginary of E.U. and non-E.U. spaces. In practice, these perceptions and imaginaries contribute to the unequal treatment of Croatia and other non-E.U. spaces.

The most recent example of the E.U.'s unequal treatment of Croatia can be seen in the response to the ongoing territorial dispute with Slovenia. As a result of Slovenia's claim to a part of Croatia's coastline, a portion of Croatia's E.U. negotiation chapters were suspended. This pause in negotiations indicates that the E.U. not only values the claims of its own members over those of outsiders, but that national and territorial issues are seen as an important hurdle for Southeastern European states to overcome.

As mentioned in the survey responses, this territorial claim was not an issue when Slovenia submitted its application to the union. Despite this, the E.U. still validates the claim by demanding that Croatia and Slovenia reach an agreement before Croatia's membership proceedings can continue. Slovenia's claim further perpetuates the imaginary that Balkan states are forever engrossed with national and territorial disagreements, and since Slovenia already has E.U. membership status, the suspension of Croatia's negotiation chapters demonstrates how 
unequal power relations create difficult conditions for outsiders who seek to gain access to the E.U.

Croatia is not the only state to have its E.U. negotiation process affected by European imaginaries. Turkey has been engaged in E.U. negotiations since 2005, and the discourse surrounding its negotiation process is often framed around its status as a Muslim state, and the degree to which it can prove itself as European, socially inclusive, and religiously secular. In this instance Said's (1979) Western imaginary of the East or Orient prevents Turkey from fully integrating with the European community. Recently, Albania, Bosnia \& Herzegovinia, Serbia, and Kosovo all submitted their applications to become candidates for E.U. admission, and Macedonia has been a candidate since 2005. Understanding how geographic imaginaries can engage states in a process of marginalization is necessary to begin stripping away the negative preconceptions that may halt the negotiation processes of these future E.U. candidates.

This study also demonstrated how the Croatian state responds to the concerns of the E.U. by downplaying its history with nationalism and emphasizing the values of free-market democracy. Popular state discourse still places importance on the uniqueness of the Croatian nation and Balkan culture when speaking to a domestic audience, but in addressing the international community, the state seeks to project an image of stability and European values. This contradiction between Croatia's domestic and international popular discourse is also reflected in the changing importance of the nation and state at the scale of the individual.

On one hand, survey respondents indicated that the nation and nationalism have a changing importance since Croatia gained its independence. Although they focused on the uniqueness of their culture and identity, it was often discussed in terms of an overall Balkan identity or culture, rather than a specific identity tied to the Croatian nation. In this way, 
respondents seem to be responding to the domestic popular discourse of the state. Respondents also discussed how relations between ethnic and national groups are improving within the former Yugoslav republics, especially among younger generations who blame politicians for the ethnic and national violence of the independence wars, rather than individuals. Generally, respondents were highly critical of the actions and policies of their government, which further demonstrated how the nation and state act as separate entities.

Although respondents demonstrated how national relations are improving regionally, they also indicated that tensions have increased between E.U. and non-E.U. spaces. The Slovenian territorial issue was discussed at length by respondents, who saw Slovenia's claims as both an attempt for the state to assert its power as an E.U. member, and an example of how the E.U. uses a different standard for members and non-members. Some respondents accused Slovenia of acting out of jealousy of Croatia's coastline, while others believed Slovenia acted out of a feeling of superiority over Croatia. These opinions further demonstrate the increasingly unequal relations between E.U. and non-E.U. spaces, as well as the remaining territorial tensions between former Yugoslav republics.

More importantly, the survey responses reveal the potential for an increase in nationalism as a response to Croatia's inability to gain access to the E.U. Although survey responses showed an improvement in national relations within Southeastern Europe, they also showed an increase in the need for young Croats to define themselves as different or unique from Western Europe, or the E.U. Estimates from the European Commission indicate that Croatia will achieve E.U. membership within the next few years, but the increasing frustration that Croats feel at being kept out of the E.U. may continue to make relations difficult, even after Croatia becomes a 
member. This study serves as an example of the difficulties the E.U. will continue to face in its expansion if unequal relations persist between E.U. and non-E.U. members.

This study takes a unique perspective to examining how international and state discourses are reflected in the opinions of the individual in Croatia. The findings discussed here have demonstrated how Western imperial imaginaries continue to affect Croatia's ability to gain membership to the European Union, and further expose the unequal relations between E.U. and non-E.U. spaces. This study reveals the improving relations among nations and ethnic groups in Southeastern Europe, but exposes the increasing tensions resulting from the perceived political boundaries between E.U. and non-E.U. members. The results indicate that as long as geographic imaginaries still exist, E.U. expansion will be especially difficult for other former Yugoslav republics.

\section{Limitations \& Areas for further Exploration}

Although this research was able to reveal important patterns and trends in Croatia's E.U. negotiation process, there are many limitations to this project. Ultimately these research findings only reveal a small portion of the relationships and processes that are ongoing in Croatia and the broader region. Questions left unanswered by this project encourage further work, not just in understanding the role that nationalism plays in Croatia's global integration, but also in developing the use of online research methodologies more thoroughly. By acknowledging these difficulties, I can contribute to my own critical reflexivity and a more rigorous research practice

The largest limitation to this study lies in the research methods themselves, and more specifically in the complicated process that is Foucault's method of discourse analysis. Although this project does employ his method to some degree, it would be incorrect to state that I followed 
this process through to its completion. The reality is that if one follows discourse analysis through to its end, knowledge folds back on itself and the process begins again. However, I do feel that I have applied discourse analysis in a way that best fits the research questions I am trying to answer. When addressing the use of his methods for the discipline of geography Foucault stated:

"...It's up to you, who are directly involved with what goes on in geography... 'If one or two of these "gadgets" of approach or method that I've tried to employ...can be of service to you, then I shall be delighted. If you find the need to transform my tools or use others then show me what they are, because it may be of benefit to me'" (Gordon, 1980, p. 65).

Although I know that an entire project could be derived from either one of the discourses I've tried to expose with this project, the adaptation of discourse analysis was the best possible way for me to analyze the data collected.

The use of the internet as a primary source for data collection also has its limitations. In choosing the internet as my medium, I was able to gain quick and easy access to information that would otherwise be difficult to obtain. Another benefit that the internet provides is English translations of Croatian articles, which the project would have been a failure without. Also, the ability for me to fact check between websites at a great speed, and the option of bookmarking sites for later use, kept my research organized, manageable, and thorough.

However, using the internet meant that I only had access to a small sampling of the Croatian sources that provided English translations. I combated this disadvantage both in the analysis of the government documents and in the examination of survey responses. However, future research on this topic would benefit from on-the-ground field work in Croatia, more specifically, with a visit to the national archives or an examination of hardcopy documents and news sources published in Croatian. 
The use of online surveys presented their own limitations, particularly in the low response rate I experienced. Despite my attempts at recruiting more survey responses, I was only able to elicit some 19 responses over several months. This is in part due to security measures on Facebook, and a lack of incentive for participants to complete the questionnaires. However, because the survey was part of a qualitative analysis, I had only hoped for some 20-30 survey responses, and I came very close to that number. Had I offered some incentive, monetary or otherwise, to survey participants, I might have received more feedback. Additionally, because Facebook is a social-networking site, people are hesitant to interact with users they don't know, which could explain my low survey response, as well as why a large number of my respondents came from snowball sampling.

In addition to the limitations set by the research methodologies, this research only reveals a small portion of the processes involved in Croatia's E.U. negotiations. Although I believe that this research accurately revealed how the process of othering and nationalism have affected, and continue to affect, relations at all scales of analysis, there are many other factors that contribute to Croatia's, and the larger Southeastern European regions', marginalization from greater Europe. The analysis of E.U. documents revealed that although nationalism is a concern for the European Commission, the biggest reforms Croatia must implement are related to free trade, economic deregulation, and privatization. A future project should explore the role that uneven development and economic exploitation play in the marginalization of Southeastern Europe, and in the growth of national movements in the region. 


\section{Contribution to Geographical Research}

Despite these limitations, this project contributes to geographical research in two important ways. Firstly, this case-study demonstrates how geographic imaginaries create real economic and political inequalities in the process of global integration, specifically in the E.U. negotiation process. Secondly, this study shows how the European Union has created a divided space between those who are in and those who are out, and why states seeking E.U. membership face difficulties in proving themselves worthy of European integration. The difficulties facing Croatia's E.U. negotiation process are just one example of how historical imaginaries and the increasing divide between E.U. and non-E.U. spaces affect the ability of states to gain equal access to social, political, and economic opportunities. By acknowledging the imperial imaginaries that shape perception, we can move beyond the historical preconceptions that create uneven relationships, and create a more equal process of E.U. expansion for other Southeastern European states. 


\section{Bibliography}

Agnew, John. "The Territorial Trap," Review of International Political Economy, Spring1994, Vol. 1, No. 1, pp. 53-80.

Anderson, Benedict. Imagined Communities, New York \& London: Verso, 1996.

Anderson, Benedict. "Introduction," in Balakrishnan, Gopal, Mapping the Nation, New York \& London: Verso, 2000.

Archer, Thomas M. "Response Rates to Expect from Web-Based Surveys and What to Do About It," Journal of Extension, June 2008, Vol. 46, Issue 3.

Balkan. Oxford Dictionary, $2^{\text {nd }}$ Edition, 1989, Oxford University Press, 2010, Retrieved January 2009 from

http://dictionary.oed.com.www.libproxy.wvu.edu/cgi/entry/50016905/50016905se3? single=1\&q uery_type=word\&queryword=balkanism \&first=1\&max_to_show=10\&hilite $=50016905 \mathrm{se} 3$

Banac, Ivo. The National Question in Yugoslavia: Origins, History, Politics, Ithaca \& London: Cornell University Press, 1984.

Bradshaw, Matt and Stratford, Elaine. "Chapter 5: Qualitative Research Design and Rigour," in Hay, Iain. Qualitative Research Methods in Human Geography, $2^{\text {nd }}$ ed. Melbourne: Oxford University Press, 2005.

Chatterjee, Partha. "Chapter 8: Whose Imagined Community?," in Balakrishnan, Gopal, Mapping the Nation, New York \& London: Verso, 2000.

Commission of the European Communities. Communication from the Commission: Opinion on Croatia's Application for Membership of the European Union, Brussels, April 20, 2004

Retrieved October 2009 from http://eur-

lex.europa.eu/LexUriServ/LexUriServ.do?uri=COM:2004:0257:FIN:EN:PDF

Commission of the European Communities. Croatia 2009 Progress Report, Brussels, October 14, 2009, Retrieved December 2009 from

http://ec.europa.eu/enlargement/pdf/key_documents/2009/hr_rapport_2009_en.pdf

Cope, Meghan. "Chapter 14: Coding Qualitative Data," in Hay, Iain. Qualitative Research Methods in Human Geography, $2^{\text {nd }}$ ed. Melbourne: Oxford University Press, 2005.

Cramer, Elizabeth P. \& Mathews, John. "Using Technology to Enhance Qualitative Research with Hidden Populations," The Qualitative Report, June 2008, Vol. 13 No. 2, pp. 301-315.

Crang, Mike. "Qualitative Methods: The New Orthodoxy?," Progress in Human Geography, 2002, Vol. 26, Issue 5, pp. 647-655. 
Dowling, Robyn. “Chapter 2: Power, Subjectivity, and Ethics in Qualitative Research,” in Hay, Iain. Qualitative Research Methods in Human Geography, $2^{\text {nd }}$ ed. Melbourne: Oxford University Press, 2005.

Dragojevic, Mila. "Competing Institutions in National Identity Construction: The Croatian Case," Nationalism \& Ethnic Politics, Spring2005, Vol. 11 Issue 1, pp. 61-87.

Drakulic, Slavenka. How We Survived Communism and even Laughed. New York: Harper Collins Books, 1993.

Dwyer, Claire \& Limb, Melanie. Qualitative Methodologies for Geographers: Issues and Debates. London \& New York: Oxford University Press, 2001.

English, Cynthia. Many in the Balkans Lack Confidence in Judicial Systems: Judicial reform considered important to eventual EU membership, Gallup, March 10, 2008, Retrieved February 2010 from http://www.gallup.com/poll/104872/Many-Balkans-Lack-Confidence-JudicialSystems.aspx

European Commission. "Public Opinion in the European Union, National Report, Executive Summary, Croatia," Eurobarometer 72, Autumn 2009, Retrieved January 2010 from http://www.delhrv.ec.europa.eu/files/file/eurobarometar/CROATIA_EB72_EXECUTIVE_SUM MARY_EN_VALIDATED.pdf

European Commission for Enlargement. EU-Western Balkans Summit-Declaration, Thessaloniki, June 21, 2003, Retrieved July 2009 from http://ec.europa.eu/enlargement/enlargement_process/accession_process/how_does_a_country_j oin_the_eu/sap/thessaloniki_summit_en.htm

European Commission for Enlargement. E.U.-Croatia Relations, Retrieved April 2009 from: http://ec.europa.eu/enlargement/candidate-countries/croatia/eu_croatia_relations_en.htm.

Flavian, Carlos \& Gurrea, Raquel. "Reading Newspapers on the Internet: The Influence of Websites' Attributes," Internet Research, 2008, Vol. 18, No. 1, pp. 25-45.

Fluri, Jennifer L. "Our Website Was Revolutionary: Virtual Spaces of Representation and Resistance," ACME: An International E-Journal for Critical Geographies, 2006, 5 (1), 89-11.

Foucault, Michel. The Archeology of Knowledge and the Discourse on Language, New York: Pantheon Books, 1972.

Fukuyama, Francis, “The End of History?,” The National Interest, 1989, Vol. 16.

Gellner, Ernest. Nationalism. New York: New York University Press, 1997.

Gellner, Ernest. "Chapter 4: The Coming of Nationalism and its Interpretation: The Myths of Nation and Class," in Balakrishnan, Gopal, Mapping the Nation, New York \& London: Verso, 2000 . 
Glenny, Misha. The Balkans: Nationalism, War, and the Great Powers, 1804-1999. New York: Viking Penguin, 1999.

Gordon, Colin. Power/Knowledge: Selected Interviews and Other Writings 1972-1977 By Michel Foucault, New York: Pantheon Books, 1980.

Governmnent of the Republic of Croatia. Actual Themes, 2007, Retrieved March 2009 from: http://vlada.hr./en/aktualne_teme_i_projekti

Gravelle, Timothy B. and Nyiri Zsolt. Corruption in the Balkans: A Real Issue for the PeopleMajorities see it as widespread and harmful for the country, Gallup, November 16, 2007, Retrieved February 2010 from http://www.gallup.com/poll/102757/Corruption-Balkans-RealIssue-People.aspx

Gregory, Derek. The Colonial Present: Afghanistan, Palestine, Iraq, Oxford: Blackwell Publishing, 2004.

Gregory, D., Johnston, R.J., Pratt, Geraldine, and Watts, Michael, The Dictionary of Human Geography, $4^{\text {th }} \mathrm{Ed}, 2000$.

Haller, Max and Ressler, Regina. "National and European Identity: A Study of Their Meanings and Interrelationships," Revue Française de Sociologie, Vol. 47, No. 4, Sociologie des valeurs: Théories et mesures appliquées au cas européen, Oct. - Dec., 2006, pp. 817-850.

Harvey, David. Justice, Nature, \& the Geography of Difference, Oxford: Blackwell Publishing, 1996.

Herb, Guntram. "Double Vision: Territorial Strategies in the Construction of National Identities in Germany, 1949-1979," Annals of the Association of American Geographers, Vol. 94, Issue 1, 2004, pp. 140-164.

Hina. "Prime Minister Kosor says EC's progress report proof that Croatia is at the beginning of the end of very important job," from Government of the Republic of Croatia, Actual Themes, October 15, 2009, Retrieved December 2009 from http://vlada.hr./en/naslovnica/novosti_i_najave/2009/listopad/predsjednica_vlade_izvjesce_ek_d okaz_da_smo_na_pocetku_kraja_vaznog_posla/\%28back\%29/temu

Hina. "Sanader says nationalism in Croatia reduced to minimum," from Government of the Republic of Croatia, News and Announcements, May 23, 2007, Retrieved December 2009 from http://vlada.hr./en/naslovnica/novosti_i_najave/2007/svibanj/predsjednik_vlade_posjetio_oxford

Hobsbawm, Eric. "Chapter 11: Ethnicity and Nationalism in Europe Today," in Balakrishnan, Gopal, Mapping the Nation, New York \& London: Verso, 2000.

Hobsbawn, Eric and Ranger, Terence. The Invention of Tradition, Cambridge: Cambridge University Press, 2000. 
Howitt, Richie and Stevens, Stan. "Chapter 3: Cross-Cultural Research: Ethics, Methods, and Relationships," in Hay, Iain. Qualitative Research Methods in Human Geography, $2^{\text {nd }}$ ed. Melbourne: Oxford University Press, 2005.

Hroch, Miroslav. "From National Movement to the Fully-Formed Nation," New Left Review, March-April 1993, I/198.

Hudson, Ray. "One Europe or Many? Reflections on Becoming European," Transactions of the Institute of British Geographers, 2000, New Series, Vol. 25, No. 4, pp. 409-426

Jacobson, David. "Doing Research in Cyberspace," Field Methods, November 1999, Vol. 11, No. 2, pp. 127-145.

Jeffrey, Alex and Painter, Joe. "Chapter 8: Imperialism and Post-Colonialism," Political Geography: An Introduction to Space and Power, London: Sage Publications, 2009.

Kee, Kerk F., Park, Namsu, and Valenzuela, Sebastián. "Being Immersed in Social Networking Environment: Facebook Groups, Uses and Gratifications, and Social Outcomes,"

CyberPsychology \& Behavior, Dec. 2009, Vol. 12 Issue 6, pp. 729-733.

Kenney, Padraic. The Burdens of Freedom: Eastern Europe since 1989. Nova Scotia: Fernwood Publishing, 2006.

Lampe, John. Yugoslavia as History: Twice there was a Country, $2^{\text {nd }}$ Edition. New York:

Cambridge University Press, 2000.

Madge, Clare. "Developing a Geographers' Agenda for Online Research Ethics," Progress in Human Geography, 2007, Vol. 31, Issue 5, pp. 654-674.

Mesić', Stjepan. "President Mesić's Speech at the Conference 'Europe's Balkan Partners'," from Ured Predsjednika Republike Hrvatske, December 5, 2006, Retrieved January 2010 from http://www.predsjednik.hr/Default.aspx?art=13366\&sec=917.

McDermott, Kevin and Stibbe, Matthew. Revolution and Resistance in Eastern Europe: Challenges to Communist Rule, New York: Berg, 2006.

McGuirk, Pauline M. and O’Neill, Phillip. “Chapter 10: Using Questionnaires in Qualitative Human Geography," in Hay, Iain. Qualitative Research Methods in Human Geography, $2^{\text {nd }}$ ed. Melbourne: Oxford University Press, 2005.

Ministry of Foreign Affairs and European Integrations of the RC. Embassy of the Republic of Croatia in the United States of America, (2006) Retrieved November 2009 from http://www.croatiaemb.org/

Ministry of Foreign Affairs and European Integrations of the RC. Foreign Policy Aims, (2006) Retrieved November 2009 from http://www.croatiaemb.org/ 
Morozov, Evgeny. “A Melting Pot it's Not,” Foreign Policy, Mar/Apr 2009, Issue 171, p. 26.

Mullings, Beverly. "Insider or Outsider, Both or Neither: Some Dilemmas of Interviewing in a Cross-Cultural Setting," Geoforum, 1999, Issue 30, pp. 337-350.

Okey, Robin. "Serbian, Croatian, Bosnian? Language and Nationality in the Lands of Former Yugoslavia," Eastern European Quarterly. 2004, Vo. 38 Issue 4, pp. 419-441.

Petrovic, Milenko. "The Role of Geography and History in Determining the Slower Progress of Post-Communist Transition in the Balkans," Communist and Post-Communist Studies, June 2008, Vol. 41 Issue 2, pp. 123-145.

Rheault, Magali. Croatians Mixed on Benefits of EU Membership: Only one-third say integration with EU would be a good thing. Gallup, June 15, 2007, Retrieved February 2010 from http://www.gallup.com/poll/27901/Croatians-Mixed-Benefits-Membership.aspx

Rice, Ronald E. "New Media/Internet Research Topics of the Association of Internet Researchers," The Information Society, 2005, Vol. 21, pp. 285-299.

Ritter, Lois A. and Sue, Valarie M. (Eds). "Chapter 1: Introduction to Using Online Surveys," The use of Online Surveys in Evaluation: New Directions for Evaluation, No. 115, Jossey-Bass, Oct. 2007.

Said, Edward W. Orientalism, New York: Random House, 1979.

Sheldon, Pavica. "The Relationship Between Unwillingness-to-Communicate and Students' Facebook Use," Journal of Media Psychology, 2008, Vol. 20, Issue 2, pp. 67-75

Smith, Anthony D. "Culture, Community, and Territory: The Politics of Ethnicity and Nationalism," International Affairs, 1996, Vol. 72, Issues 3, pp. 445-458.

Skrzypek, Stanislaw. "The Political, Cultural, and Social Views of Yugoslav Youth," The Public Opinion Quarterly, Spring 1965, Vol. 29, No. 1, pp. 87-106.

Tanner, Marcus. Croatia: A Nation Forged in War. London: Yale University Press, 1997.

Todorova, Maria. Imagining the Balkans. New York: Oxford University Press, 1997.

Virkkunen, Joni. "Post-Socialist Borderland: Promoting or Challenging the Enlarged European Union?," Geografiska Annaler, Series B, Human Geography, 2001, Vol. 83, No. 3, pp. 141-151

Waitt, Gordon. "Chapter 11: Doing Discourse Analysis," in Hay, Iain. Qualitative Research Methods in Human Geography, $2^{\text {nd }}$ ed. Melbourne: Oxford University Press, 2005.

Warnick, Barbara. "Online Ethos: Source Credibility in an "Authorless" Environment," The American Behavioral Scientist, October 2004, Vol. 48, Issue 2, pp. 256-265. 
Zeigler, D.J. "Post-communist Eastern Europe and the Cartography of Independence," Political Geography, 2002, Vol. 21, pp. 671-686.

Žižek, Slavoj. Tarrying with the Negaive: Kant, Hegel, and the Critique of Ideology, Durham: Duke University Press, 1993.

Žižek, Slavoj. In Defense of Lost Causes, New York and London: Verso Publishing, 2008. 


\section{$\underline{\text { Appendices }}$}

\section{A. Methods Materials}

\section{Survey Questions:}

Surveys: Thank you for volunteering to be a part of this research project. By taking this survey, you acknowledge that you have read the consent letter found at www.geo.wvu.edu/ jititanski/Croatia_surveys, and that you are 18 years of age or older, and that you give permission for your answers to be used for this study. Any identifying information you provide, including your email address, will be kept completely confidential. Your answers will be anonymous.

Directions:

- Answer the following questions as honestly as you can.

- You may skip any questions you are uncomfortable with, or quit the survey at any time.

- Once you have answered all the questions below, save this document to your computer, and email it as an attachment to jtitans1@ mix.wvu.edu

- If after emailing the survey, you wish to have your answers withdrawn from the research, send another email to jtitans1@mix.wvu.edu, and your survey will be removed from the study and none of your answers will be saved.

- Thank you for your time!

\section{Demographic Information:}

1. Are you male or female?

2. What is your age (You must be at least 18 to complete this survey)?

3. What city in Croatia are you from?

4. Are you a university student?

5. What ethnicity do you identify with most?
a. Croatian
b. Serbian
c. Bosniak
d. Slovenian
e. Roma f. Other

6. What religion do you identify with most? 


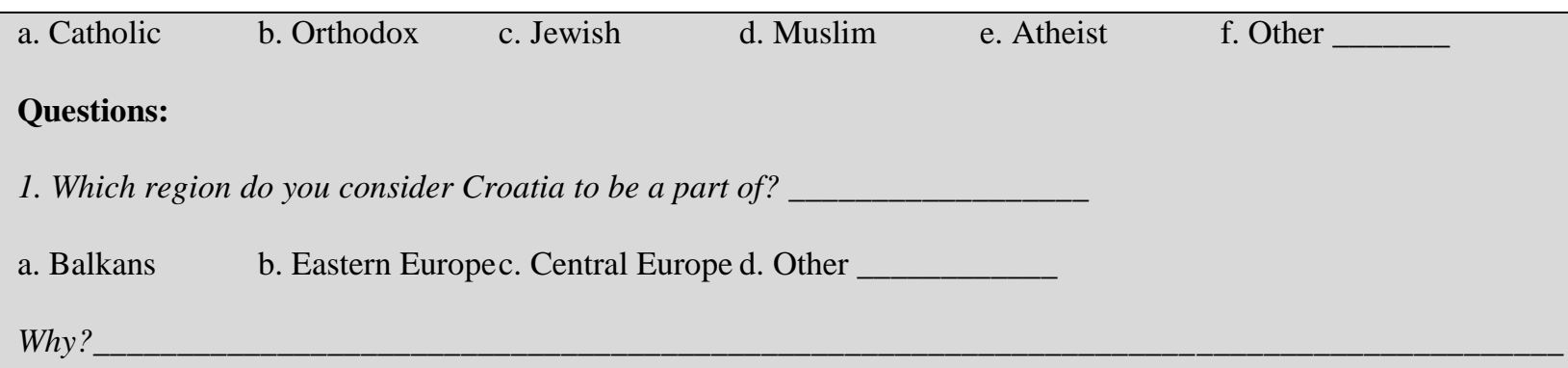

2. What are some of the regional differences in Croatia?

a. Between the north and south?

b. In Eastern Slavonia or the former Krajina?

c. On the coast?

3. Slovenia has been criticized as trying to prevent Croatia's entrance to the E.U., because of a territorial dispute.

a. Do you think that Slovenia is unfairly stopping Croatia from joining the E.U.?

b. Should Slovenia be allowed to gain control over part of the Croatian coastline? Please explain.

4. Do you think the Croatian government should encourage the Serbs and Bosnians that lived in Croatia before the war to immigrate back into the country? Why or why not?

5. Since the end of the independence wars, do you think that the relationship between individual Croats and Serbs has improved? Please Explain.

6. Even though Croatia has been independent for some time now, do you think there is a possibility that Croatia could lose its independence in the future? If not, why do you think so? If yes, do you think that other countries in Southeastern Europe or in the West threaten Croatia's sovereignty? Please Explain.

7. Do you think that joining the European Union will take away some of Croatia's independence, or will E.U. membership protect Croatia from future threats of invasion from others? Why or why not? 
8. Do you think there could ever be another conflict between Croatia and Serbia, what about Serbia and Slovenia or Bosnia?

9. What are some of the good things that the E.U. can do for Croatia's economy and society? What are some of the bad?

10. Croatia has been trying to get into the E.U. since 2003, and E.U. members argue that Croatia needs to make some political, social, and economic changes before admission will be granted.

a. Do you agree that Croatia needs to make changes? If so, what kinds of changes should the country make?

b. Do you think that Western countries are treating Croatia unfairly? Explain.

Sources for Textual Analysis:

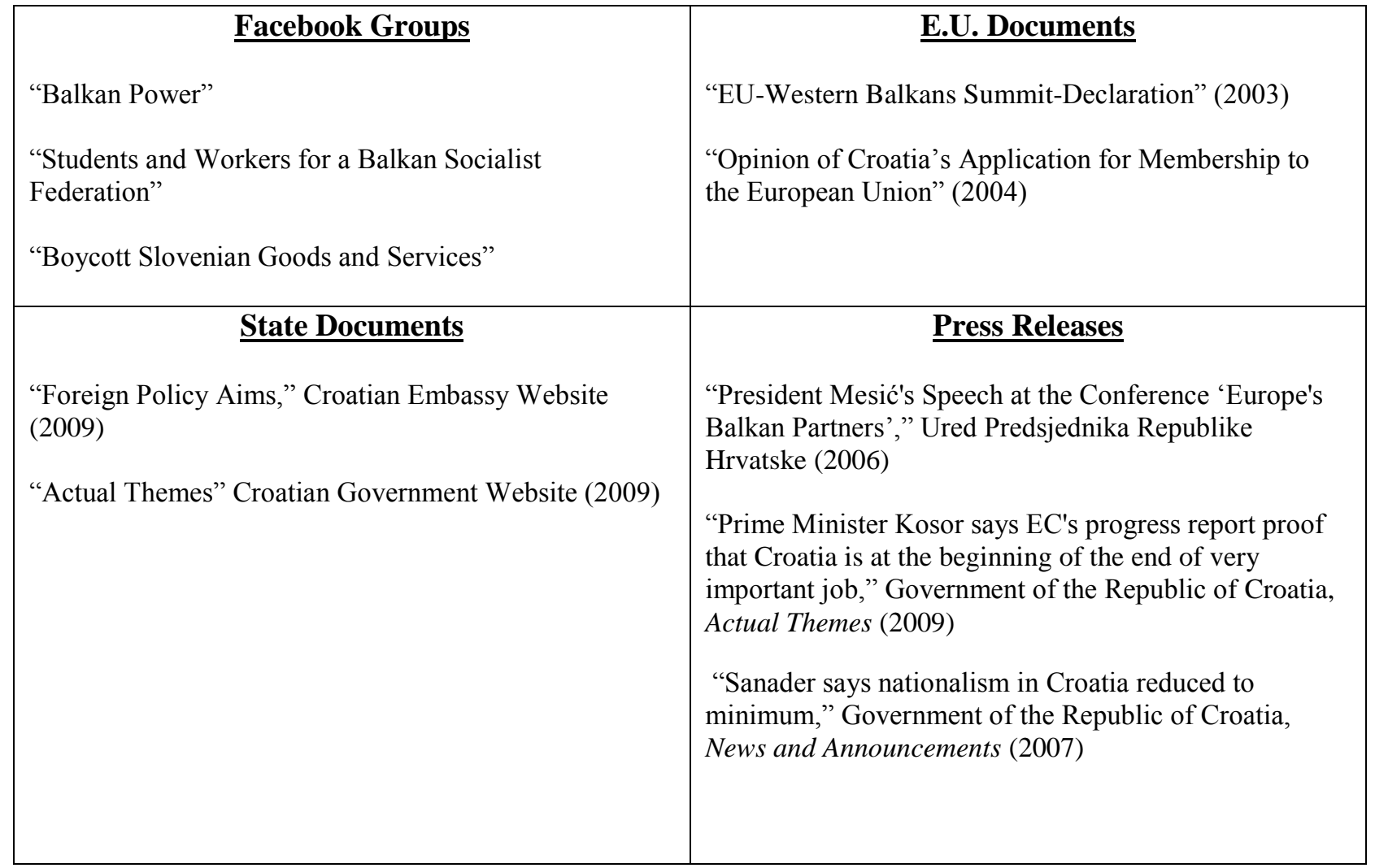




\section{B. Institutional Requirements}

IRB approval:

\begin{tabular}{|c|}
\hline Tracking \#: H-21775 \\
\hline PI: Oberhauser, Ann \\
\hline Title: Ethnicity, Nationalism, and Boundaries in a 'European' Croatia \\
Version: 3 \\
Status: Exempt \\
\hline Status Date: 7/14/2009 2:11:40 PM \\
Board: Board Gold \\
Meeting Date \\
Approval Date: 07/14/2009 \\
Expiration Date \\
\hline
\end{tabular}

